Universidad de Lima

Facultad de Ingeniería y Arquitectura

Carrera de Ingeniería Industrial

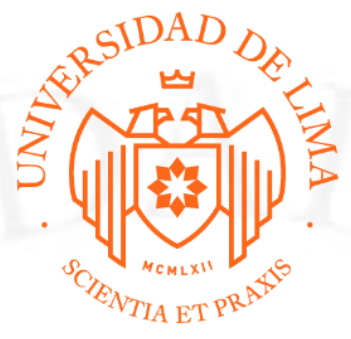

\title{
ANÁLISIS Y DISEÑO DE UN EMPRENDIMIENTO PARA LA FABRICACIÓN DE ARTÍCULOS DECORATIVOS DOMÉSTICOS UTILIZANDO TECNOLOGÍAS DE FABRICACIÓN DIGITAL
}

Trabajo de investigación para optar el Título Profesional de Ingeniero Industrial

Nicolas Santiago Newton Bedoya

Código 20110855

Asesor

Fabricio Paredes Larroca

Lima - Perú

Enero de 2019 
Análisis y diseño de un emprendimiento para la fabricación de artículos decorativos domésticos utilizando tecnologías de fabricación digital 


\section{TABLA DE CONTENIDO}

\section{RESUMEN EJECUTIVO}

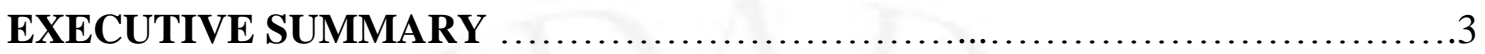

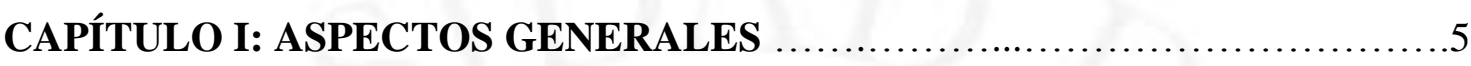

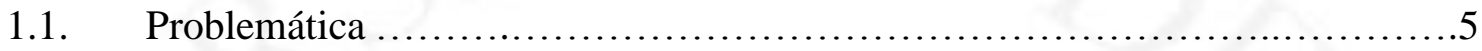

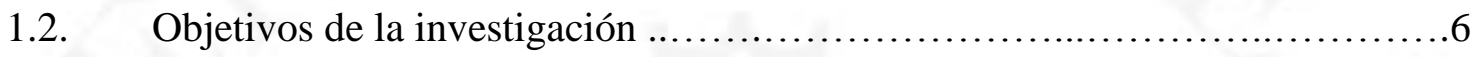

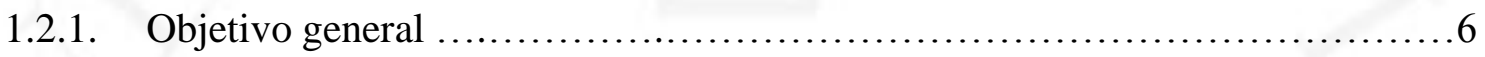

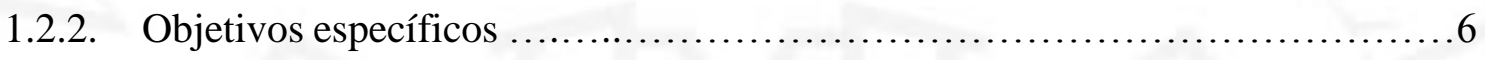

1.3. Alcance de la investigación ..........................................6

1.3.1. Unidad de análisis ..................................................

1.3.2. Población ...........................................................

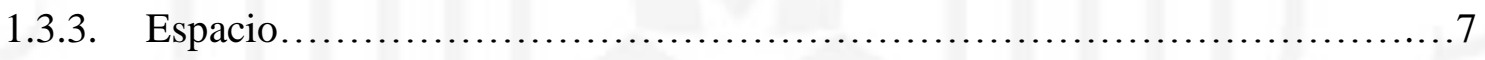

1.3.4. Tiempo.....................................................

1.3.5. Limitaciones de la investigación....................................

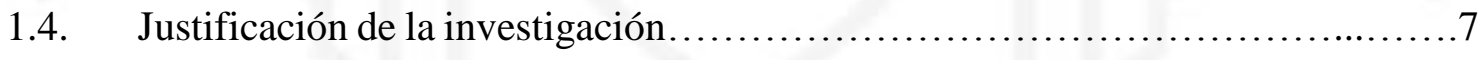

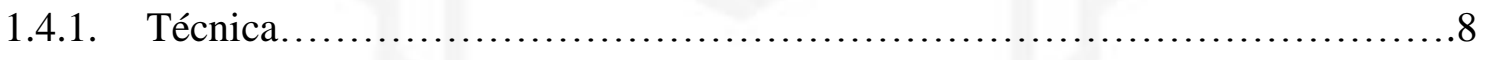

1.4.2. Económica.....................................................8

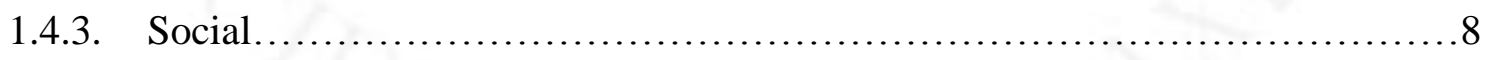

1.5. Hipótesis del trabajo................................................

1.6. Marco referencial.................................................... 10

1.7. Marco conceptual.................................................11

CAPÍTULO II: ESTUDIO DE MERCADO...................................13

2.1. Aspectos generales del estudio de mercado.............................13 
2.1.1. Definición comercial del producto

2.1.2. Usos del producto, bienes sustitutos y complementarios.....................14

2.1.3. Determinación del área geográfica que abarca el producto....................14

2.1.4. Análisis del sector industrial (cinco fuerzas de Porter)........................14

2.1.5. Modelo de negocios (Canvas) .......................................... 16

2.2. Metodología para emplear en la investigación de mercado....................16

2.3. Demanda potencial..................................................... 16

2.3.1. Patrones de consumo: incremento poblacional, estacionalidad y aspectos

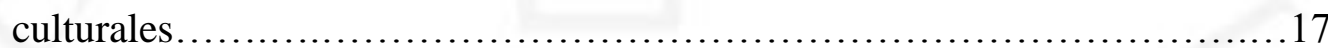

2.3.2. Determinación de la demanda potencial en base a patrones de consumo similares.............................................................

2.4. Determinación de la demanda de mercado en base a fuentes secundarias o primarias......................................................... 21

2.4.1. Determinación de la demanda del proyecto sin data histórica..................22

2.4.1.1. Cuantificación y proyección de la población...............................22

2.4.1.2. Definición del mercado objetivo......................................23

2.4.1.3. Diseño y aplicación de encuestas....................................... 25

2.4.1.4. Resultado de la encuesta............................................ 26

2.4.1.5. Determinación de la demanda del proyecto................................28

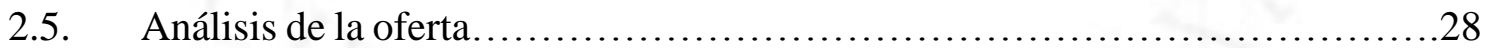

2.5.1. Empresas productoras, importadoras y comercializadoras...................28

2.5.2. Participación de mercado de los competidores actuales........................29

2.5.3. Competidores potenciales si hubiera..................................29

2.6. Definición de la estrategia de comercialización..............................29

2.6.1. Políticas de comercialización y distribución...............................30 


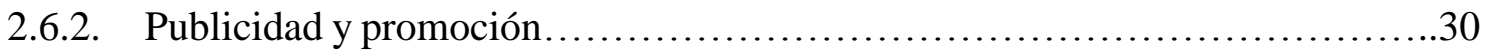

2.6.3. Análisis de precios.............................................. 30

2.6.3.1. Tendencia histórica de precios.......................................... 30

2.6.3.2. Precios actuales.........................................................

2.6.3.3. Estrategia de precio................................................. 32

CAPÍTULO III: LOCALIZACIÓN DE PLANTA....................................33

3.1. Identificación y análisis detallado de factores de localización.................33

3.2. Identificación y descripción de las alternativas de localización.................34

3.3. Determinación del modelo de evaluación a emplear.........................35

3.4. Evaluación y selección de la localización...................................

3.4.1. Evaluación y selección de la macro localización...........................35

3.4.2. Evaluación y selección de la micro localización...........................37

CAPÍTULO IV: DIMENSIONAMIENTO DEL SERVICIO......................39

4.1. Relación Tamaño-Mercado................................................. 39

4.2. Relación Tamaño-Recursos............................................. 39

4.3. Relación Tamaño-Tecnología..........................................39

4.4. Relación Tamaño-punto de equilibrio..................................40

4.5. Selección del tamaño de planta........................................42

CAPITULO V: INGENIERÍA DEL PROYECTO.............................43

5.1. Definición técnica del producto........................................43

5.1.1. Especificaciones técnicas, composición y diseño del producto...............43

5.2. Tecnologías existentes y procesos de producción........................53

5.2.1. Descripción de la tecnología existente .................................53

5.2.1.1. Selección de la tecnología.............................................55

5.2.2. Proceso de producción............................................56 
5.2.2.1. Descripción del proceso...........................................56

5.2.2.2. Diagrama de operaciones del proceso: DOP ..............................69

5.2.2.3. Balance de materia.................................................. 70

5.3. Características de las instalaciones y equipos.............................. 71

5.3.1. Selección de maquinaria y equipos..................................... 72

5.3.2. Especificaciones de la maquinaria................................... 78

5.4. Capacidad instalada.................................................. 81

5.4.1. Cálculo detallado del número de máquinas y operarios..................... 82

5.4.2. Cálculo de la capacidad instalada........................................ 83

5.5. Cálculo de la calidad y/o inocuidad del producto..........................84

5.5.1. Calidad de la materia prima, de los insumos, del proceso y del producto.......84

5.6. Estudio de impacto ambiental....................................... 85

5.7. Seguridad y salud ocupacional.................................... 87

5.8. Sistema de mantenimiento........................................... 88

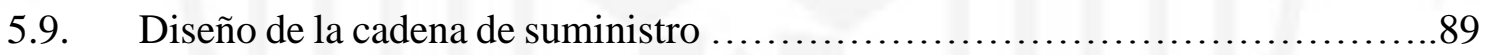

5.10. Programa de producción...............................................90

5.11. Requerimiento de insumos, servicios y personal indirecto................. 90

5.11.1. Materia prima, insumos y otros materiales............................. 90

5.11.2. Servicios: Energía eléctrica, agua, vapor, combustible, etc..................92

5.11.3. Determinación del número de trabajadores indirectos.......................92

5.11.4. Servicios de terceros............................................... 93

5.12. Disposición de planta...............................................93

5.12.1. Características físicas del proyecto..................................93

5.12.2. Determinación de las zonas físicas requeridas.............................94

5.12.3. Cálculo de áreas para cada zona......................................95 
5.12.4. Dispositivos de seguridad industrial y señalización .99

5.12.5. Disposición de detalle de la zona productiva 101

5.12.6. Disposición general. 103

5.13. Cronograma de implementación del proyecto 104

CAPÍTULO VI: ORGANIZACIÓN Y ADMINISTRACIÓN. .106

6.1. Formación de la organización empresarial. 106

6.2. Requerimientos de personal directivo, administrativo y de servicios; y funciones generales de los principales puestos

6.3. Esquema de la estructura organizacional 109

CAPÍTULO VII: ASPECTOS ECONÓMICOS Y FINANCIEROS. 112

7.1. Inversiones. 112

7.1.1. Estimación de las inversiones de largo plazo (tangibles e intangibles).

7.1.2. Estimación de las inversiones de corto plazo.

7.2. Costos de producción 116

7.2.1. Costos de las materias primas. 116

7.2.2. Costos de la mano de obra directa. 116

7.2.3. Costos indirectos de fabricación

7.3. Presupuesto operativo 118

7.3.1. Presupuesto de ingresos por ventas. 118

7.3.2. Presupuesto operativo de costos 118

7.3.3. Presupuesto operativo de gastos

7.4. Presupuesto financiero

7.4.1. Presupuesto de servicio de deuda....

7.4.2. Presupuesto estado de resultados.....

7.4.3. Presupuesto estado de situación financiera. 124 
7.4.4. Flujo de fondos netos............................................. 125

7.4.4.1. Flujo de fondos económicos........................................... 125

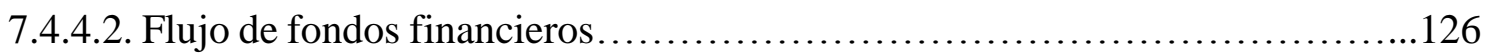

7.5. Evaluación económica y financiera........................................ 127

7.5.1. Evaluación económica................................................. 127

7.5.2. Evaluación financiera................................................ 127

7.5.3. Análisis de ratios.................................................. 128

7.5.4. Análisis de sensibilidad del proyecto............................... 128

CAPÍTULO VIII: EVALUACIÓN SOCIAL DEL PROYECTO..................132

8.1. Indicadores sociales........................................... 132

CONCLUSIONES..............................................................134

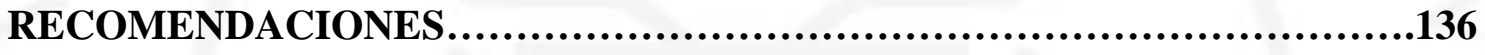

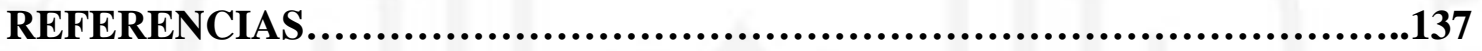

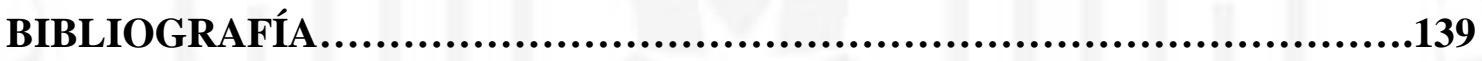

ANEXOS.....................................................................141 


\section{ÍNDICE DE TABLAS}

Tabla 1.1. Marco referencial............................................... 10

Tabla 2.1. Perú: Crecimiento y distribución de la población, $2017 \ldots \ldots \ldots \ldots \ldots \ldots \ldots \ldots 17$

Tabla 2.2. Encuesta para la muestra piloto....................................25

Tabla 2.3. Resultados: Encuesta para la muestra piloto..........................26

Tabla 2.4. Encuesta para la muestra real...................................27

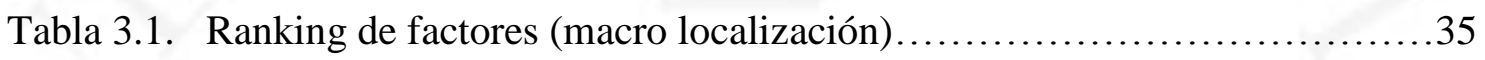

Tabla 3.2. Características de Santiago de Surco y La Molina..............................

Tabla 3.3. Ranking de factores (macro localización)................................ 36

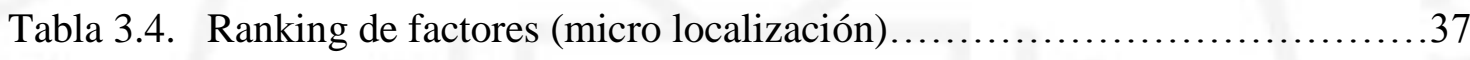

Tabla 3.5. Ranking de factores (micro localización) ............................ 38

Tabla 4.1. Lista de mantenimientos preventivos para la cortadora láser..............40

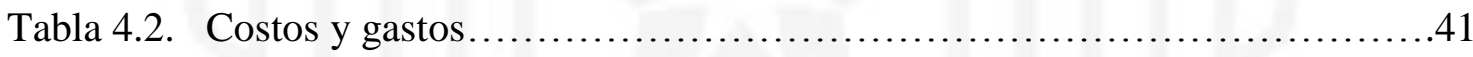

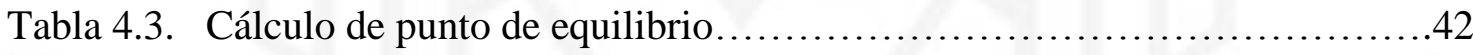

Tabla 4.4. Dimensionamiento del servicio...................................42

Tabla 5.1. Especificaciones técnicas - Lámpara infantil.......................45

Tabla 5.2. Software de modelado paramétrico...............................54

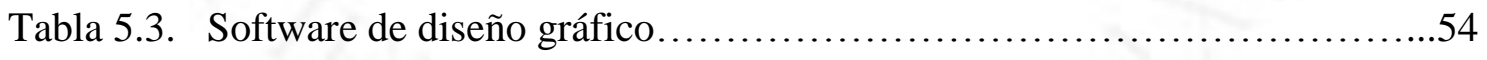

Tabla 5.4. Tecnologías de corte láser.......................................55

Tabla 5.5. Balance de materiales......................................... 70

Tabla 5.6. Características de la cortadora láser modelo RDJ-1390 - Robotek..........73

Tabla 5.7. Características de la cortadora láser modelo LS-5070 - Láser Edge.........73

Tabla 5.8. Características de la cortadora láser modelo Fusion 40 - Epilog..........73 
Tabla 5.9. Comparación de modelos de cortadora láser.............................74

Tabla 5.10. Características del compresor Pitbull modelo ZBM-25a $\ldots \ldots \ldots \ldots \ldots \ldots \ldots . . . \ldots 4$

Tabla 5.11. Características del compresor Bauker modelo Euro 225 .................75

Tabla 5.12. Características del compresor Daewoo modelo DAC 24D..................75

Tabla 5.13. Características del extractor marca Maquicorte..........................76

Tabla 5.14. Características de una desktop Dell modelo Optiplex 7010...............76

Tabla 5.15. Características de una desktop HP modelo Elite 8200...................77

Tabla 5.16. Características de una desktop Lenovo modelo ThinkCenter M92p........77

Tabla 5.17. Características de una carretilla hidráulica de tipo genérico..............78

Tabla 5.18. Características de una carretilla hidráulica marca Rhyno..................78

Tabla 5.19. Lista de tiempos no productivos del operario de corte láser................83

Tabla 5.20. Cálculo de capacidad diaria por operario/técnico de corte láser............83

Tabla 5.21. Matriz de Leopold........................................... 86

Tabla 5.22. Matriz de análisis preliminar de riesgos (APR) $\ldots \ldots \ldots \ldots \ldots \ldots \ldots \ldots \ldots \ldots . \ldots 8$

Tabla 5.23. Mantenimiento preventivo y reactivo................................ 89

Tabla 5.24. Programa de producción 2019 - 2023 (cajas)..........................90

Tabla 5.25. Balance de materiales...............................................91

Tabla 5.26. Requerimiento de materiales.....................................91

Tabla 5.27. Consumo eléctrico por máquina / equipo.............................92

Tabla 5.28. Método de Guerchet (elementos estáticos) .............................96

Tabla 5.29. Método de Guerchet (elementos móviles)............................96

Tabla 5.30. Método de Guerchet (cálculo de área total)..........................97

Tabla 5.31. Área de almacén de materias primas................................98

Tabla 5.32. Área administrativa............................................. 98

Tabla 5.33. Superficie por área......................................... 99 
Tabla 5.34. Cronograma del proyecto. 104

Tabla 5.35. Diagrama de Gantt.............................................. 105

Tabla 6.1. Requerimiento de servicios de terceros...............................109

Tabla 7.1. Inversión fija tangible e intangible....................................112

Tabla 7.2. Capital de trabajo................................................ 114

Tabla 7.3. Inversión total.................................................. 115

Tabla 7.4. Modelo de valorización de activos financieros..........................115

Tabla 7.5. Costos de materia prima, insumos y materiales proyectadas..............116

Tabla 7.6. Costos de la mano de obra directa...................................117

Tabla 7.7. Costos de servicios indirectos...................................117

Tabla 7.8. Presupuesto de ingreso por ventas...............................118

Tabla 7.9. Costos de materia prima, insumos y materiales proyectados............118

Tabla 7.10. Presupuesto de depreciación y amortización.........................119

Tabla 7.11. Amortización de activos fijos intangibles..............................120

Tabla 7.12. Presupuesto CIF............................................... 121

Tabla 7.13. Presupuesto de costos de producción.................................121

Tabla 7.14. Presupuesto de gastos generales.................................121

Tabla 7.15. Cronograma de pagos del financiamiento (en soles) ....................122

Tabla 7.16. Estado de resultados (en soles) .....................................123

Tabla 7.17. Estado de situación financiera....................................... 124

Tabla 7.18. Flujo de fondos económicos (en soles).............................125

Tabla 7.19. Flujo de fondos financieros (en soles) ...............................126

Tabla 7.20. Cálculo del CCPP del proyecto...................................127

Tabla 7.21. Evaluación económica............................................... 127

Tabla 7.22. Evaluación financiera.......................................... 128 
Tabla 7.23. Análisis de sensibilidad del escenario pesimista (FCF) .................129

Tabla 7.24. Análisis de sensibilidad escenario moderado (FCF) ....................129

Tabla 7.25. Análisis de sensibilidad escenario optimista (FCF) .....................130

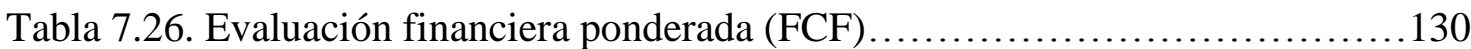

Tabla 7.27. Análisis de la evaluación financiera ponderada $(\mathrm{FCF}) \ldots \ldots \ldots \ldots \ldots \ldots \ldots 1$

Tabla 8.1. Proyección del valor agregado del proyecto...........................132 


\section{ÍNDICE DE FIGURAS}

Figura 1.1. Porcentaje de plantas de producción que enfrentan el reto doble de desarrollo constante de nuevos productos y servicios

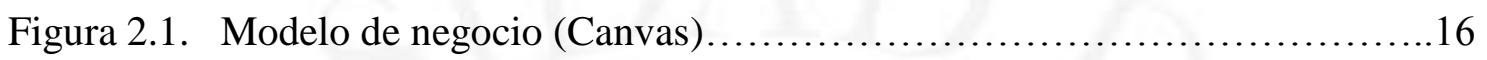

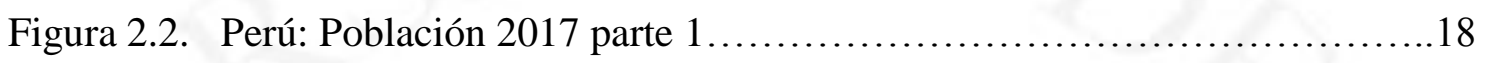

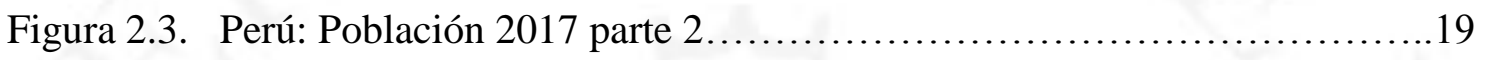

Figura 2.4. Lima Metropolitana: Personas según nivel socioeconómico 2017........20

Figura 2.5. Lima Metropolitana: Población por segmento de edad $2017 \ldots \ldots \ldots \ldots \ldots . .21$

Figura 2.6. Crecimiento demográfico en Lima Metropolitana......................22

Figura 2.7. Crecimiento demográfico de niños y niñas en su primera infancia (0-5 años)

Figura 2.8. Crecimiento demográfico de niños y niñas en su primera infancia (0-5 años) de NSE C y D.... .24

Figura 2.9. Demanda potencial del proyecto (en base a nacimiento anuales).........25

Figura 2.10. Demanda del proyecto (en base a nacimientos anuales) $\ldots \ldots \ldots \ldots \ldots \ldots . .28$

Figura 2.11. Perú: Producto bruto interno total y por habitante, 1994-2017.............31

Figura 5.1. Ficha técnica de foco ahorrador marca Daiku.........................44

Figura 5.2. Centro de ensamble de piezas inferior.............................46

Figura 5.3. Centro de ensamble de piezas superior............................47

Figura 5.4. Lado de ensamble............................................48

Figura 5.5. Lado de ensamble con soporte.....................................49

Figura 5.6. Centro de ensamble de piezas inferior extruido.....................50

Figura 5.7. Centro de ensamble de piezas superior extruido.....................50 
Figura 5.8. Lado de ensamble extruido......................................51

Figura 5.9. Lado de ensamble con soporte extruido.............................51

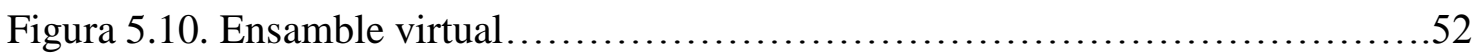

Figura 5.11. Vistas isométricas del producto con cotas...........................53

Figura 5.12. Visualización del diseño en el software Adobe Ilustrator.................57

Figura 5.13. Parámetros de corte laser........................................58

Figura 5.14. Tiempo de corte láser........................................59

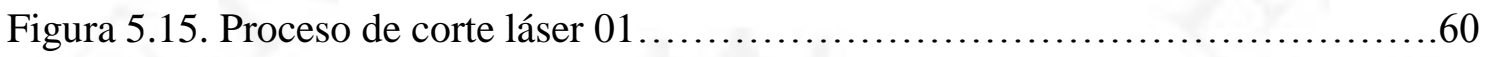

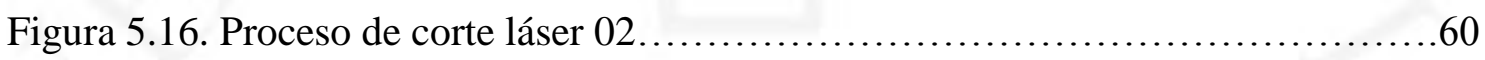

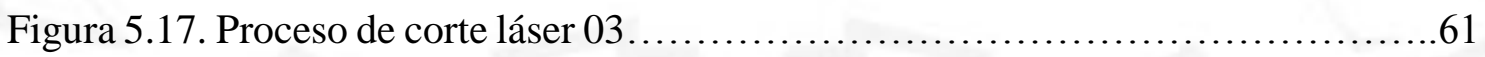

Figura 5.18. Herramientas e insumos para la fabricación de una lámpara..............62

Figura 5.19. Corte de cable mellizo.......................................63

Figura 5.20. Pelado de cable mellizo.......................................63

Figura 5.21. Acoplamiento de cable mellizo al enchufe...........................64

Figura 5.22. Cable mellizo acoplado al enchufe................................65

Figura 5.23. Acoplamiento de cable mellizo al soquete...........................65

Figura 5.24. Piezas cortadas...............................................66

Figura 5.25. Prototipo ensamblado visto desde arriba...........................67

Figura 5.26. Prototipo ensamblado vista isométrica..............................68

Figura 5.27. Diagrama de operaciones del proceso...............................69

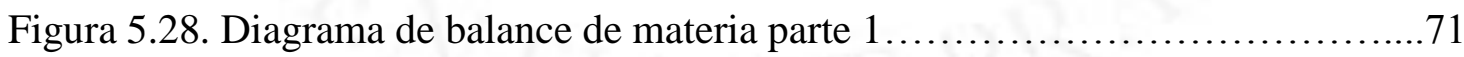

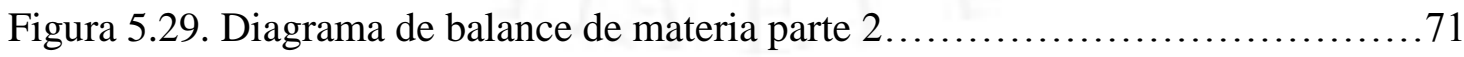

Figura 5.30. Especificaciones técnicas de una cortadora láser Robotek RDJ-1390.....79

Figura 5.31. Especificaciones técnicas de un compresor de aire Pitbull ZBM-25A....80

Figura 5.32. Especificaciones técnicas de una desktop Dell Optiplex-7010............81 
Figura 5.33. Dimensiones para la movilidad de la carretilla hidráulica...............99

Figura 5.34. Plano de seguridad............................................. 100

Figura 5.35. Plano de disposición de taller...................................... 102

Figura 5.36. Diagrama relacional............................................. 103

Figura 5.37. Diagrama relacional de actividades................................. 103

Figura 6.1. Organigrama preoperativo del proyecto........................... 110

Figura 6.2 . Organigrama de la empresa....................................111 


\section{ÍNDICE DE ANEXOS}

Anexo 1: Encuesta realizada: sección 1....................................... 141

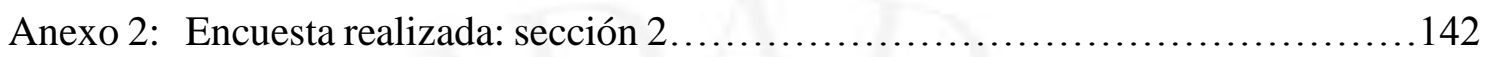

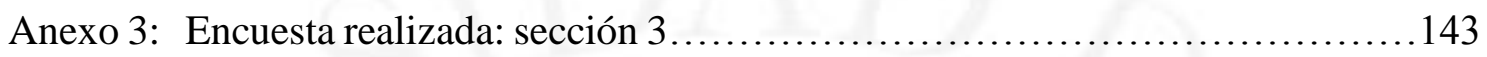

Anexo 4: Resultado de la encuesta: edad................................... 144

Anexo 5: Resultado de la encuesta: genero................................. 144

Anexo 6: Resultados de la encuesta: porcentaje de encuestados con hijos de 0-5 años de edad...................................................... 145

Anexo 7: Resultado de la encuesta: intención de compra parte $1 \ldots \ldots \ldots \ldots \ldots \ldots \ldots . . \ldots 145$

Anexo 8: Resultado de la encuesta: intención de compra parte $2 \ldots \ldots \ldots \ldots \ldots \ldots \ldots . \ldots 146$

Anexo 9: Resultado de la encuesta: intensidad de compra parte $1 \ldots \ldots \ldots \ldots \ldots \ldots \ldots . \ldots 146$

Anexo 10: Resultado de la encuesta: intensidad de compra parte $2 \ldots \ldots \ldots \ldots \ldots \ldots \ldots 147$ 


\section{RESUMEN EJECUTIVO}

El presente análisis tiene como objetivo la implementación de un taller de fabricación digital de lámparas infantiles y surge de las nuevas necesidades que surgen en nuestro mercado con el fin de buscar la originalidad. Al utilizar tecnologías de corte láser se logra una gran facilidad para generar nuevos diseños ajustándose a la demanda cambiante. Es debido a esto que se decidió evaluar su prefactibilidad.

Inicialmente, se realiza un estudio para calcular la demanda del proyecto. Dicho estudio usa herramientas de fuentes primarias y secundarias como: tesis, información de fuentes estatales (INEI, CPI) y 2 encuestas. En base a la información que se recopilo los padres y madres de recién nacidos y niños/as de 1 año son quienes tienen la mayor probabilidad de comprar el producto 92,7\% (padres con hijos de 2-5 años reportaron una probabilidad de $33,33 \%$ ), eso dirige a que este proyecto se enfoque en los padres de recién nacidos como público objetivo. Por otro lado, los gráficos del CPI demuestran que existe una mayoría (67\%) de habitantes de nivel socioeconómico C y D en Lima Metropolitana que generaran la demanda para el proyecto demostrando ser un segmento apropiado al cual apuntar. También pudo observar que los padres y madres jóvenes de 24 a 30 años de edad forman la mayor parte de nuestro mercado objetivo 70,23\%. Esta encuesta a su vez nos revelo la intención e intensidad de compra de nuestro público y se realizó a 369 personas en un rango de edad de 24 a 55 años.

En relación con la oferta se investigaron las compañías que compiten en nuestro segmento de la población como SODIMAC para analizar tanto sus estrategias como los precios de sus productos que actualmente se venden en Lima Metropolitana. Esto tiene gran valor para la investigación pues nos permite contrastar modelos de negocio que actualmente están desempeñando en el mercado real acercándonos lo más posible a un modelo más realista.

Otro aspecto importante es la localización de la planta, se realizó un análisis comparativo de las diferentes posibilidades de localización para el taller utilizando el método de ranking de factores y se determinó que el taller/planta estará ubicada en el área 
de Monterrico en Surco por su disponibilidad de terreno, proximidad al mercado objetivo, disponibilidad eléctrica y densidad de población.

Para el dimensionamiento del taller se determinó que el tamaño óptimo de la planta seria en base a la relación tamaño-tecnología que es de 12182 lámparas anuales. Luego se realizaron los cálculos necesarios y se determinó que la capacidad instalada de la planta será de 1015 lámparas mensuales. El área total del taller incluyendo las oficinas será de 90 metros cuadrados de los cuales se designarán 23 metros cuadrados para el área de operaciones.

La empresa será constituida como una sociedad anónima cerrada bajo el régimen tributario general. La organización de la empresa estará conformada por 1 operarios y 3 empleados. Se considerará de alta importancia que todos los integrantes de la empresa estén alineados con la cultura organizacional de la empresa.

La inversión total necesaria para realizar el proyecto será de 158 113,41 soles que serán financiados $63,25 \%$ a través de una entidad bancaria (BCP) y el resto aportado por los accionistas. En relación con la evaluación económica y financiera se obtuvo: VANE $=105238,99$ y VANF = 112 013,51 en ambos casos positivo; además, la TIRE = 37,65\% y la TIRF $=58,37 \%$ fueron mayores al CCPP del proyecto de $14,52 \%$.

Finalmente, se concluye que el proyecto es sostenible y viable, entregara beneficios a los socios y generara un impacto social positivo ya que agregara valor (genera PBI) y generara empleos con prácticas seguras para el medio ambiente. 


\section{EXECUTIVE SUMMARY}

The present pre-feasibility study for the implementation of a digital fabrication workshop for kids' bedside lamps is created by the new needs that appear in our market in search of originality. Utilizing laser cutting technologies it becomes easier to generate new models and designs adjusting to the changing demand. It is because of this that its prefeasibility is evaluated.

Initially, a study is conducted to determine the demand for the project. This study uses primary and secondary sources such as: thesis, state sources and 2 interviews as its main sources of information. Based on the collected information the parents of new born babies and 1-year old's have a higher probability of buying our product 92,7\% (parents with children from 2 to 5 years old have a probability of buying a lamp of 33,33\%) this directs our study towards parents of new born babies as our target market. On the other hand, the graphs provided by the CPI demonstrate that the majority of lima is in the socioeconomic sectors C and D (67\%) whom will generate the demand for our products. It was also observed that young parents (from 24 to 30 years old) form the biggest portion of our target market with 70,23\%. This interview also revealed the intention and intensity to buy of our target market and was asked to 369 people in the age range of 24 to 55 years of age.

In relation to the offer companies that compete in our sector were investigated such as SODIMAC to analyze their strategies and prices set on the products they sell in Metropolitan Lima. This has great value to our study because It allows us to compare the business models being used in the present and help us get our model as close as possible to reality.

Another important aspect is geographical location for the workshop, a comparison analysis was done to different locations around Metropolitan Lima using the Factor Ranking method and it was determined that the location for the workshop will be in the area of Monterrico, Surco because of its land availability, proximity to the target market, electrical availability and population density. 
Regarding the sizing of the workshop it was determined that the optimum size would be based in the relationship between size and technology which results in 12182 lamps per year. Following, it was calculated that the installed capacity for the workshop will be of 1015 lamps per month. The total area for the workshop including offices will be $90 \mathrm{~m}^{2}$ from which 23 will be destined to the operations area.

The company will be constituted as a Closed Anonymous Society under the regular tributary regime. The company's organization will be made up by 1 worker and 3 employees. It is considered of high importance that all members of the enterprise are aligned with the organizational culture for the company.

The total investment needed to carry out the project will be of 158113,41 Peruvian soles that will be financed 63,25\% through a bank (BCP) and the rest will be supplied by the shareholders. In regard to the economic and financial evaluation the next stats were obtained: ENPV $=105$ 238,99 and FENP $=112$ 013,51 both cases positive; also, the EIRR $=37,65 \%$ and the FIRR $=58,37 \%$ which were both higher than the WAAC for the project of $14,52 \%$.

Finally, we conclude that the project is feasible and sustainable, it will return benefits to its shareholders and generate a positive social impact by generating value (generating GDP) and generating jobs with safe practices for the environment. 


\section{CAPÍTULO I: ASPECTOS GENERALES}

\subsection{Problemática}

El mundo en los últimos años ha incorporado la fabricación digital a múltiples rubros de las prácticas existentes. Esta es una nueva forma de entregar artículos de calidad al cliente ya que se pueden adaptar fácilmente para darle un toque personalizado. Este tipo de producción no incurre en los típicos costos del rubro debido a la digitalización del proceso de diseño y prototipado dándole una ventaja competitiva para generar artículos de calidad a un bajo costo.

En los últimos años el turismo ha ido incrementando en nuestro país, mientras aumenta la estabilidad económica y la calidad de vida en nuestro país muchas oportunidades para este rubro se han hecho posibles donde antes no lo eran. Según los datos del INEI la cifra de visitantes que ingresaron al país en el año 2010 superó los 2 787000 y solo dos años luego en el 2012 se registró un aumento de aproximadamente 700 mil visitantes, así mismo los ingresos por este rubro también aumentaron demostrando un claro crecimiento de este sector.

La propuesta de manera resumida será generar lámparas domésticas infantiles personalizadas. Estos artículos podrán captar una demanda todavía no satisfecha en su totalidad del mercado económicamente activo de la población de Lima, Perú. Lo que pone dicha propuesta en un mercado aún no satisfecho es la rápida personalización por un bajo costo que ofrece a sus clientes pudiendo al mismo tiempo masificar los diseños y atender al consumidor directamente. Observando el crecimiento de este sector y la falta de alcance de las marcas disponibles debido a sus altos costos o limitada capacidad de adaptar sus diseños a la demanda local podemos percibir una oportunidad para generar desarrollo en el país entregando un servicio de calidad para que sea más agradable y económica la decoración e iluminación del hogar. 


\subsection{Objetivos de la investigación:}

A continuación se detalla el objetivo general y los objetivos específicos de la investigación.

\subsubsection{Objetivo general:}

Proponer un emprendimiento que utilice tecnologías de fabricación digital para la producción de lámparas infantiles domesticas personalizadas de bajo costo es económicamente viable en Lima, Perú.

\subsubsection{Objetivos específicos:}

- Verificar la viabilidad tecnológica de implementar el diseño, la producción y la venta de artículos domésticos personalizados utilizando la tecnología de fabricación digital en Lima, Perú (Disponibilidad de Mano de Obra calificada y Maquinaria).

- Establecer la prefactibilidad, sostenibilidad y viabilidad de un taller de fabricación digital para lámparas infantiles de diseños innovadores, mediante el uso de la metodología de análisis de proyectos.

- Identificar un mercado para la venta de artículos domésticos modulares, innovadores y personalizados fabricados con tecnologías de corte láser en Lima, Perú.

- Verificar la viabilidad económica de implementar el diseño, la producción y la venta de artículos domésticos personalizados utilizando la tecnología de fabricación digital en Lima, Perú.

\subsection{Alcance de la investigación}

A continuación se detalla el alcance de la investigación refiriéndose a: la unidad de análisis, la población, el espacio, el tiempo y las limitaciones de la investigación. 


\subsubsection{Unidad de análisis:}

Una lámpara innovadora y segura fabricada con tecnologías de corte láser y programas de diseño 3D.

\subsubsection{Población:}

La población estará conformada por los grupos de peruanos interesados en lámparas infantiles con diseños personalizados que también poseen una capacidad adquisitiva de nivel medio y tienen hijos de 0 a 5 años de edad.

\subsubsection{Espacio:}

El área geográfica de estudio será Lima Metropolitana.

\subsubsection{Tiempo:}

El intervalo de tiempo para la investigación será desde el 30/11/2018 hasta el 30/03/2019.

\subsubsection{Limitaciones de la investigación:}

Se utilizará muestreo no probabilístico por el alto costo económico y la alta dificultad de realizar una encuesta verdaderamente aleatoria como un muestreo probabilístico requiere. Se intentará realizar el muestreo de la manera más objetiva y aleatoria posible, pero no se tomarán todas las medidas necesarias para llamar el tipo de muestreo probabilístico.

\subsection{Justificación de la Investigación}

En este subcapítulo se detallará la justificación técnica, económica y social de la investigación. 


\subsubsection{Técnica:}

La justificación técnica para la investigación se basa en que ya existen emprendimientos de este tipo en el mundo. También es un hecho que hay un gran grupo de peruanos que utilizan la fabricación digital en sus diferentes rubros para darles una ventaja competitiva lo que demuestra la disponibilidad de dichas tecnologías en el mercado local. Por otro lado, existen profesionales. capacitados para utilizar la fabricación digital y generar los diseños necesarios para el emprendimiento propuesto.

\subsubsection{Económica:}

Para justificar económicamente la investigación nos basamos en que ya existen diferentes empresas rentables utilizando este tipo de fabricación en todo el mundo. Se utilizará publicidad mediante redes como Facebook y Instagram reduciendo drásticamente los costos. Por otro lado, la formación de alianzas comerciales y estratégicas con artistas locales para introducir sus diseños en forma de colaboración conjunta apoyarán la rentabilidad del proyecto. Finalmente, para conseguir el financiamiento el emprendimiento podrá recurrir a inversionistas locales y bancos.

\subsubsection{Social:}

Una marca de artículos personalizados hechos con tecnologías de fabricación digital basa su justificación social en múltiples factores como el desarrollo de la exposición de nuestra cultura y arte local incrementando dicha exposición no solo en el Perú sino al mundo a través de redes sociales como Instagram. Por otro lado, incrementa la variedad y la oferta de productos domésticos personalizados en el mercado peruano. Finalmente, esto aumentará el PBI del país acelerando la adopción de una nueva tecnología con mucho potencial de crecimiento en un entorno que demanda desarrollo de nuevos productos en paralelo a la producción de los actuales como lo muestra la figura siguiente. 
Figura 1.1

Porcentaje de plantas de producción que enfrentan el reto doble de desarrollo constante de nuevos productos y servicios

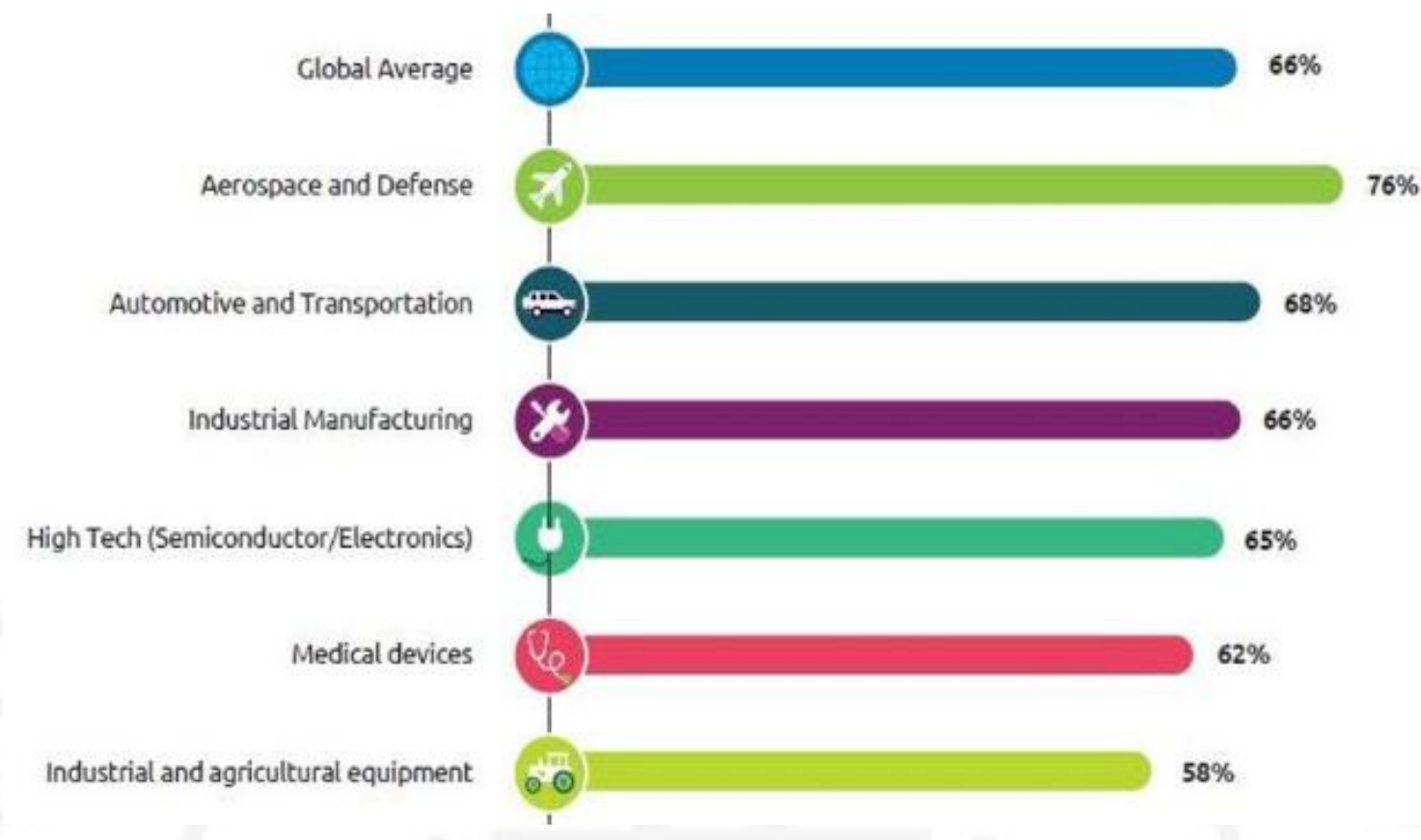

Fuente: Capgemini Digital Transformation Institute (2018)

\subsection{Hipótesis de trabajo}

La fabricación y venta de lámparas infantiles domésticas personalizados utilizando tecnologías de fabricación digital en Lima, Perú es viable económica, tecnológica y socialmente. 


\subsection{Marco referencial}

\section{Tabla 1.1}

\section{Marco referencial}

\begin{tabular}{|c|c|c|}
\hline Investigaciones Previas & Similitudes & Diferencias \\
\hline $\begin{array}{l}\text { Estudio tecnológico: } \\
\text { fabricación de artículos de } \\
\text { madera para uso } \\
\text { doméstico. } \\
\text { Pipoli Velarde, Franco }\end{array}$ & $\begin{array}{l}\text { Se enfocan en productos de madera } \\
\text { para uso doméstico. } \\
\text { Se propone venderlos dentro del } \\
\text { Perú. }\end{array}$ & $\begin{array}{l}\text { Se enfoca en } \\
\text { métodos } \\
\text { anticuados de } \\
\text { manufactura } \\
\text { mientras que mi } \\
\text { propuesta utilizará } \\
\text { métodos de } \\
\text { fabricación digital. }\end{array}$ \\
\hline $\begin{array}{l}\text { Proyecto de prefactibilidad } \\
\text { para la creación de una } \\
\text { empresa dedicada a la } \\
\text { fabricación de muebles de } \\
\text { madera: línea de oficina } \\
\text { Klima Haidinger, Pedro } \\
\text { Eduardo } \\
\end{array}$ & $\begin{array}{l}\text { Estudian la viabilidad económica de } \\
\text { basar un negocio en la venta de } \\
\text { artículos de madera dentro del } \\
\text { Perú. }\end{array}$ & $\begin{array}{l}\text { Se investiga la } \\
\text { venta de muebles } \\
\text { de oficina mientras } \\
\text { que mi propuesta } \\
\text { estudia la venta de } \\
\text { artículos } \\
\text { domésticos. }\end{array}$ \\
\hline $\begin{array}{l}\text { Estudio tecnológico para la } \\
\text { elaboración de muebles de } \\
\text { madera no ensamblados } \\
\text { "kits" } \\
\text { Carranza Llerena, Álvaro } \\
\text { Jorge }\end{array}$ & $\begin{array}{l}\text { Plantean vender productos no } \\
\text { ensamblados o press fits. }\end{array}$ & $\begin{array}{l}\text { Esta investigación } \\
\text { plantea vender } \\
\text { muebles mientras } \\
\text { que la mía propone } \\
\text { vender artículos } \\
\text { domésticos como } \\
\text { lámparas y } \\
\text { adornos. }\end{array}$ \\
\hline $\begin{array}{l}\text { Estudio tecnológico para la } \\
\text { elaboración de muebles de } \\
\text { oficina de madera } \\
\text { Sandoval Palacios, Cecilia }\end{array}$ & $\begin{array}{l}\text { Estudian la viabilidad económica de } \\
\text { basar un negocio en la venta de } \\
\text { artículos de madera dentro del } \\
\text { Perú. }\end{array}$ & $\begin{array}{l}\text { Se investiga la } \\
\text { venta de muebles } \\
\text { de oficina mientras } \\
\text { que mi propuesta } \\
\text { estudia la venta de } \\
\text { artículos } \\
\text { domésticos. }\end{array}$ \\
\hline $\begin{array}{l}\text { Estudio preliminar para la } \\
\text { implementación de una } \\
\text { pequeña fábrica de muebles } \\
\text { modulares de madera (línea } \\
\text { juvenil) } \\
\text { Vega Menéndez, María } \\
\text { Helena }\end{array}$ & $\begin{array}{l}\text { Estudian la viabilidad económica de } \\
\text { basar un negocio en la venta de } \\
\text { artículos de madera dentro del } \\
\text { Perú. }\end{array}$ & $\begin{array}{l}\text { Se investiga la } \\
\text { venta de muebles } \\
\text { modulares de } \\
\text { madera para } \\
\text { niños/as mientras } \\
\text { que mi propuesta } \\
\text { estudia la venta de } \\
\text { artículos } \\
\text { domésticos. } \\
\end{array}$ \\
\hline
\end{tabular}

Elaboración propia 


\subsection{Marco conceptual}

La fabricación digital es una tecnología relativamente nueva en nuestro país, aparte de generar ventajas para empresas existentes también ofrece la oportunidad para que nuevos modelos de emprendimientos surjan reduciendo el daño al medio ambiente, los costos e incrementando la calidad de los productos junto con su adaptabilidad. Mediante este estudio apoyándonos en diversas herramientas de ingeniería podremos verificar la viabilidad de la fabricación y venta de artículos domésticos personalizados utilizando tecnologías de fabricación digital en Lima metropolitana apoyando a su economía sin sacrificar su valioso ecosistema.

Glosario de términos:

- Tecnologías de Fabricación Digital: Se refiere a todas las tecnologías de fabricación que apoyándose en el diseño digitalizado pueden producir de manera consistente objetos y adaptaciones a objetos con un muy bajo riesgo de error y una alta calidad consistentemente.

- Negocio Sostenible: Se le llama a un negocio que genera utilidades sin consumir recursos no renovables ni dañando al medio ambiente.

- Análisis FODA: es el análisis de las debilidades, fortalezas, oportunidades y amenazas de una empresa y su entorno.

- Técnica Blue Ocean: Se utiliza para redirigir la empresa hacia un nuevo mercado objetivo donde no tenga que luchar con otras empresas por su participación en el mercado.

- Press fit: Manera de ensamblar únicamente utilizando la fricción natural entre las piezas de un objeto.

- Diagrama de Gozinto: Es un gráfico que muestra las relaciones que existen entre los diferentes componentes que conforman un producto. Esta realizado en estilo de esquema para facilitar la visualización de cómo se fabrica el producto de manera conceptual.

- MDF: Tablero de fibra de densidad media, es un producto derivado de la madera al compactarla utilizando $85 \%$ fibras de maderas varias y $15 \%$ resinas sintéticas dándole una mayor densidad que a los aglomerados tradicionales. 
- Diseño modular: Diseño basado en la modulación reticular de los espacios que permite optimizar la velocidad de fabricación, el fácil transporte del mismo tanto así como le permiten ser desarmable.

- Software de diseño 2D: Programa que permite el diseño paramétrico virtual en 2 dimensiones, puede utilizar pixeles o vectores.

- Software de diseño 3D: Programa que permite el modelado paramétrico virtual de sólidos en 3 dimensiones. 


\section{CAPÍTULO II: ESTUDIO DE MERCADO}

\subsection{Aspectos generales del estudio de mercado}

En este subcapítulo se detallarán los aspectos generales del estudio de mercado siendo estos: la definición comercial del producto, los usos de este, sus bienes sustitutos y complementarios, el área geográfica que abarcará, el análisis de su sector industrial y su modelo de negocio utilizando el modelo canvas.

\subsubsection{Definición comercial del producto}

Los productos serán lámparas domesticas infantiles personalizadas estilo press fit cuyo principal objetivo será satisfacer la demanda de artículos de calidad con mayor personalización en el mercado de Lima Metropolitana.

Producto básico: Lámpara doméstica infantil.

Producto real: Será una Lámpara doméstica infantil moderna producida con tecnologías de Fabricación Digital y generada con diseños novedosos para el usuario con una calidad consistente y opciones para adaptar su modelo que estará embalado en una caja de cartón.

Producto aumentado: Se ofrecerán lámparas domesticas infantiles personalizadas para su público objetivo en tiendas de venta al por menor con una alta rotación no solo de inventarios sino también de diseños logrando cumplir con el deseo del público de diferenciarse mientras se logra una decoración agradable de su hogar. Por otro lado, se generará publicidad y diseños artísticos realizando colaboraciones con artistas locales siendo esto publicado a través de redes sociales como Instagram y Facebook.

Nuestros diseños serán generados por un diseñador industrial siendo este capacitado constantemente para mejorar y aumentar la variedad de modelos disponibles exponiendo empíricamente la versatilidad del emprendimiento. 


\subsubsection{Usos del producto, bienes sustitutos y complementarios}

El principal uso del producto será alumbrar una zona específica dentro del hogar como también decorar el ambiente doméstico generando una sensación positiva en sus usuarios.

Los bienes sustitutos a las lámparas serían las adaptaciones al sistema de iluminación doméstico y los dispositivos con iluminación propia.

Los bienes complementarios para las lámparas serán objetos donde se pueden colocar las lámparas como mesas y multiconectores.

\subsubsection{Determinación del área geográfica que abarca el producto}

El área geográfica que abarca el producto será Lima Metropolitana.

\subsubsection{Análisis del sector industrial (cinco fuerzas de PORTER)}

Amenaza de nuevos participantes (ALTO): Los nuevos participantes serían otros negocios de fabricación digital lo que forzará al emprendimiento a enfocarse más en los diseños únicos y sacar nuevos diseños consistentemente para diferenciarse, incrementar el valor de sus productos y mantener a sus clientes.

Barreras de entrada

- Se necesitarán tecnologías de fabricación digital de alta gama para poder ofrecer un servicio de alta calidad.

- La disponibilidad de nuestro país para los materiales de producción es limitada.

- No se posee la patente de los productos lo que momentáneamente permite que otras empresas utilicen nuestros diseños.

- A inicios del proyecto este no será muy rentable, pues su rentabilidad se basará en relación con el nivel de ventas y este se refleja en la adquisición de contratos con los puntos de venta al por menor.

Por estas razones el nivel de amenaza de nuevos participantes es ALTO. 
Poder de negociación de los proveedores (BAJO): Existen múltiples proveedores de las máquinas y materiales necesarios para este sector. La mayor limitante es la logística de traerlos al Perú, pero es factible tercerizando el desaduanaje lo que les da a los proveedores un poder de negociación BAJO.

Poder de negociación de los compradores (MEDIO): El producto se venderá a un precio definitivo, pero este precio se elegirá tomando en consideración la capacidad adquisitiva y cultura de compra de su mercado dándoles un poder de negociación MEDIO.

Amenaza de los sustitutos (BAJO): La amenaza de los productos sustitutos es baja ya que no compiten por el mismo tipo de clientes, normalmente los clientes que adaptan sus hogares de manera estructural para no necesitar lámparas son pocos y a los clientes les agrada tener sus hogares bien iluminados. Por otro lado, el alto costo de las adaptaciones también separa nuestros mercados generando una oportunidad de estar apuntando al espacio de océano azul o mercado no satisfecho, dándoles a los sustitutos un nivel de amenaza BAJO.

Rivalidad entre los competidores (ALTO): Todos los competidores apuntan al mismo mercado lo que dificulta mantener a nuestros clientes y por la variabilidad de la demanda será complicado elegir la capacidad de producción en relación con la inversión en las maquinarias. Debido a esto el nivel de rivalidad entre los competidores será ALTO. 


\subsubsection{Modelo de Negocios (Canvas)}

A continuación se detalla el modelo de negocio estilo canvas para la investigación.

Figura 2.1

Modelo de negocio (Canvas)

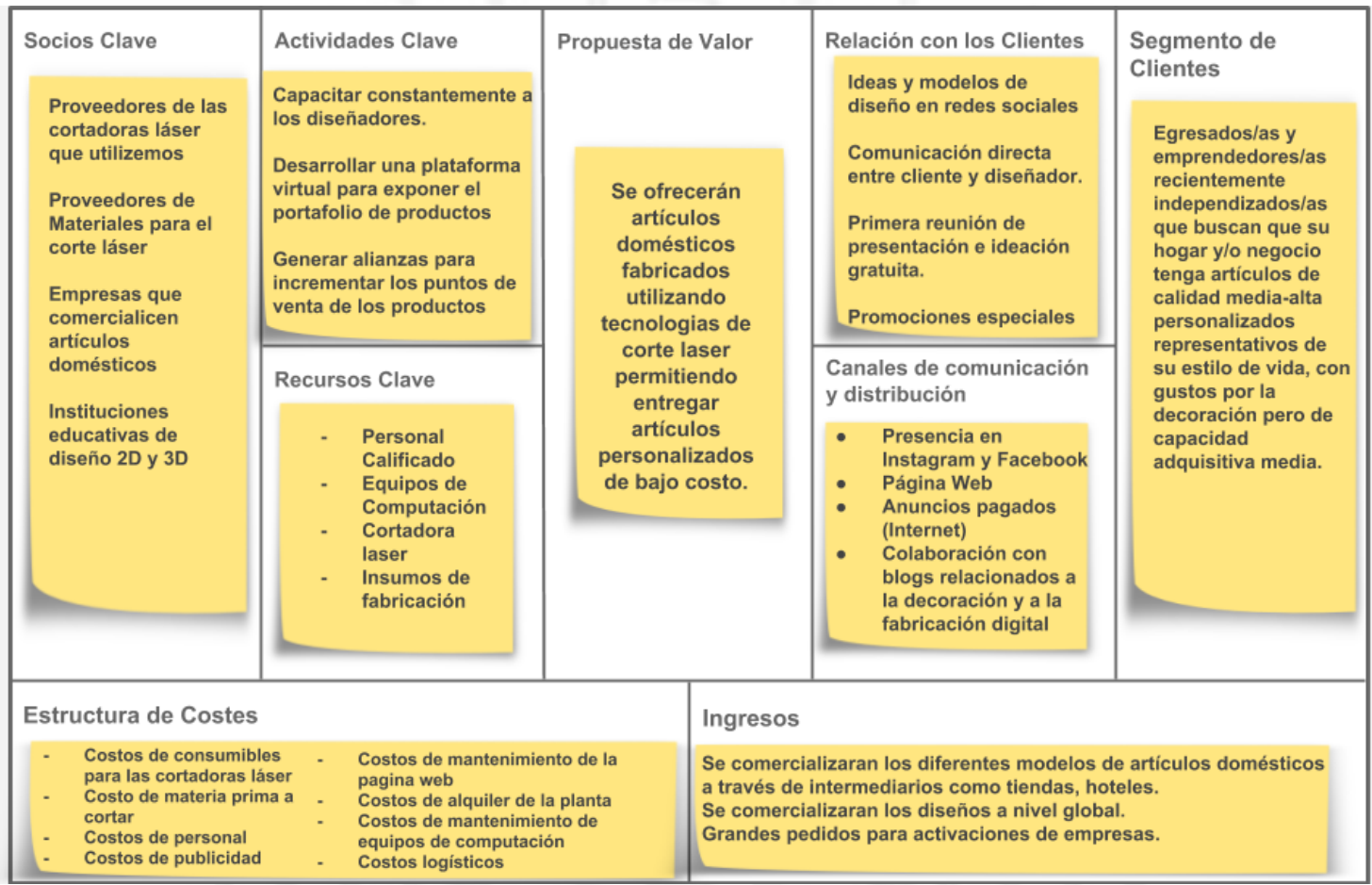

Elaboración propia

\subsection{Metodología para emplear en la investigación de mercado}

La metodología que se utilizará para realizar este proyecto requiere de múltiples fuentes de información, primarias y secundarias. Se recopilará información de Internet, pues para el proyecto que se está proponiendo las otras fuentes de información secundarias no contendrán suficiente información relevante. Para recopilar información primaria se realizarán encuestas para conseguir información cuantitativa.

\subsection{Demanda potencial}

En este subcapítulo se demostrará la demanda potencial del proyecto según su segmentación de mercado según los patrones de consumo que incluyen incremento 
poblacional, estacionalidad y aspectos culturales de la población que habita en el área geográfica del producto.

\subsubsection{Patrones de consumo: incremento poblacional, estacionalidad y aspectos culturales}

La población peruana viene incrementando en promedio 301 mil habitantes al año según los censos realizados en el país por el INEI en el 2007 y el 2017. Al representar Lima Metropolitana a un 32,68\% (10 millones 209 mil habitantes en el 2017) de la población según el estudio realizado por el CPI su incremento poblacional será en promedio de 98 367 habitantes al año lo que significa que nuestro mercado objetivo de niños y niñas de 0 a 5 años de edad está incrementando 9148 anualmente tomando en cuenta un 9,3\% de niños y niñas de dichas edades en Lima Metropolitana según el estudio mencionado del CPI.

\section{Tabla 2.1}

Perú: Crecimiento y distribución de la población, 2017

\section{Cuadro 01}

PERÚ: POBLACIÓN CENSADA, OMITIDA Y TOTAL, SEGÚN CENSOS REALIZADOS, 1940 - 2017

\begin{tabular}{rrrr}
\hline \multirow{2}{*}{ AÑo } & \multicolumn{3}{c}{ POBLACIÓN } \\
\cline { 2 - 3 } & \multicolumn{1}{c}{ CENSADA } & OMITIDA & TOTAL \\
\hline 1940 & 6207967 & 815144 & 7023111 \\
1961 & 9906746 & 513611 & 10420357 \\
1972 & 13538208 & 583356 & 14121564 \\
1981 & 17005210 & 757021 & 17762231 \\
1993 & 22048356 & 591087 & 22639443 \\
2007 & 27412157 & 808607 & 28220764 \\
2017 & 29381884 & 1855501 & 31237385
\end{tabular}


Figura 2.2

Perú: Población 2017 parte 1

\begin{tabular}{|c|c|c|c|c|}
\hline No. & DISTRITO & POBLACIÓN & $\%$ & HOGARES \\
\hline 1 & San Juan de Lurigancho & $1,121.3$ & 11.0 & 275.9 \\
\hline 2 & San Martin de Porres & 722.3 & 7.1 & 175.2 \\
\hline 3 & Ate & 646.9 & 6.3 & 158.6 \\
\hline 4 & Comas & 541.2 & 5.3 & 139.0 \\
\hline 5 & Villa El Salvador & 475.5 & 4.7 & 115.7 \\
\hline 6 & Villa María del Triunfo & 461.2 & 4.5 & 114.8 \\
\hline 7 & San Juan de Miraflores & 416.0 & 4.1 & 107.4 \\
\hline 8 & Los Olivos & 382.8 & 3.7 & 107.4 \\
\hline 9 & Puente Piedra & 362.1 & 3.5 & 88.3 \\
\hline 10 & Santiago de Surco & 357.6 & 3.5 & 107.8 \\
\hline 11 & Chorrillos & 335.6 & 3.3 & 89.4 \\
\hline 12 & Carabayllo & 310.1 & 3.0 & 75.2 \\
\hline 13 & Lima & 282.8 & 2.8 & 92.5 \\
\hline 14 & Santa Anita & 234.8 & 2.3 & 59.9 \\
\hline 15 & Lurigancho (Chosica) & 224.9 & 2.2 & 56.0 \\
\hline 16 & Independencia & 223.6 & 2.2 & 67.8 \\
\hline 17 & El Agustino & 196.9 & 1.9 & 52.1 \\
\hline 18 & La Molina & 178.2 & 1.7 & 48.0 \\
\hline 19 & La Victoria & 177.7 & 1.7 & 56.4 \\
\hline 20 & Rimac & 170.6 & 1.7 & 50.5 \\
\hline 21 & San Miguel & 140.9 & 1.4 & 44.8 \\
\hline 22 & Pachacamac & 132.8 & 1.3 & 32.4 \\
\hline 23 & San Borja & 116.7 & 1.1 & 37.8 \\
\hline 24 & Surquillo & 94.9 & 0.9 & 33.0 \\
\hline 25 & Lurin & 87.4 & 0.9 & 21.5 \\
\hline
\end{tabular}

Fuente: Compañía Peruana de Estudios de Mercados y Opinión Pública, CPI. (2017) 
Figura 2.3

Perú: Población 2017 parte 2

\begin{tabular}{|c|c|c|c|c|}
\hline 26 & Miraflores & 85.8 & 0.8 & 33.7 \\
\hline 27 & Pueblo Libre & 79.4 & 0.8 & 27.7 \\
\hline 28 & Breña & 78.9 & 0.8 & 26.4 \\
\hline 29 & Jesús Maria & 74.7 & 0.7 & 23.9 \\
\hline 30 & San Luis & 59.6 & 0.6 & 19.5 \\
\hline 31 & Magdalena del Mar & 56.9 & 0.6 & 19.0 \\
\hline 32 & San Isidro & 56.8 & 0.6 & 23.2 \\
\hline 33 & Lince & 52.4 & 0.5 & 18.9 \\
\hline 34 & Cieneguilla & 48.4 & 0.5 & 11.8 \\
\hline 35 & Chaclacayo & 44.9 & 0.4 & 13. \\
\hline 36 & Ancón & 44.6 & 0.4 & 12.0 \\
\hline 37 & Barranco & 31.2 & 0.3 & 10.9 \\
\hline 38 & Santa Rosa & 19.3 & 0.2 & 4.7 \\
\hline 39 & Pucusana & 17.5 & 0.2 & 4.3 \\
\hline 40 & Punta Negra & 8.1 & 0.1 & 2.2 \\
\hline 41 & San Bartolo & 7.9 & 0.1 & 2.2 \\
\hline 42 & Punta Hermosa & 7.8 & 0.1 & 2.2 \\
\hline 43 & Santa Maria del Mar & 1.6 & 0.0 & 0 \\
\hline & Total Provincia De Lima & 9.170 .6 & 89.8 & 2.463 .6 \\
\hline 44 & Callao & 433.0 & 4.3 & 109.7 \\
\hline 45 & Ventanilla & 360.0 & 3.6 & 92.0 \\
\hline 46 & Bellavista & 79.4 & 0.8 & 21.8 \\
\hline 47 & La Perla & 65.2 & 0.6 & 17 \\
\hline 48 & Mi Perú & 53.3 & 0.5 & 13.6 \\
\hline 49 & Carmen de La Legua Reynoso & 43.7 & 0.4 & 13.7 \\
\hline 50 & La Punta & 4.1 & 0.0 & 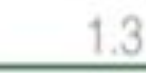 \\
\hline \multicolumn{2}{|c|}{ Total Provincia del Callao } & $1,038.7$ & 10.2 & 269 \\
\hline \multicolumn{2}{|c|}{ Total Lima Metropolitana } & $10,209.3$ & 100.0 & 2732.7 \\
\hline
\end{tabular}

Fuente: Compañía Peruana de Estudios de Mercados y Opinión Pública, CPI. (2017) 
Existen incrementos estacionales en los gastos de nuestro mercado objetivo debido a las gratificaciones que se otorgan según la ley a finales de los meses de julio y diciembre lo que incrementa el poder adquisitivo de los habitantes de Lima durante dichas fechas. La estacionalidad también afecta a nuestros productos debido a las vacaciones pues incrementa la compra de lámparas para el hogar debido a los hogares vacacionales de los habitantes de Lima.

\subsubsection{Determinación de la demanda potencial en base a patrones de consumo similares}

La demanda potencial será que todas las personas que habiten en Lima Metropolitana de un NSE (Nivel Socioeconómico) de los sectores C y D con hijos de 0 a 5 años. Según el estudio realizado por el CPI en base a información del INEI los porcentajes de hogares según su NSE para los sectores C y D son de 43 y 24 respectivamente sumando en total el $67 \%$ de los hogares de Lima metropolitana.

Figura 2.4

Lima Metropolitana: Personas según nivel socioeconómico 2017

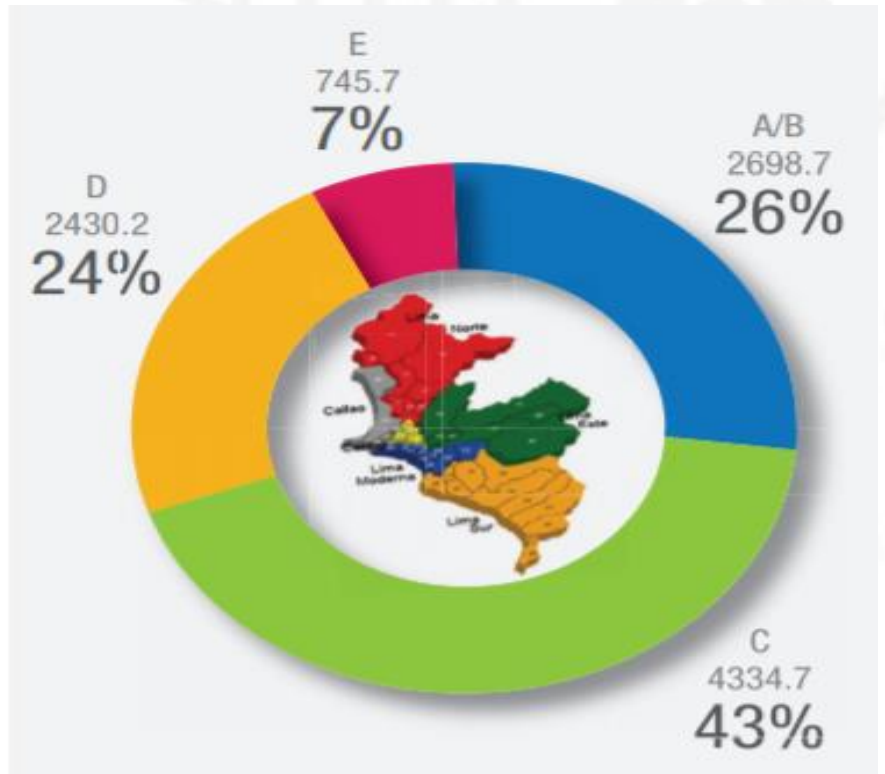

Fuente: Compañía Peruana de Estudios de Mercados y Opinión Pública, CPI. (2017) 
Según un estudio publicado por el CPI sobre Lima metropolitana en el 2017 habitaban 954500 niños y niñas entre las edades de 0 a 5 años (aproximadamente el 9,3\% de la población total de Lima metropolitana). Tomando en consideración el incremento poblacional de 98367 habitantes al año podemos asumir que la población de niños de 0 a 5 años ha incrementado 9148 este último año incrementando el total de niños y niñas de dichas edades a 963648 niños y niñas. Tomando en consideración que nuestro mercado objetivo son solo los sectores C y D nuestra demanda potencial seria de 645644 niños y niñas.

Figura 2.5

Lima Metropolitana: Población por segmento de edad 2017

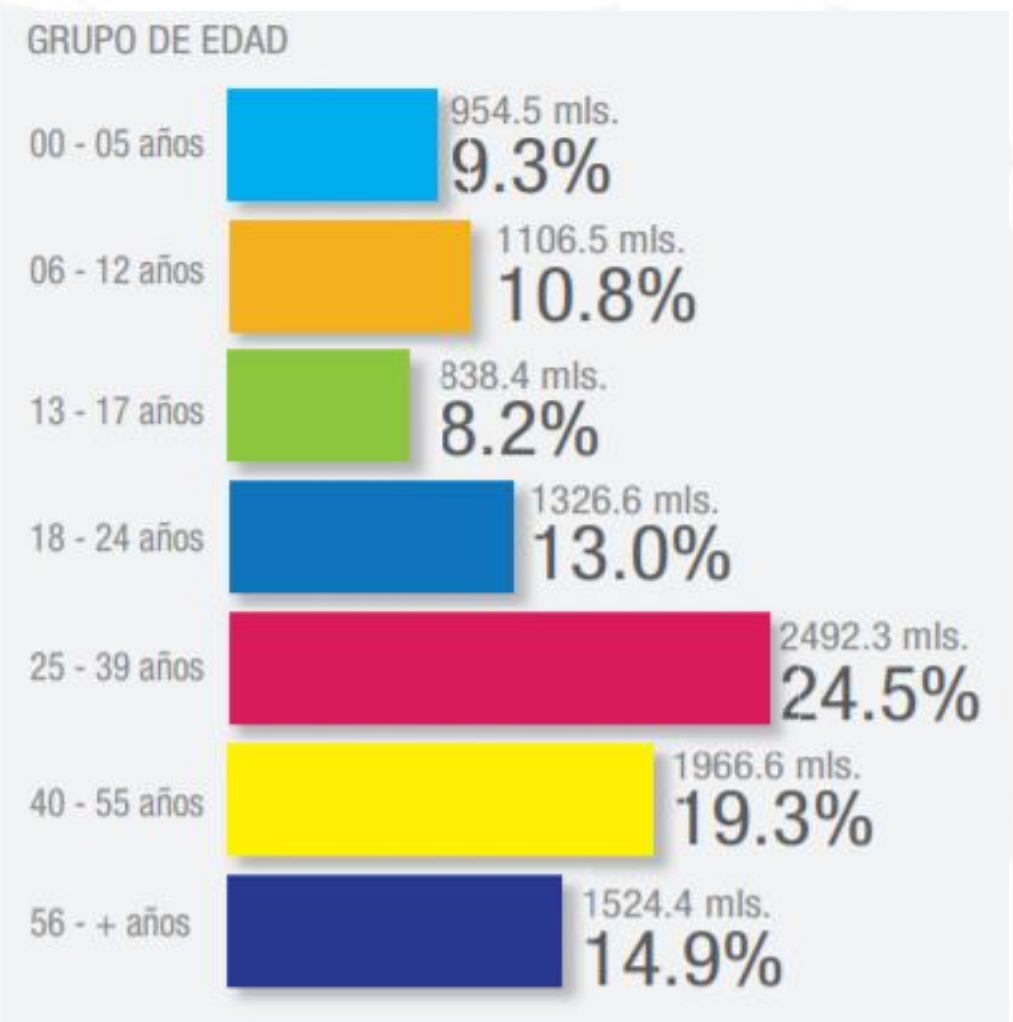

Fuente: Compañía Peruana de Estudios de Mercados y Opinión Pública, CPI. (2017)

\subsection{Determinación de la demanda de mercado en base a fuentes secundarias o primarias}

Utilizando una encuesta (fuente primaria) y fuentes secundarias diversas se proyectará la demanda del mercado en este subcapítulo. 


\subsubsection{Determinación de la demanda del proyecto sin data histórica}

A continuación se muestra el cálculo de la demanda del proyecto en base a la cuantificación y proyección de la población segmentando un mercado objetivo en contraste con los resultados de una encuesta realizada a una muestra aleatoria de dicho mercado objetivo.

\subsubsection{Cuantificación y proyección de la población}

El proyecto se enfoca en la población de Lima metropolitana de niños y niñas de 0 a 5 años de edad. Según el estudio del CPI expuesto previamente en el 2017 habitaban 954 500 niños y niñas que podrían estar dentro de nuestro mercado objetivo. Asumiendo que la tasa de crecimiento va a variar en medidas desestimables la proyección de la población se dará de manera lineal utilizando el dato obtenido anteriormente (Lima metropolitana incrementa en 98367 habitantes anualmente de los cuales 9148 son niños de 0 a 5 años).

Utilizando la fórmula de proyección lineal basándonos en la ratio de crecimiento mencionado previamente (98 367 anualmente) llegamos a esta proyección de la población en Lima metropolitana para los próximos 5 años (2019-2023).

Figura 2.6

Crecimiento Demográfico en Lima metropolitana

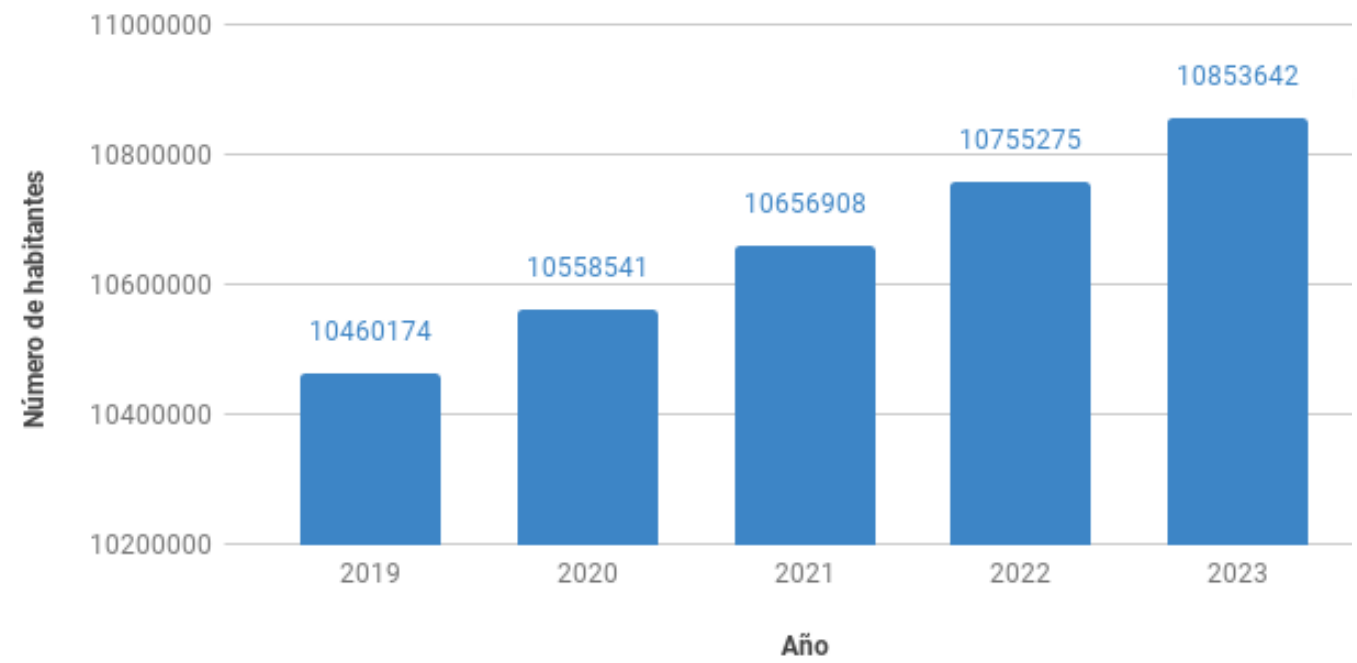

Elaboración propia 


\subsubsection{Definición del mercado objetivo}

De la proyección anterior utilizando la estadística del CPI (9,3\% de la población son niños y niñas de 0 a 5 años de edad en Lima metropolitana) podemos proyectar la población de nuestro mercado objetivo para los próximos 5 años (2019-2023).

Figura 2.7

Crecimiento Demográfico de niños y niñas en su primera infancia (0-5 años)

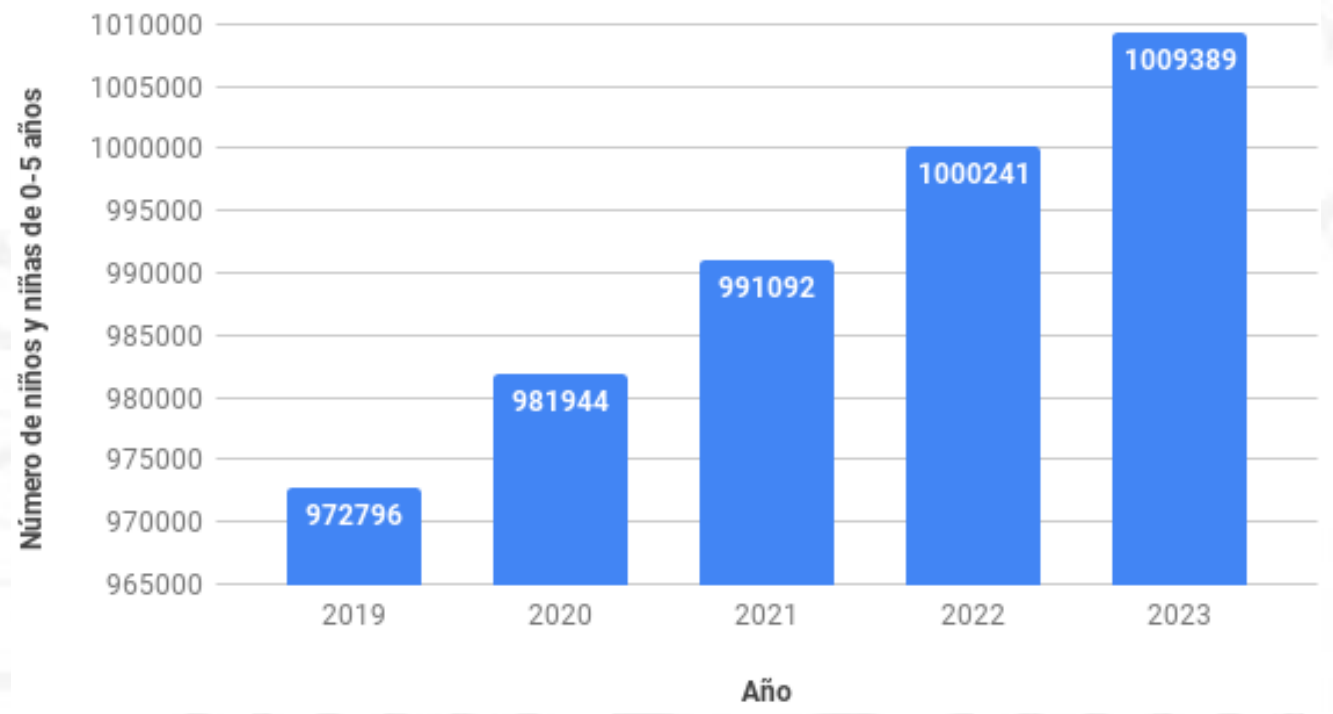

Elaboración propia

Nuestro mercado objetivo será: los niños y niñas de 0 a 5 años de edad en Lima metropolitana que se encuentren en un NSE entre los sectores C y D. Dicha proporción suma $67,0 \%$ según el estudio del CPI mostrado previamente. Esto nos permitirá proyectar nuestro mercado objetivo (niños y niñas de 0 a 5 años de edad en Lima metropolitana de un NSE dentro de los sectores C y D) para los próximos 5 años. 
Figura 2.8

Crecimiento Demográfico de niños y niñas en su primera infancia (0-5 años) de NSE C y D.

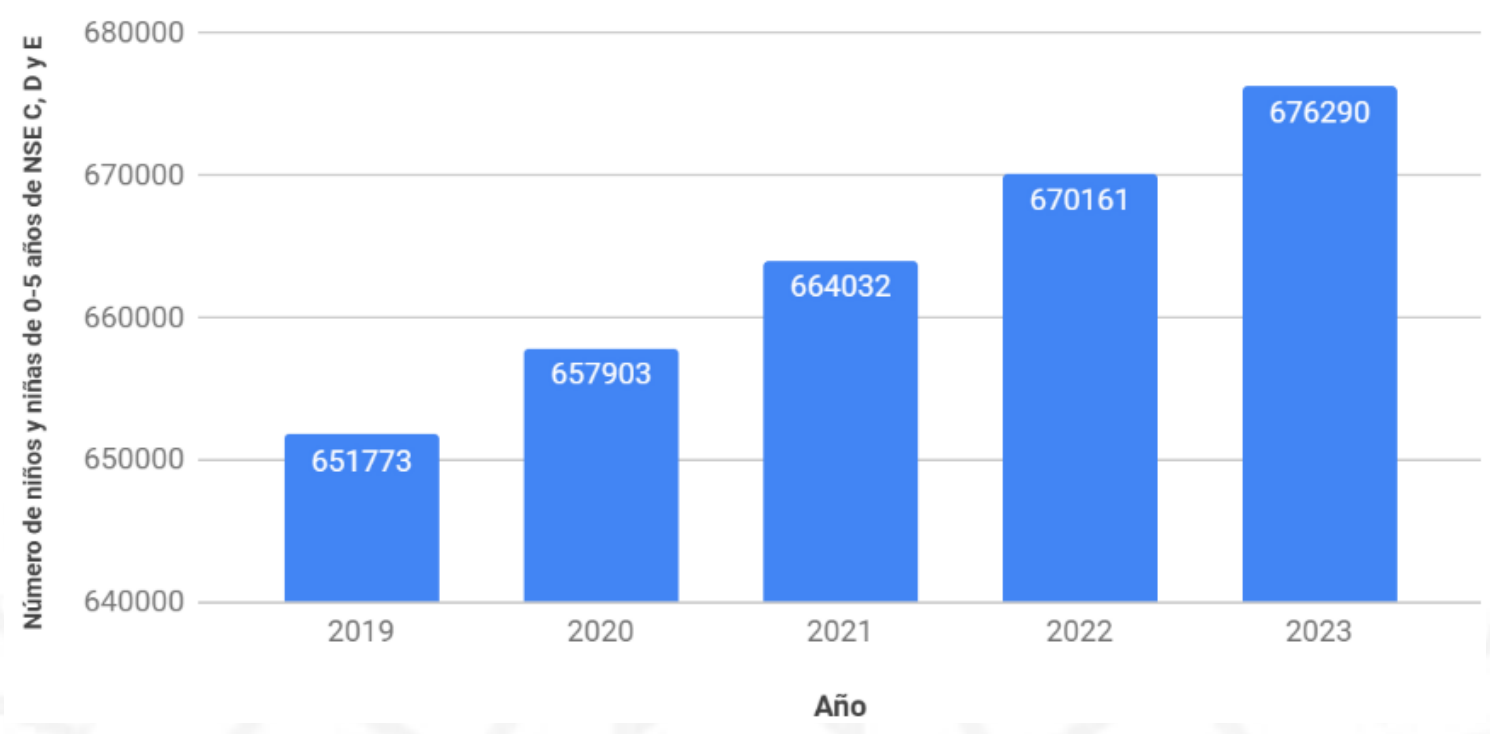

Elaboración propia

Finalmente, podemos observar que nuestro mercado objetivo supera los $650 \mathrm{mil}$ clientes. Este número solo nos prueba que existe un mercado objetivo suficientemente grande, pero en la realidad nuestra producción será mucho menor debido a nuestra capacidad instalada. Debido a esto utilizaremos la estadística de crecimiento poblacional para apuntar solamente a los niños y niñas recién nacidos en Lima metropolitana con un NSE de los sectores C y D. Esto nos asegura que no poseen una lámpara volviéndolos clientes reales. Este número corresponde al 67,0\% de los 180 mil nacimientos anuales (ratio de crecimiento demográfico en Lima Metropolitana) según la estadística reportada por el INEI al 2016 en Lima metropolitana.

Luego de computar los datos anteriores nuestro nuevo mercado objetivo desciende a 120600 niños y niñas recién nacidos en el primer año, un número mucho más realista, sin embargo sigue siendo mucho mayor a la capacidad de producción a la que apunta el emprendimiento. Finalmente, asumiendo un incremento de 3\% para el crecimiento en los nacimientos anuales en Lima metropolitana en base a su crecimiento demográfico en general llegamos al siguiente gráfico. 
Figura 2.9

Demanda potencial del Proyecto (en base a nacimientos anuales)

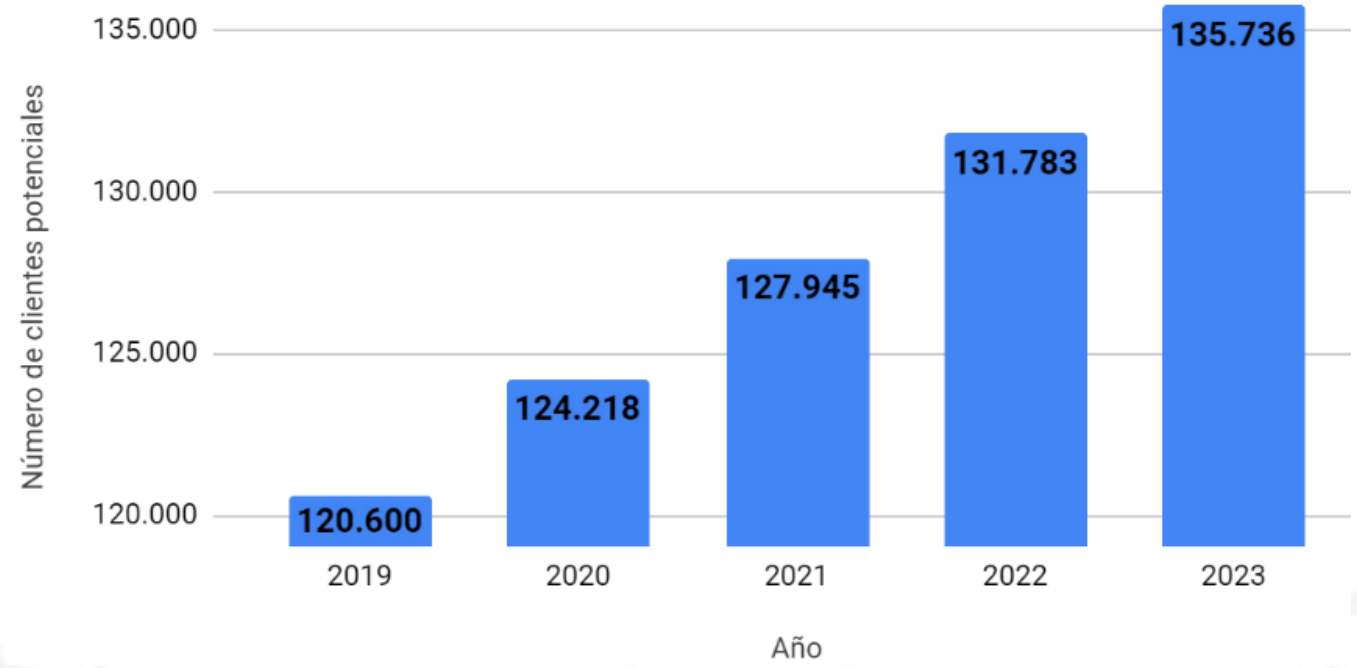

Elaboración propia

\subsubsection{Diseño y aplicación de encuestas}

Para calcular el tamaño de muestra se realizará la encuesta a una muestra piloto a 30 personas considerando la población como infinita por ser mayor a 10000 nuestra población. Se realizo la siguiente encuesta a la muestra piloto ya que nuestro objetivo era ver intención de compra en términos de proporción no fue considerado si tenían o no hijos.

Tabla 2.2

Encuesta para la muestra piloto

\begin{tabular}{|c|c|c|}
\hline Encuesta para la muestra piloto: 30 encuestados & Opciones & Respuesta \\
\hline Edad & $\#$ & \\
\hline Genero & $\mathbf{M} / \mathbf{F}$ & \\
\hline \multicolumn{3}{|l|}{ Preguntas } \\
\hline \multirow{2}{*}{$\begin{array}{l}\text { 1. ¿Compraría una lámpara moderna y segura para } \\
\text { niños/as en su primera infancia }(0-5 \text { años }) \text { fabricada } \\
\text { con tecnologías de corte láser y diseños innovadores? }\end{array}$} & SI & \\
\hline & NO & \\
\hline $\begin{array}{l}\text { 2. ¿Que tan probable es que compre una lámpara con } \\
\text { estas características siendo } 1 \text { muy probable y } 5 \text { nunca? }\end{array}$ & De 1 a 5 & \\
\hline \multirow{4}{*}{$\begin{array}{l}\text { 3. ¿Cuánto estaría dispuesto a pagar por una lámpara } \\
\text { con estas características? }\end{array}$} & 35 soles & \\
\hline & 50 soles & \\
\hline & 60 soles & \\
\hline & 80 soles o mas & \\
\hline
\end{tabular}

Elaboración propia 
Luego de calcular la proporción de compra que la muestra piloto reporto ser (60\%) se utilizó esta para calcular el tamaño de muestra para la encuesta. Para llegar al tamaño de muestra se asumió un error absoluto de 5\% por temas económicos, pues reducirlo incrementa demasiado el tamaño de muestra incrementando los tiempos y costos de realizar la encuesta. Asimismo, se consideró un nivel de confianza de 95\% como contraparte del error absoluto llegando al tamaño de muestra real que será de 369 encuestados.

\subsubsection{Resultados de la encuesta}

La tabla siguiente muestra los resultados de la muestra piloto realizada en un mercado en Surco.

\section{Tabla 2.3}

Resultados: Encuesta para la muestra piloto

\begin{tabular}{|c|c|c|c|}
\hline Encuesta para la muestra piloto: 30 encuestados & Opciones & Respu & \\
\hline Edad & \# & $26-44$ & \\
\hline Genero & $\mathbf{M} / \mathbf{F}$ & $16 \mathrm{M}$ & $14 \mathrm{~F}$ \\
\hline Preguntas & & & \\
\hline $\begin{array}{l}\text { 1. ¿Compraría una lámpara moderna y segura } \\
\text { para niños/as en su primera infancia (0-5 años) } \\
\text { fabricada con tecnologías de corte láser y diseños }\end{array}$ & SI & 18 & \\
\hline jres? & NO & 12 & \\
\hline $\begin{array}{l}\text { 2. ¿Que tan probable es que compre una lámpara } \\
\text { con estas características siendo } 1 \text { muy probable y } \\
5 \text { nunca? }\end{array}$ & $1-5$ & 2,3 & \\
\hline & 35 soles & 1 & \\
\hline 3. ¿Cuánto estaría dispuesto a pagar por una & 50 soles & 7 & \\
\hline lámpara con estas características? & 60 soles & 7 & \\
\hline & Mas de 60 soles & 2 & \\
\hline
\end{tabular}

Elaboración propia

Luego de realizar la muestra piloto se determinó el tamaño de muestra real y se realizó la siguiente encuesta para poder determinar nuestro mercado objetivo y proyectarlo a la vida del proyecto. 
Tabla 2.4

Encuesta para la muestra real

\begin{tabular}{|l|l|l|l|}
\hline Muestra real: 369 encuestados & Opciones & \multicolumn{2}{|l|}{ Respuesta } \\
\hline Edad & $\#$ & $24-55$ \\
\hline Genero & M/F & 172 M & 197 F \\
\hline Preguntas & & & \\
\hline $\begin{array}{l}\text { 1. ¿Usted tiene un/a hijo/a de 0 a 5 años de edad? } \\
\text { (Si la respuesta es No terminar encuesta) }\end{array}$ & SI & 247 \\
\cline { 2 - 4 } & NO & 122 \\
\hline $\begin{array}{l}\text { 2. ¿Compraría una lámpara moderna y segura } \\
\text { para niños/as en su primera infancia (0-5 años) } \\
\text { fabricada con tecnologías de corte láser y diseños } \\
\text { innovadores? }\end{array}$ & SI & 131 \\
\cline { 2 - 4 } & NO & 116 \\
\hline $\begin{array}{l}\text { 3. ¿Que tan probable es que compre una lámpara } \\
\text { con estas características siendo 1 muy probable y } \\
\text { 5 nunca? }\end{array}$ & 1 - 5 & 2,7 \\
\hline $\begin{array}{l}\text { 4. ¿Cuánto estaría dispuesto a pagar por una } \\
\text { lámpara con estas características? }\end{array}$ & 25 soles & 8 \\
\cline { 2 - 4 } & 45 soles & 30 \\
\cline { 2 - 4 } & 60 soles & 76 \\
\cline { 2 - 4 } & más de 60 soles & 17 \\
\hline
\end{tabular}

Elaboración propia

La encuesta se realizó en un mercado de Surco a 369 personas (172 hombres y 197 mujeres) de las cuales 247 tenían hijos de entre 0 y 5 años de edad. De los encuestados que respondieron si a la primera pregunta 131 respondieron que comprarían la lámpara marcando una proporción que compraría nuestros productos de 35,5\%. La intensidad de compra fue de 2,7/5 luego de promediar todos los que respondieron si a las 2 primeras preguntas y el precio promedio fue de 57,02 soles por lampará, pero se elegirá el precio de 65 soles para alcanzar la rentabilidad adecuada considerando que el producto es novedoso, el impuesto general a las ventas y un $20 \%$ de margen para los puntos de venta al por menor con los que se establecerán contratos generando al emprendimiento un valor por la venta de cada lámpara de 42,64 soles. 


\subsubsection{Determinación de la demanda del proyecto}

El porcentaje de los encuestados que compraría nuestras lámparas es de (131/369) 35,5\%. De esos casos los clientes que definitivamente comprarían la lámpara serian el 54\% $(2,7 / 5)$ demostrando la verdadera demanda del proyecto representada en el grafico siguiente luego de afectar el grafico anterior con los datos adquiridos en la encuesta.

Figura 2.10

Demanda del proyecto (en base a nacimientos anuales)

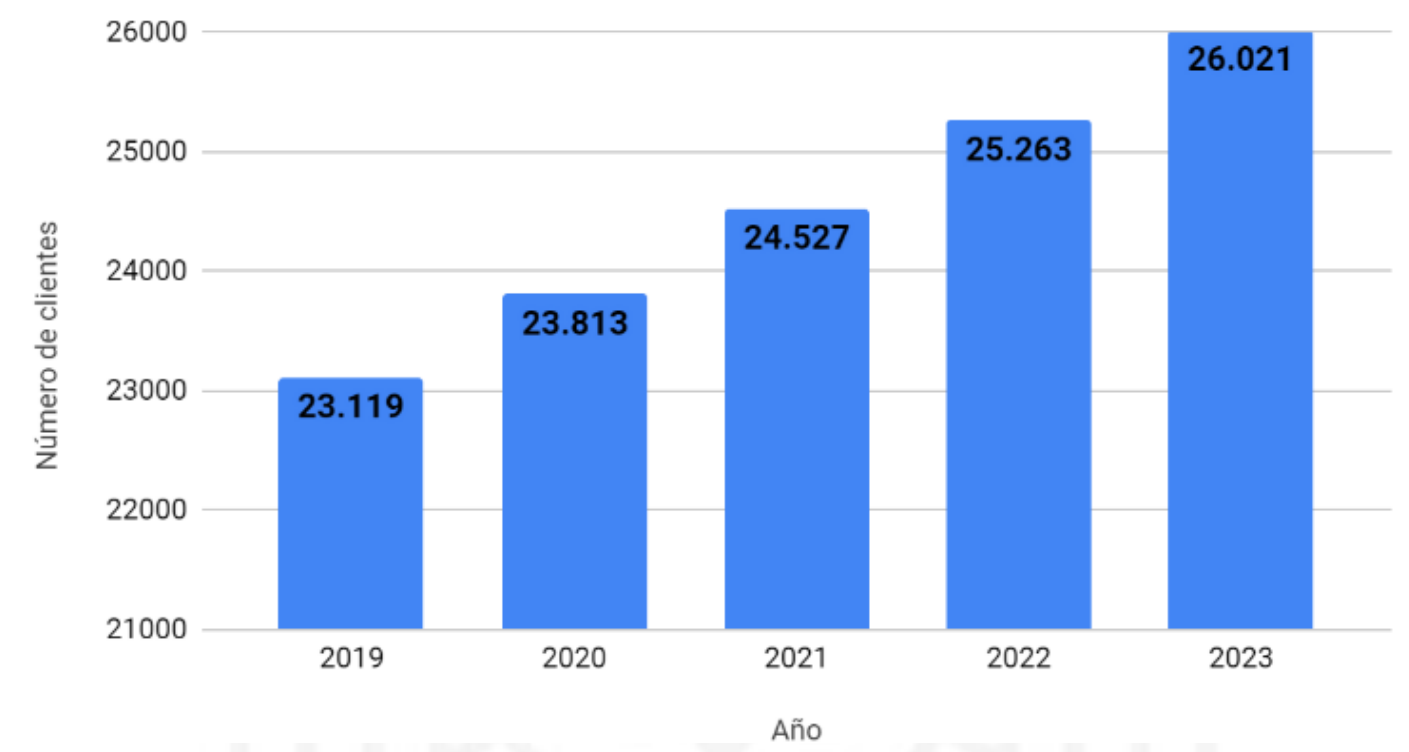

Elaboración Propia

\subsection{Análisis de la oferta}

En este subcapítulo utilizando fuentes secundarias se analizará la oferta existente de productos similares a los propuestos, su participación de mercado y otros competidores potenciales si los hubiera.

\subsubsection{Empresas productoras, importadoras y comercializadoras}

En el Perú no existen empresas productoras de lámparas para niños formalizadas, no hay duda de que existen de manera informal pero su capacidad de producción es sumamente reducida y su alcance también volviéndolos irrelevantes para este estudio. Las empresas 
importadoras y comercializadoras que han sido identificadas luego de investigar el mercado local y filtrar a las que venden lámparas de alta gama son:

- SODIMAC PERU S.A.

- PHILIPS PERUANA S.A.

- NAKARE S.A.C. (Nombre comercial: Nana Luna)

- EGLO PERU S.A.C.

- DH EMPRESAS PERU S.A. (Nombre comercial: Casa Ideas)

\subsubsection{Participación de mercado de los competidores actuales}

Sabiendo que las lámparas son un activo de baja rotación podemos asumir que gran parte del mercado existente ya fue captado por los competidores. Por otro lado, podemos deducir que un gran porcentaje de las lámparas usadas en los cuartos de los niños y niñas de 0 a 5 años no son lámparas infantiles debido al bajo nivel de variedad. Por último, nuestra capacidad de producción no alcanzara a tomar ni el $1 \%$ del mercado objetivo percibido por lo que la participación de mercado de nuestros competidores es irrelevante.

\subsubsection{Competidores potenciales si hubiera}

Nuestros competidores potenciales serían las compañías de corte láser que existen en Lima, pues contratando a diseñadores industriales o especialistas en fabricación digital podrían producir productos similares a los propuestos por nuestro emprendimiento.

\subsection{Definición de la estrategia de comercialización}

En este subcapítulo se definirá la estrategia de comercialización del emprendimiento incluyendo políticas de comercialización y distribución y publicidad y promoción seguido de un análisis de precios relacionados a los precios que existen históricamente en el mercado de Lima Metropolitana según sus competidores. 


\subsubsection{Políticas de comercialización y distribución}

La política de comercialización será la tercerización de las ventas a través de tiendas preexistentes como Sodimac y Casa Ideas que ya estén vendiendo productos de esta índole sin importar el tipo de tecnología que utilicen para fabricarlos (o la tecnología utilizada para fabricar los productos que ellos importan), pues eso nos ayudara a diferenciar nuestros productos y aumentar las ventas. Por otro lado, la distribución también se tercerizará con ALMACO S.A. que es una empresa que se encargaría del recojo transporte y entrega de los productos a nuestros puntos de venta expuestos previamente para enfocar todos nuestros recursos en el diseño y la fabricación de nuevos productos.

\subsubsection{Publicidad y promoción}

Los productos se promoverán a través de las redes sociales, publicidad pagada por internet y activaciones en eventos del rubro. La red social principal para promover las lámparas será Instagram, pero no se limita a esta ya que también se utilizará Facebook y Twitter. Finalmente, se invertirá en activaciones en eventos que puedan permitir la viralización de los productos enfocándose en mostrar las ventajas del corte láser y la variedad de diseños posibles.

\subsubsection{Análisis de precios}

En este subcapítulo se realizará el previamente mencionado análisis de precios utilizando tendencias históricas, precios actuales y posteriormente se definirá la estrategia de precios del emprendimiento.

\subsubsection{Tendencia histórica de precios}

La capacidad adquisitiva en nuestro país viene aumentando de manera constante desde hace casi 20 años. Esto se demuestra por el crecimiento constante del PBI y del PBI per cápita que podemos apreciar en la figura siguiente. 
Figura 2.11

Perú: Producto bruto interno total y por habitante, 1994-2017

\begin{tabular}{|c|c|c|c|c|c|c|}
\hline \multirow{2}{*}{ Año } & \multicolumn{2}{|c|}{ Producto Bruto Interno } & \multirow{2}{*}{ Población ${ }^{1 /}$} & \multicolumn{2}{|c|}{$\begin{array}{l}\text { Producto Bruto Interno } \\
\text { por habitante }\end{array}$} & \multirow{2}{*}{$\begin{array}{c}\text { Tasa } \\
\text { Anual de } \\
\text { Crecimiento } \\
\text { del Deflactor } \\
\text { Implíito del PBI }\end{array}$} \\
\hline & $\begin{array}{l}\text { Millones } \\
\text { de } \\
\text { Soles }\end{array}$ & $\begin{array}{l}\text { Tasas Anuales de } \\
\text { Crecimiento }\end{array}$ & & Soles & $\begin{array}{c}\text { Tasas } \\
\text { Anuales de } \\
\text { Crecimiento }\end{array}$ & \\
\hline 1994 & 98,579 & - & $23,501,974$ & 4,194 & - & - \\
\hline 1995 & 120,263 & 22.0 & $23,926,300$ & 5,026 & 19.8 & 13.6 \\
\hline 1996 & 135,606 & 12.8 & $24,348,132$ & 5,569 & 10.8 & 9.7 \\
\hline 1997 & 154,905 & 14.2 & $24,767,794$ & 6,254 & 12.3 & 7.3 \\
\hline 1998 & 162,586 & 5.0 & $25,182,269$ & 6,456 & 3.2 & 5.4 \\
\hline 1999 & 169,859 & 4.5 & $25,588,546$ & 6,638 & 2.8 & 2.9 \\
\hline 2000 & 180,584 & 6.3 & $25,983,588$ & 6,950 & 4.7 & 3.5 \\
\hline 2001 & 182,527 & 1.1 & $26,366,533$ & 6,923 & -0.4 & 0.5 \\
\hline 2002 & 192,691 & 5.6 & $26,739,379$ & 7,206 & 4.1 & 0.1 \\
\hline 2003 & 204,337 & 6.0 & $27,103,457$ & 7,539 & 4.6 & 1.8 \\
\hline 2004 & 227,935 & 11.5 & $27,460,073$ & 8,301 & 10.1 & 6.3 \\
\hline 2005 & 250,749 & 10.0 & $27,810,540$ & 9,016 & 8.6 & 3.5 \\
\hline 2006 & 290,271 & 15.8 & $28,151,443$ & 10,311 & 14.4 & 7.7 \\
\hline 2007 & 319,693 & 10.1 & $28,481,901$ & 11,224 & 8.9 & 1.5 \\
\hline 2008 & 352,719 & 10.3 & $28,807,034$ & 12,244 & 9.1 & 1.1 \\
\hline 2009 & 363,943 & 3.2 & $29,132,013$ & 12,493 & 2.0 & 2.1 \\
\hline 2010 & 416,784 & 14.5 & $29,461,933$ & 14,147 & 13.2 & 5.7 \\
\hline 2011 & 473,049 & 13.5 & $29,797,694$ & 15,875 & 12.2 & 6.7 \\
\hline 2012 & 508,131 & 7.4 & $30,135,875$ & 16,861 & 6.2 & 1.2 \\
\hline 2013 & 543,556 & 7.0 & $30,475,144$ & 17,836 & 5.8 & 1.1 \\
\hline 2014 & 570,593 & 5.0 & $30,814,175$ & 18,517 & 3.8 & 2.5 \\
\hline 2015P/ & 604,269 & 5.9 & $31,151,643$ & 19,398 & 4.8 & 2.6 \\
\hline $2016 P /$ & 647,707 & 7.2 & $31,488,625$ & 20,570 & 6.0 & 3.1 \\
\hline 2017E/ & 687,037 & 6.1 & $31,826,018$ & 21,587 & 4.9 & 3.5 \\
\hline
\end{tabular}

Fuente: Instituto Nacional de Estadística e Informática, INEI. (2017)

Considerando esto podemos asumir que los precios de lámparas o la calidad de las lámparas ofrecidas han ido incrementando con el tiempo para reflejar este cambio en la economía nacional. Considerando que los rangos de precios de empresas formales actuales van de 22 a 70 soles en las lámparas de baja gama podemos asumir que históricamente han subido de un valor menor, asumiendo 15 soles en el límite inferior y 40 soles como el límite superior en 1994 y han alcanzado los precios actuales investigados en el 2019. Por otro lado, este incremento en el PBI ha permitido el ingreso y desarrollo de nuevas tecnologías en el Perú que logran satisfacer en mayor medida las necesidades el mercado peruano en contraste con las tecnologías de fabricación previas. 


\subsubsection{Precios actuales}

Investigamos a los competidores actuales a través de sus páginas web de ventas online que reflejan el mismo precio que en tienda. La página web utilizada para encontrar los precios actuales fue sodimac.com,pe (SODIMAC PERU S.A.), se descubrió que las lámparas infantiles de calidad media-baja se están vendiendo en un rango de precios desde 22 soles hasta 70 soles siendo el rango de precios más común de 45 a 55 soles.

\subsubsection{Estrategia de precio}

Se utilizara principalmente la penetración de mercado iniciando con un precio relativamente bajo, pero también se estará aplicando la estrategia de diferenciación al estar utilizando nuevas tecnologías aunque en menor medida ya que el enfoque es llegar a la mayor cantidad de clientes de NSE dentro de los sectores C y D. Gracias a las nuevas tecnologías utilizadas en este emprendimiento el bajo precio de venta será posible debido al bajo costo de producirlas lo que permitirá superar nuestro punto de equilibrio. Por otro lado, gracias a los software de diseño 3D utilizados la rápida generación de nuevos diseños facilitara aplicar la estrategia de diferenciación (aunque en menor medida que la estrategia de penetración de mercado). 


\section{CAPÍTULO III: LOCALIZACIÓN DE PLANTA}

\subsection{Identificación y análisis detallado de factores de localización}

Los factores para la macro localización serán:

Disponibilidad de terreno: La disponibilidad de terreno no es muy importante pues las dimensiones del terreno necesario son pequeñas por la reducida cantidad de colaboradores y maquinas.

Proximidad al mercado objetivo: La proximidad al mercado objetivo es muy importante para este proyecto, pues las lámparas se venderán a través de tercerización con negocios existentes y por ello es importante estar cerca de las tiendas para reducir costos logísticos. Asimismo, la proximidad a universidades que enseñen arquitectura (alto uso de cortadoras láser) nos permitirá comercializar los tiempos inoperativos de la/s cortadora/s láser.

Disponibilidad de electricidad: La disponibilidad de electricidad es sumamente importante, pues para que el servicio que se quiere ofrecer tenga la calidad que se espera se necesitará que el abastecimiento de electricidad sea constante para poder operar las cortadoras láser y las computadoras para el diseño.

Densidad de población: La población es importante por la misma razón que la proximidad al mercado objetivo también lo es, esto aumentara las ventas pues los terceros seleccionados tendrán un mayor flujo de consumidores, sin embargo, no es tan importante como la proximidad al mercado objetivo, pues en nuestro caso el alto flujo de clientes no garantiza altos niveles de ventas.

Los factores para la micro localización serán:

Precio del alquiler: El precio del alquiler tendrá mediana importancia, pues al necesitar un pequeño espacio será un costo moderado, aunque sigue siendo uno de los mayores costos del proyecto.

Proximidad al mercado objetivo: La proximidad al mercado objetivo es muy importante para este proyecto, pues las lámparas se venderán a través de tercerización 
con negocios existentes y por ello es importante estar cerca de las tiendas para reducir costos logísticos. Asimismo, la proximidad a universidades que enseñen arquitectura (alto uso de cortadoras láser) nos permitirá comercializar los tiempos inoperativos de la/s cortadora/s láser.

Disponibilidad de mano de obra capacitada: La disponibilidad de mano de obra capacitada es importante, pues el tipo de fabricación a utilizar es de alto riesgo y relativamente nueva para el Perú, sin embargo, con un especialista en fabricación digital o un diseñador industrial se podría capacitar a los demás operarios los cuales solo necesitaran haber cumplido secundaria, aunque será preferible que tengan un desarrollo técnico lo que agilizara la curva de aprendizaje.

Disponibilidad de servicios de Transporte: La disponibilidad de servicios de transporte no es el factor más importante, pero afectara el desempeño de los trabajadores de la compañía y como su desempeño se refleja directamente la productividad del emprendimiento y la calidad de los diseños y productos generados.

\subsection{Identificación y descripción de las alternativas de localización}

Lima metropolitana fue elegida por su gran población, tener el único aeropuerto internacional del país, la disponibilidad de mano de obra capacitada, su nivel de infraestructura vial y su nivel de infraestructura para telecomunicaciones. Para realizar el ranking de factores consideraremos 3 zonas/distritos de Lima metropolitana de los cuales elegiremos 2 que serán evaluados a mayor profundidad.

Las 3 alternativas de localización que se eligieron fueron: Surco, La Molina y La provincia constitucional del Callao. Por la lejanía al público objetivo que es nuestro factor más importante y por su dificultad en términos de transporte se eliminó La provincia constitucional del Callao para culminar con Surco y Magdalena como alternativas de localización.

Surco y La Molina se eligieron por su proximidad al mercado objetivo, cabe recalcar que no estamos hablando del porcentaje de habitantes de Surco de NSE C y D, pues este número es relativamente bajo comparado con otros distritos sino por la cantidad de peruanos de NSE C y D que ingresan al distrito para laburar y estudiar durante el día permitiéndole al emprendimiento estar cerca de las Universidades que más utilizan el 
corte láser (Universidad de Lima, Universidad Ricardo Palma, Universidad Peruana de Ciencias Aplicadas, Universidad Femenina, Universidad San Martin de Porres, Universidad de Ciencias y Artes de América Latina, Universidad Esan, Universidad Nacional Agraria La Molina, Universidad San Ignacio de Loyola, etc.).

\subsection{Determinación del modelo de evaluación a emplear}

Se utilizará el ranking de factores para seleccionar la macro y micro localización.

\subsection{Evaluación y selección de la localización}

En el siguiente sub capitulo se utilizará el método de ranking de factores para determinar ambas la macro localización y la micro localización seleccionando los diferentes factores principales para cada una optando por diferentes distritos dentro de Lima metropolitana para la macro localización y diferentes zonas dentro del distrito seleccionado para la micro localización.

\subsubsection{Evaluación y selección de la macro localización}

En el siguiente cuadro se presenta la tabla de enfrentamiento de los factores que influyen en la macro localización:

Tabla 3.1

Ranking de factores (macro localización)

\begin{tabular}{|c|c|c|c|c|c|c|}
\hline & $\begin{array}{l}\text { Disponibilida } \\
\text { d de Terreno }\end{array}$ & $\begin{array}{l}\text { Proximidad al } \\
\text { mercado objetivo }\end{array}$ & $\begin{array}{l}\text { Disponibilidad } \\
\text { de Electricidad }\end{array}$ & $\begin{array}{l}\text { Densidad de } \\
\text { Población }\end{array}$ & Conteo & Pond. \\
\hline $\begin{array}{l}\text { Disponibilidad de } \\
\text { Terreno }\end{array}$ & $X$ & 0 & 1 & 0 & 1 & 0,1429 \\
\hline $\begin{array}{l}\text { Proximidad al } \\
\text { mercado objetivo }\end{array}$ & 1 & $X$ & 1 & 1 & 3 & 0,4285 \\
\hline $\begin{array}{l}\text { Disponibilidad de } \\
\text { Electricidad }\end{array}$ & 1 & 0 & $X$ & 1 & 2 & 0,2857 \\
\hline $\begin{array}{ll}\text { Densidad } & \text { de } \\
\text { Población } & \end{array}$ & 1 & 0 & 0 & $X$ & 1 & 0,1429 \\
\hline \multicolumn{5}{|l|}{ Total } & 7 & 1 \\
\hline
\end{tabular}

Elaboración propia 
Del cuadro anterior se concluye que la Proximidad al mercado objetivo es el factor más importante al momento de decidir la macro localización del proyecto seguido por la disponibilidad de electricidad.

Tabla 3.2

Características de Santiago de Surco y La Molina

\begin{tabular}{|l|l|l|l|}
\hline Distrito & $\begin{array}{l}\text { Área } \\
\left(\mathrm{m}^{2}\right)\end{array}$ & $\begin{array}{l}\text { Número de Universidades } \\
\text { que dictan Arquitectura }\end{array}$ & $\begin{array}{l}\text { Densidad de } \\
\text { población }\end{array}$ \\
\hline Surco & 52 & 4 & 9472 \\
\hline La Molina & 65,75 & 4 & 2139,6 \\
\hline
\end{tabular}

Fuente: Instituto Nacional de Estadística e Informática, INEI. (2017)

Tabla 3.3

Ranking de factores (macro localización)

\begin{tabular}{|c|c|c|c|c|c|}
\hline & & Surco & & La Molina & \\
\hline Factor & Ponderado & Calificación & Puntaje & Calificación & Puntaje \\
\hline $\begin{array}{l}\text { Disponibilidad de } \\
\text { Terreno }\end{array}$ & 0,1429 & 3 & 0,4287 & 4 & 0,5716 \\
\hline $\begin{array}{l}\text { Proximidad al } \\
\text { mercado objetivo }\end{array}$ & 0,4285 & 4 & 1,714 & 4 & 1,714 \\
\hline $\begin{array}{l}\text { Disponibilidad de } \\
\text { Electricidad }\end{array}$ & 0,2857 & 4 & 1,1428 & 4 & 1,1428 \\
\hline \multirow[t]{2}{*}{$\begin{array}{ll}\text { Densidad } & \text { de } \\
\text { Población } & \\
\end{array}$} & 0,1429 & 4 & 0,5716 & 1 & 0,1429 \\
\hline & & Total & 3,8571 & Total & 3,2857 \\
\hline
\end{tabular}

Elaboración propia

Luego de realizar el método de ranking de factores se concluye que para la macro localización Surco cuenta con las mejores características. Esto es debido a que es el territorio con la mayor densidad de población por una gran diferencia, sin embargo, La Molina tiene una mayor disponibilidad de terreno, pero no por una gran diferencia debido a las dimensiones necesarias para nuestro taller. 


\subsubsection{Evaluación y selección de la micro localización.}

En el siguiente cuadro se presenta la tabla de enfrentamiento de los factores que influyen en la micro localización:

Tabla 3.4

Ranking de factores (micro localización)

\begin{tabular}{|l|l|l|l|l|l|l|}
\hline Factores & $\begin{array}{l}\text { Precio } \\
\text { del } \\
\text { alquiler }\end{array}$ & $\begin{array}{l}\text { Proximidad } \\
\text { al mercado } \\
\text { objetivo }\end{array}$ & $\begin{array}{l}\text { Disponibilidad } \\
\text { de mano de } \\
\text { obra capacitada }\end{array}$ & $\begin{array}{l}\text { Disponibilidad } \\
\text { de servicios de } \\
\text { Transporte }\end{array}$ & Conteo & Ponderado \\
\hline $\begin{array}{l}\text { Precio del } \\
\text { alquiler }\end{array}$ & $\mathrm{X}$ & 0 & 1 & 1 & 0,1429 \\
\hline $\begin{array}{l}\text { Proximidad al } \\
\text { mercado } \\
\text { objetivo }\end{array}$ & 1 & $\mathrm{X}$ & 1 & 1 & 3 & 0,4285 \\
\hline $\begin{array}{l}\text { Disponibilidad } \\
\text { de mano de } \\
\text { obra capacitada }\end{array}$ & 1 & 0 & $\mathrm{X}$ & 1 & $\mathrm{X}$ & 2 \\
\hline $\begin{array}{l}\text { Disponibilidad } \\
\text { de servicios de } \\
\text { Transporte }\end{array}$ & 1 & 0 & 0 & & 1 & 0,2857 \\
\hline Total & & & & 7 & 0,1429 \\
\hline
\end{tabular}

Elaboración propia

Del cuadro anterior se concluye que la infraestructura de telecomunicaciones es el factor más importante seguido de la disponibilidad de mano de obra capacitada para seleccionar la micro localización del proyecto. 
Tabla 3.5

Ranking de factores (micro localización)

\begin{tabular}{|c|c|c|c|c|c|c|c|}
\hline & & \multicolumn{2}{|l|}{ Monterrico } & \multicolumn{2}{|l|}{ Chacarilla } & \multicolumn{2}{|l|}{ Higuereta } \\
\hline Factor & Ponderado & Calificación & Puntaje & Calificación & Puntaje & Calificación & Puntaje \\
\hline $\begin{array}{l}\text { Precio del } \\
\text { alquiler }\end{array}$ & 0,1429 & 2 & 0,286 & 1 & 0,1429 & 3 & 0,4287 \\
\hline $\begin{array}{l}\text { Proximidad al } \\
\text { mercado } \\
\text { objetivo }\end{array}$ & 0,4285 & 4 & 1,714 & 3 & 1,2855 & 3 & 1,2855 \\
\hline $\begin{array}{l}\text { Disponibilidad } \\
\text { de mano de } \\
\text { obra } \\
\text { capacitada }\end{array}$ & 0,2857 & 4 & 1,143 & 2 & 0,5714 & 3 & 0,8571 \\
\hline \multirow[t]{2}{*}{$\begin{array}{l}\text { Disponibilidad } \\
\text { de servicios de } \\
\text { Transporte }\end{array}$} & 0,1429 & 4 & 0,572 & 4 & 0,4287 & 4 & 0,5716 \\
\hline & & Total & 3,714 & Total & 2,8572 & Total & 3,1429 \\
\hline
\end{tabular}

Elaboración propia

Se concluye a partir del ranking de factores que Monterrico es la mejor opción para la implementación de un taller de fabricación digital desde el cual se supervisará y asesorará la creación de diversos modelos de lámparas innovadoras y seguras fabricadas con tecnologías de corte láser para niños de 0-5 años de NSE C y D en Lima metropolitana. 


\section{CAPÍTULO IV: DIMENSIONAMIENTO DEL SERVICIO}

\subsection{Relación Tamaño-Mercado}

El tamaño según el mercado será como máximo claramente todo niño o niña de 0 a 5 años de NSE C y D que habite en Lima metropolitana. Según los cálculos realizados previamente podemos proyectar un tamaño de mercado de 679290 para el 2023 lo cual sería el tamaño máximo del taller en términos de capacidad de producción.

\subsection{Relación Tamaño-Recursos}

El tamaño según los recursos será ilimitado ya que los únicos recursos necesarios para producir nuestras lámparas serias planchas de diferentes espesores de distintos materiales que se ofrecen en cantidad a precios bajos por diversos proveedores y energía eléctrica para hacer funcionar las maquinas. Gracias a esto a medida que incrementa la demanda solo será necesario comprar más materia prima.

\subsection{Relación Tamaño-Tecnología}

El tamaño según el límite de la tecnología será de aproximadamente 1015 lámparas al mes o 12182 lámparas al año con 1 turno de 8 horas al día y 6 días laborables por semana inicialmente y un factor de utilización estimado de $87,95 \%$. Para incrementar este límite se tendría que invertir en más máquinas de corte láser o más turnos laborables, pero inicialmente solo se adquirirá 1 para optimizar sus tiempos y volver la inversión lo más rentable posible. A continuación se muestra la tabla del calculo del factor de utilización de la cortadora laser. 


\section{Tabla 4.1}

Lista de mantenimientos preventivos para la cortadora láser

\begin{tabular}{|l|l|l|l|}
\hline & & Ratio & $\begin{array}{l}\text { Tiempos Muertos (en } \\
\text { un periodo de 28 días) }\end{array}$ \\
\hline Limpieza del filtro & 1 vez cada 28 días & 2 horas & 2 horas \\
\hline Limpieza interna (cama y recamaras) & 1 vez cada 7 días & 1 hora & 4 horas \\
\hline Limpieza del lente & 3 veces al día & 5 minutos & 7 horas \\
\hline Encendido & 1 vez al día & 10 minutos & 4,67 horas \\
\hline Cambio de piezas & 4 veces al día & 5 minutos & 9,33 horas \\
\hline Total & & & 27 horas \\
\hline Factor de utilización & & $197 / 224$ & 0,8795 \\
\hline
\end{tabular}

Elaboración propia

El factor de eficiencia de la cortadora laser será de 100\% al tener una precisión exacta en la duración de sus operaciones determinando que su tiempo real y su tiempo estándar son el mismo.

Capacidad de producción anual (1 turno por día): (303 dias $\times 8$ horas $\div$ dia $\times$ $0,8795) \div(10.5 \mathrm{~min} \div 60$ horas $\times$ lampara $)=12182$ lámparas anualmente

Por otro lado, los diseños generados podrán ser patentados y vendidos a nivel global. Debido a esto el tamaño en relación con la tecnología para los diseños no tendría limite.

\subsection{Relación Tamaño-punto de equilibrio}

El tamaño según el punto de equilibrio se determinó calculando la suma del costo fijo y los costos variables de fabricar las lámparas. Luego de calcular el costo total y dividirlo entre el precio de cada lámpara menos el costo variable de producir 1 lámpara llegamos a la conclusión de que se necesitarían producir y vender 653 lámparas mensualmente para alcanzar nuestro punto de equilibrio. 
Tabla 4.2

Costos y gastos

\begin{tabular}{|l|l|}
\hline Costos y gastos & Precio Mensual (Soles) \\
\hline Gerente General (1) & 3987,5 \\
\hline Diseñador Industrial/ Experto en Fabricación Digital (1) & 2900 \\
\hline Jefe de Ventas & 1812,5 \\
\hline Técnico de Corte Láser (1) & 1348,5 \\
\hline Servicio de Limpieza (Tercerizado) & 1200 \\
\hline Servicio de Vigilancia (Tercerizado) & 1200 \\
\hline Servicio de Transporte (Tercerizado) & 1200 \\
\hline Agua & 70 \\
\hline Electricidad & 1000 \\
\hline Internet (Telefónica) & 120 \\
\hline $\begin{array}{l}\text { Mantenimiento y Seguridad de Computadoras (Kunaq \& } \\
\text { Asociados) }\end{array}$ & 200 \\
\hline Licencia Autodesk Inventor (mensual) & 537 \\
\hline Licencia Autodesk Fusion 360 (mensual) & 166,5 \\
\hline Licencia Adobe Ilustrator (mensual) & 66,7 \\
\hline Renta-67.5 m² (Surco-Monterrico) & 4273,33 \\
\hline Capacitaciones (2\% del costo laboral) & 55 \\
\hline Contador (Tercerizado) & 930 \\
\hline Planchas de MDF x lámpara (Costo Variable) & 0,89 \\
\hline Focos (Costo Variable) & 4,99 \\
\hline Caja de Cartón (Costo variable) & 0,55 \\
\hline Cable mellizo 1 metro (Costo variable) & 1,40 \\
\hline Enchufe simple (Costo variable) & 0,90 \\
\hline Soquete (Costo Variable) & 1,50 \\
\hline Etiqueta (Costo Variable) & 0,30 \\
\hline Costo Total Fijo & 21067,03 \\
\hline Costo Total (653 lámparas) & 27812,52 \\
\hline & \\
\hline
\end{tabular}

Elaboración propia

Los salarios del personal contratado estarán incluyendo las retenciones y gratificaciones considerando un 1,45 del sueldo base. Considerando este como nuestro costo fijo anual el monto a generar para alcanzar el punto de equilibrio seria de S/. 333 750,24 más el costo variable multiplicado por la cantidad de lámparas producidas.

21067,03 soles $\div\left(42,64\right.$ soles $\left.-10,33 \frac{\text { soles }}{\text { lámpara }}\right)=$

Punto de equilibrio (\# de lámparas) $=653$ lámparas 
Tabla 4.3

Cálculo de punto de equilibrio

\begin{tabular}{|l|c|}
\hline Costo mensual fijo & 21067,03 soles \\
\hline Costo variable (por lámpara) & 10,33 soles \\
\hline Valor generado por lámpara & 42,64 soles \\
\hline Punto de equilibrio & 653 lámparas \\
\hline
\end{tabular}

Elaboración Propia

\subsection{Selección del tamaño de planta}

A continuación se muestra una tabla que resume el dimensionamiento del servicio en base a: el mercado, los recursos, la tecnología y el punto de equilibrio.

Tabla 4.4

Dimensionamiento del servicio

\begin{tabular}{|l|l|l|l|l|}
\hline Factor & Mercado & Recursos & Tecnología & Punto de Equilibrio \\
\hline Tamaño & $\begin{array}{l}23119 \\
\text { lámparas }\end{array}$ & No limitante & $\begin{array}{l}\text { 12 182 lámparas } \\
\text { anualmente }\end{array}$ & $\begin{array}{l}7 \text { 836 lámparas } \\
\text { anualmente }\end{array}$ \\
\hline
\end{tabular}

Elaboración propia

Como se puede apreciar en la tabla la dimensión del servicio el límite inferior (mínimo número de lámparas vendidas anualmente) será de 7836 lámparas y viene del factor limitante que es la relación Tamaño-Punto de Equilibrio. El tamaño a planear para el taller será utilizando el tamaño determinado por la tecnología de 12182 lámparas al año. 


\section{CAPÍTULO V: INGENIERÍA DEL PROYECTO}

\subsection{Definición técnica del producto.}

El producto propuesto es una lampará domestica infantil que vendrá en múltiples diseños personalizados. Se produce con tecnologías de corte láser utilizando planchas de MDF de $4 \mathrm{~mm}$ de espesor con un diseño modular que permite su rápida producción. Su función es la iluminación del hogar utilizando 220 voltios para emanar luz fría de 520 lúmenes que previene riesgos de incendio y la decoración de este con formas variadas inspiradas en la cultura local y los intereses de su mercado objetivo con dimensiones de $20 \mathrm{~cm}$ de diámetro y 20 centímetros de altura pesando 361 gramos aproximadamente.

\subsubsection{Especificaciones técnicas, composición y diseño del producto.}

La figura siguiente detalla los atributos generales de un foco ahorrador marca Daiku como el material, el voltaje, la luminosidad que emana entre otros. 


\section{Figura 5.1}

Ficha técnica de foco ahorrador marca Daiku

\begin{tabular}{|c|c|}
\hline Atributos & Detalles \\
\hline Marca & Daiku \\
\hline Modelo & Espiral \\
\hline Tipo de luz & Cálida \\
\hline Base de Foco & E27 (roscaestándar) \\
\hline Potencia & Consume: $20 \mathrm{~W}$ - llumina: $120 \mathrm{~W}$ \\
\hline Luminosidad & $1450 \mathrm{Im}$ \\
\hline Voltaje & $220-240 V$ \\
\hline Frecuencia & $50-60 \mathrm{~Hz}$ \\
\hline Temperatura & $2700 \mathrm{~K}$ \\
\hline Tiempo de vida & 8000 horas \\
\hline Garantia & 1 año (Por defecto de fábrica) \\
\hline Contenido & 1unid. \\
\hline Encendido & Instantáneo \\
\hline Material & Plástico \\
\hline Color & Blanco \\
\hline Uso & Ideal para iluminar cualquier ambiente interno y externo. \\
\hline Procedencia & China \\
\hline Características & $\begin{array}{l}\text { Ahorra } 80 \% \text { de energla en comparación con bombillas incandescentes de salida luminosa similar. Con forma de } \\
\text { espiral y tamaño súper compacto. Encendido inmediato. }\end{array}$ \\
\hline Recomendaciones & No tocar directamente con los dedos cuando está encendida. No exponer al aire frío. Proteger de la lluvia. \\
\hline Tipo & Foco ahorrador \\
\hline
\end{tabular}

Fuente: Alibaba, (2019)

En la tabla que sigue se detallan las especificaciones técnicas de mayor importancia para una lámpara infantil fabricada con tecnologías de corte láser. 


\section{Tabla 5.1}

Especificaciones técnicas - Lámpara infantil

\begin{tabular}{|l|l|}
\hline $\begin{array}{l}\text { Especificaciones Técnicas - Lámpara infantil } \\
\text { (Fabricada con corte láser) }\end{array}$ \\
\hline Material & MDF 4 mm de espesor \\
\hline Color & Marrón claro \\
\hline Con Atenuador & No \\
\hline Tipo de Foco & Ahorrador Espiral (Max 20W) \\
\hline Alto & $20 \mathrm{~cm}$ \\
\hline Diámetro & $20 \mathrm{~cm}$ \\
\hline Peso & 361 gramos \\
\hline \multirow{2}{*}{ Alimentación } & 220 voltios \\
\cline { 2 - 2 } & $60 \mathrm{~Hz}$ \\
\hline Garantía & 3 años \\
\hline Cantidad de focos & 1 \\
\hline Color de la luz & Blanco frio \\
\hline Diseño especial para & Dormitorio \\
\hline Estilo & Estilo moderno \\
\hline Tipo de lámpara & Lámpara de mesa \\
\hline Elaboración propia & \\
\hline
\end{tabular}

El diseño será realizado con los software de Autodesk: Inventor y Fusion 360. Ambos son paquetes de modelado paramétrico de sólidos en 3D de manera virtual. Esto permitirá visualizar el prototipo antes de utilizar los recursos para fabricarlo permitiendo reducir drásticamente en sobrecostos por errores. Por otro lado, para evitar la necesidad de usar mucha cola (o cola en general) se realizará un diseño press fit que permitirá usar en parte o en su totalidad la fricción como adherente. Finalmente, el maquinado se realizará con el corte láser y al preservar el modelo se podrá reproducir las piezas necesarias para aprovechar su característica modular generando repuestos para garantizar la calidad y proveer a los clientes con piezas nuevas por si dañaran alguna de sus lámparas.

A continuación, un ejemplo de diseño de una lámpara realizado para probar la facilidad de su adaptabilidad ya que dicho diseño fue realizado en 30 minutos incluyendo el ensamble para la previsualización y asegurarse de que los encajes funcionen.

Al inicio se generan bocetos en 2D utilizando medidas parametrizadas para asegurarse de que las dimensiones de las piezas a cortar no excedan los límites de los 
modelos y estas encajen perfectamente optimizando la utilización de recursos (todas las medidas están en milímetros).

Figura 5.2

Centro de ensamble de piezas inferior

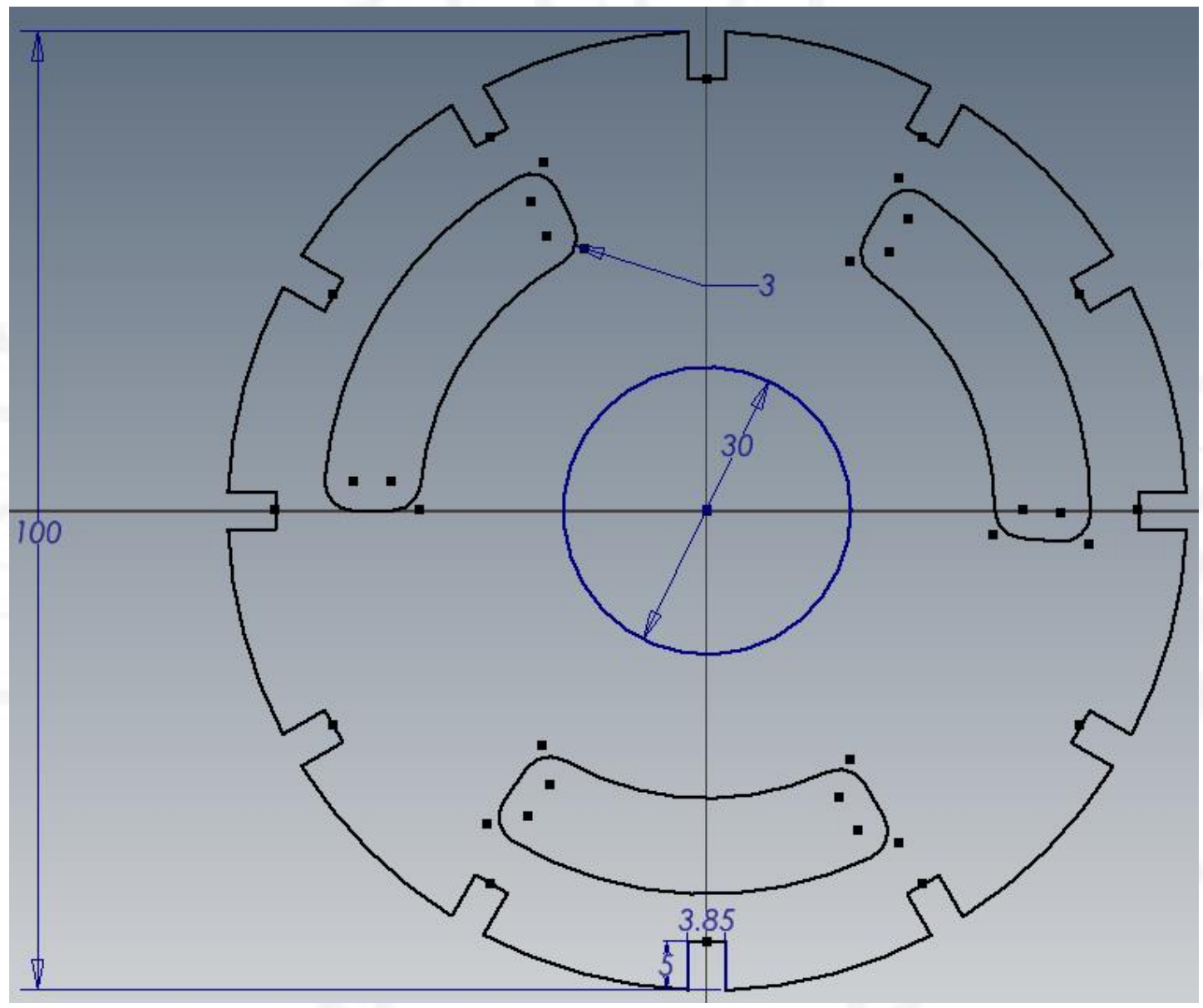

Elaboración propia 
Figura 5.3

Centro de ensamble de piezas superior

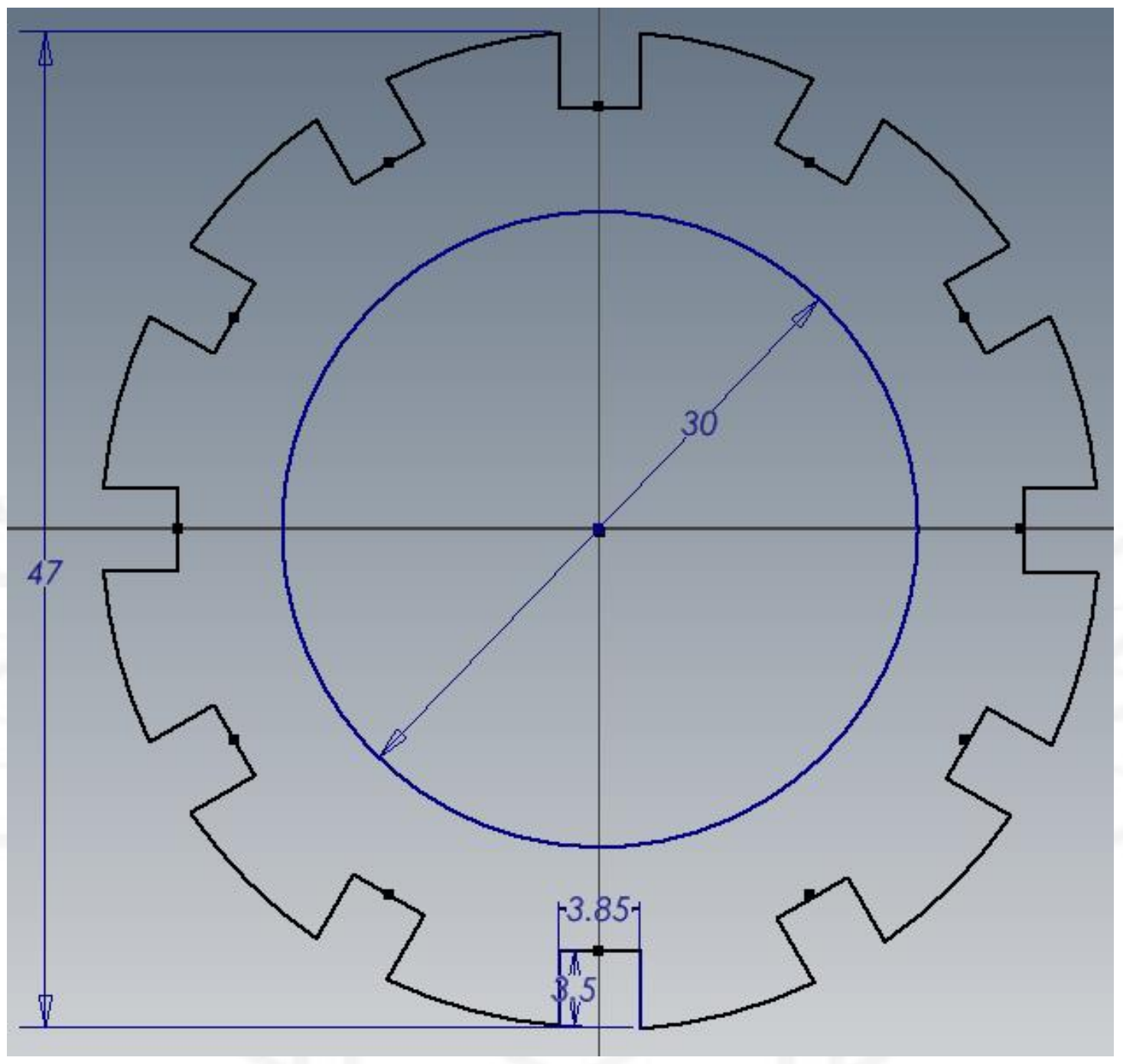

Elaboración propia 
Figura 5.4

Lado de ensamble

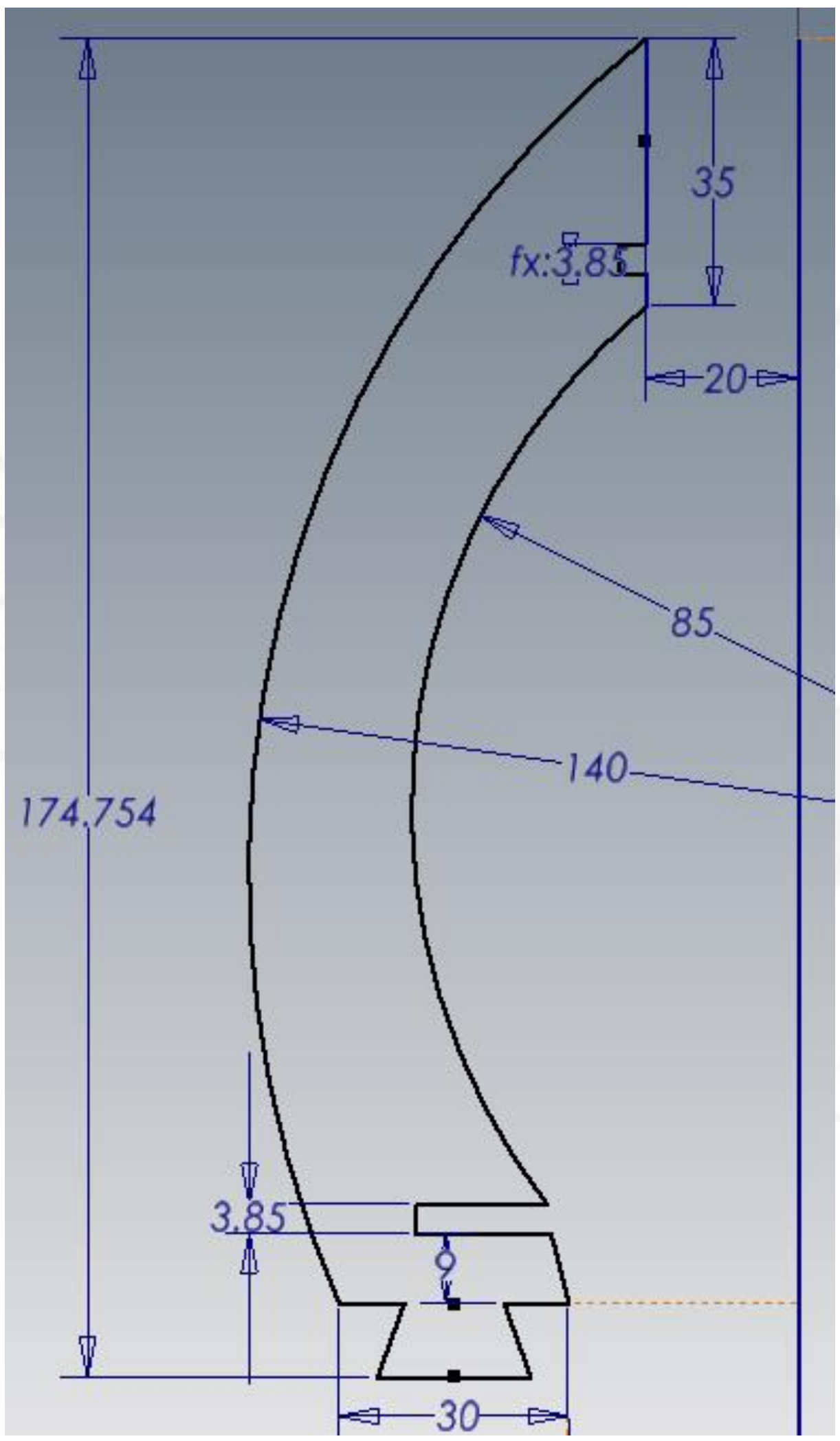

Elaboración propia 
Figura 5.5

Lado de ensamble con soporte

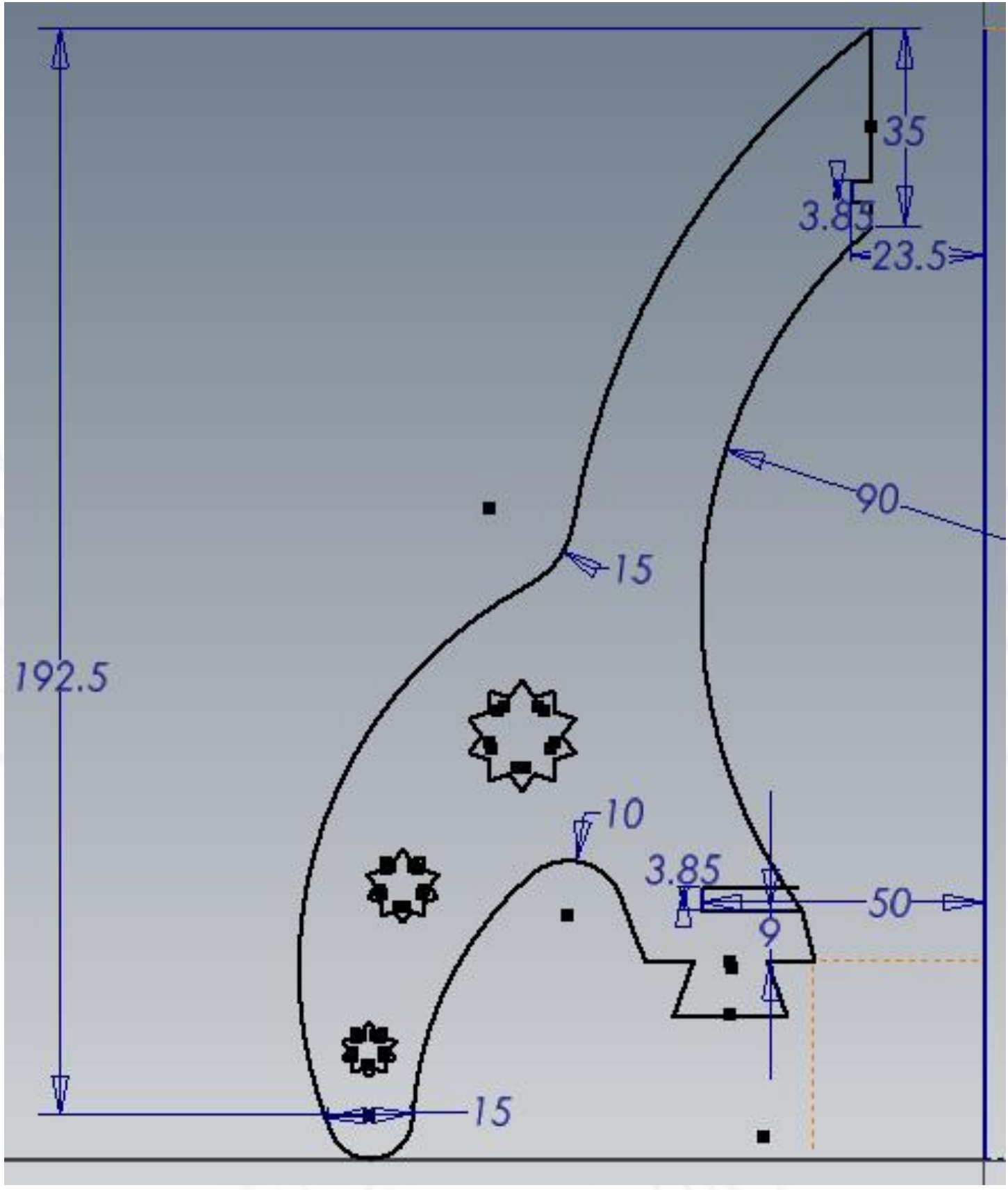

Elaboración propia

Luego se procede a convertir los bocetos en solidos virtuales a través de las herramientas de modelado 3D que incluye Autodesk Inventor como muestran las siguientes figuras. 
Figura 5.6

Centro de ensamble de piezas inferior extruido

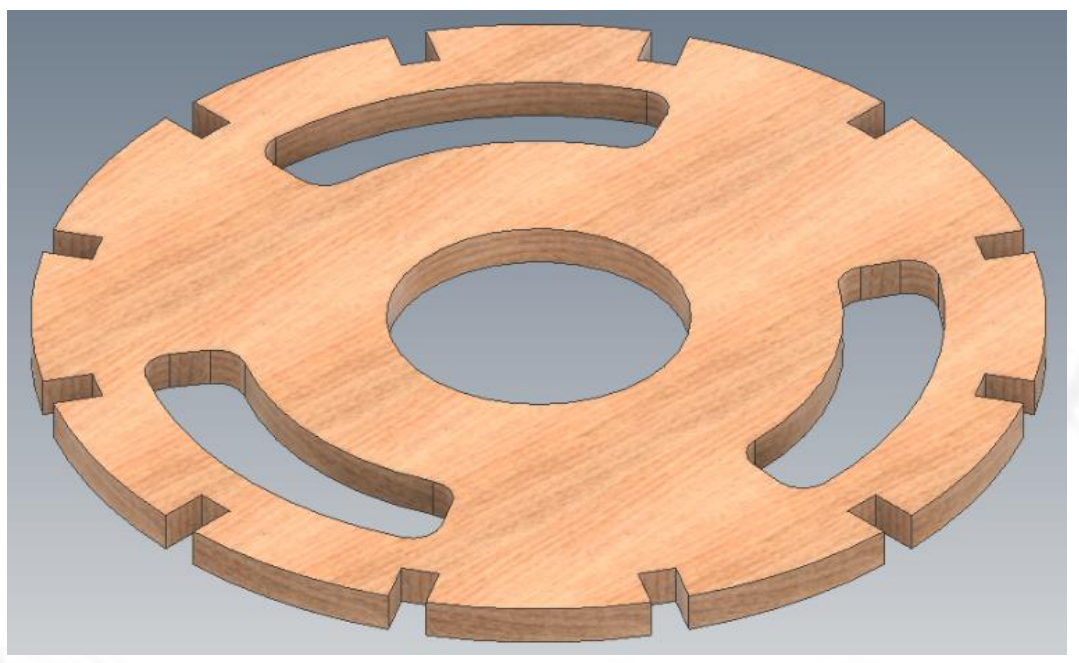

Elaboración propia

Figura 5.7

Centro de ensamble de piezas superior extruido

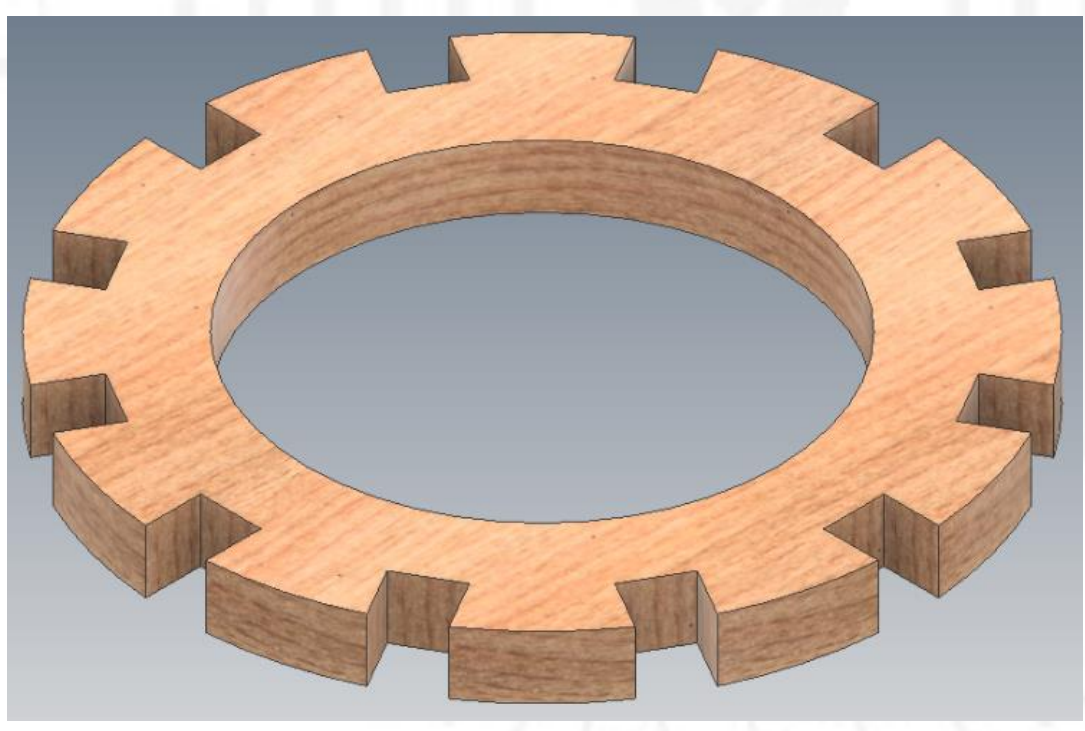

Elaboración propia 
Figura 5.8

Lado de ensamble extruido

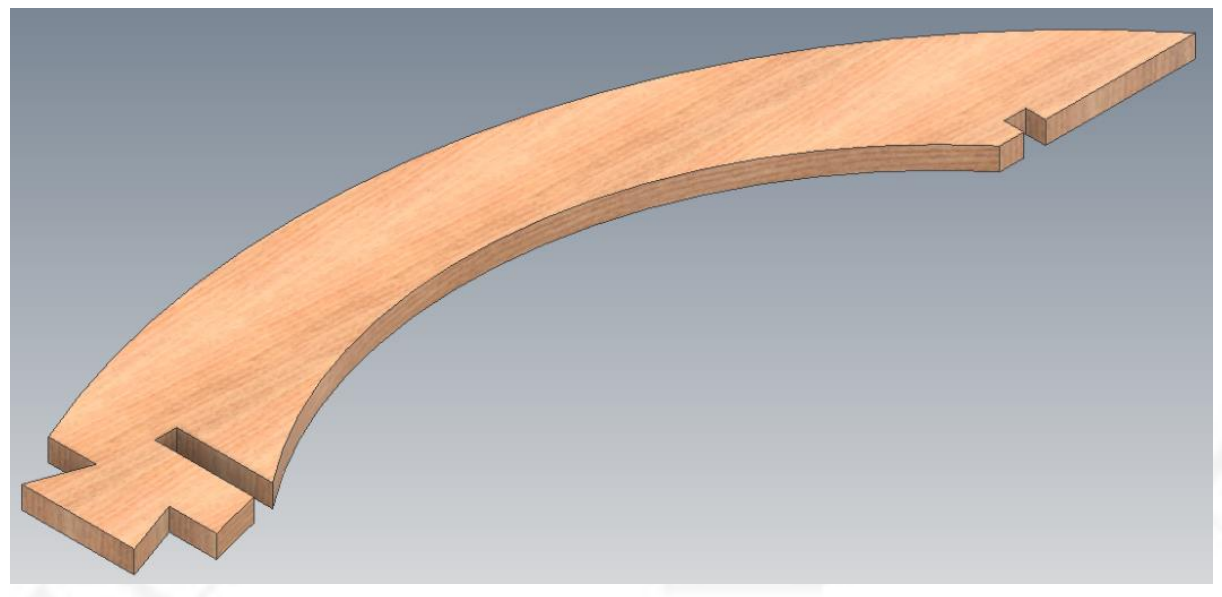

Elaboración propia

Figura 5.9

Lado de ensamble con soporte extruido

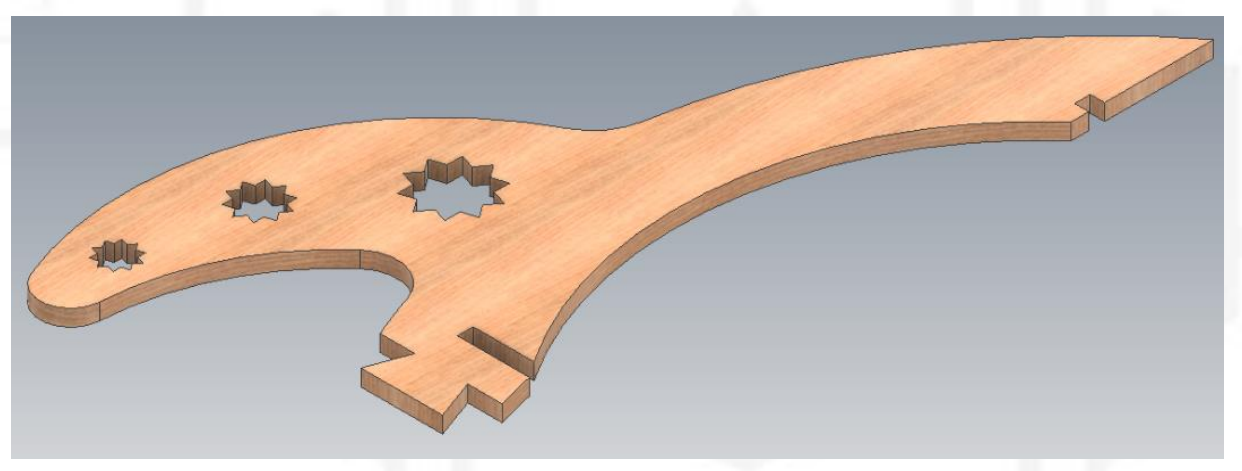

Elaboración propia

Posteriormente se ensamblan las piezas para generar un modelo de cómo se vería la lámpara una vez ensamblada y asegurarse de no encontrar errores a la hora de producir optimizando la utilización de los recursos del emprendimiento. 
Figura 5.10

Ensamble virtual

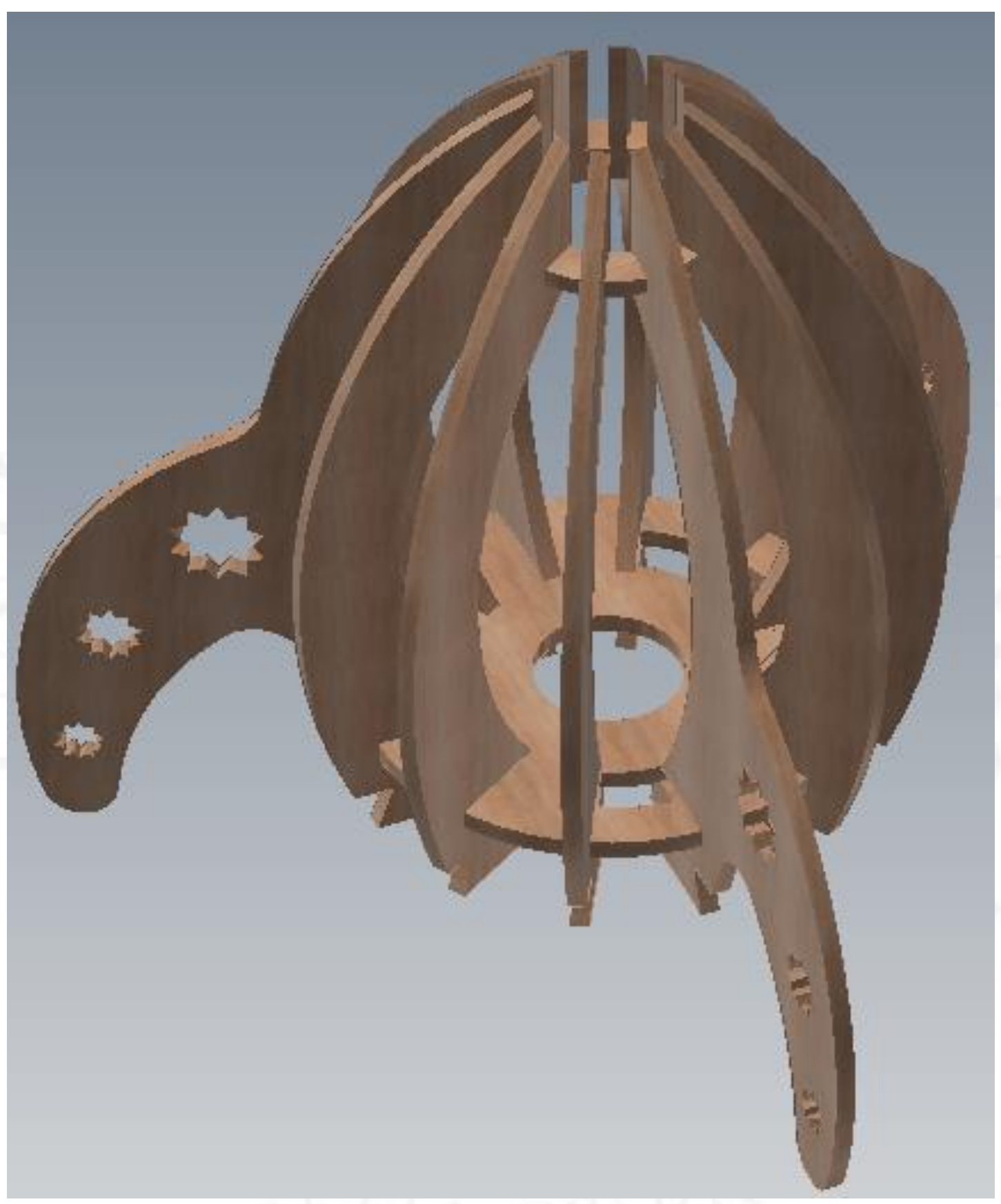

Elaboración propia

Finalmente, se pueden exportar planos de las vistas del producto con las dimensiones necesarias por si estas fueran necesarias como lo muestra la siguiente figura. 
Figura 5.11

Vistas isométricas del producto con cotas

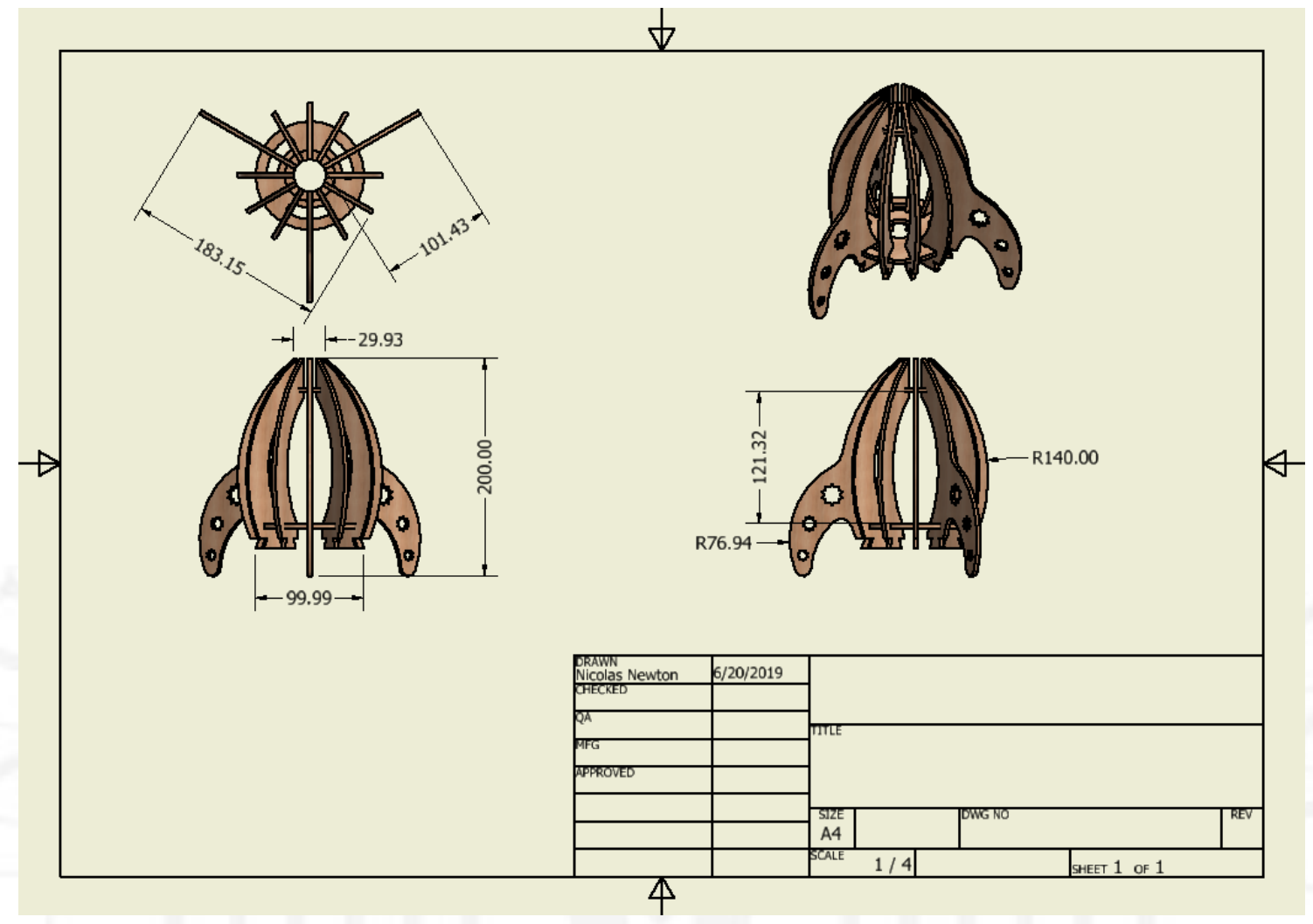

Elaboración propia

\subsection{Tecnologías existentes y procesos de producción}

En este subcapítulo se detallarán las tecnologías existentes como son los software de diseño vectorial en 2 dimensiones (2D), los software de diseño paramétrico de modelado de sólidos en 3 dimensiones (3D) y las máquinas de corte láser que se podrían utilizar para la fabricación de las lámparas. Por otro lado, también se detallarán los procesos de producción de estas contrastando sus diferencias.

\subsubsection{Descripción de tecnología existente}

Para producir las lámparas propuestas se utilizarán tecnologías de fabricación digital. En relación con el software utilizado, se utilizarán software de modelado paramétrico que permiten generar los diseños en 2D para maquinar con la cortadora láser y tanto poder 
reducir la probabilidad de errores a la hora de maquinar realizando ensambles como visualizar el producto antes de producirlo con diseños 3D y visualizaciones virtuales.

Por otro lado, para el prototipado y fabricación de las lámparas se utilizará una cortadora láser. Existen múltiples opciones en el mercado global de cortadoras láser para utilizar variando en velocidad de corte (debido a la potencia del láser) y tamaño de cama de corte. Aparte de la maquina se necesitará utilizar un software de diseños gráficos y 2D (Adobe Ilustrator) que servirá de intermediario para mandar los diseños controlando su posición en la cama de corte al software específico de la cortadora láser adquirida donde se regulará la potencia, frecuencia y velocidad de corte.

Tabla 5.2

Software de modelado paramétrico

\begin{tabular}{|l|l|}
\hline Software de Modelado paramétrico & Precio (USD/año) \\
\hline Autodesk Inventor & 1935 \\
\hline SolidWorks & 2700 \\
\hline Autodesk Fusion 360 & 600 \\
\hline ZBrush & 900 (un solo pago) \\
\hline Rhino & 2100 \\
\hline Onshape & 3000 \\
\hline Alias & 4130 \\
\hline AutoCAD & 1700 \\
\hline FreeCAD & Gratis \\
\hline Blender & Gratis \\
\hline
\end{tabular}

Elaboración propia

Tabla 5.3

Software de diseño grafico

\begin{tabular}{|l|l|}
\hline Software de Diseño Grafico & Precio (USD/año) \\
\hline Adobe Ilustrator & 240 \\
\hline Adobe Photoshop & 240 \\
\hline CorelDraw & 200 \\
\hline Inkscape & Gratis \\
\hline Krita & Gratis \\
\hline GIMP & Gratis \\
\hline
\end{tabular}

Elaboración propia 
Tabla 5.4

Tecnologías de corte láser

\begin{tabular}{|l|l|}
\hline Tecnologías de Corte Láser & Precio (Desde) \\
\hline Epilog & 5000 USD \\
\hline Full Spectrum & 6000 USD \\
\hline Trotek & 8000 USD \\
\hline Importaciones Chinas & 2000 USD \\
\hline
\end{tabular}

Elaboración Propia

Existen otros métodos para producir lámparas como lo es generarlas a través de trabajos de carpintería donde se arma la lámpara utilizando herramientas de corte como una sierra circular o una caladora. Por otro lado, también se pueden producir lámparas de concreto con diseños simples utilizando moldes hechos con madera para luego reproducir las carcasas de las lámparas hechas con concreto.

\subsubsection{Selección de la tecnología}

Se eligió la tecnología de corte laser por su superioridad en términos de velocidad de producción, adaptabilidad de modelos y calidad del acabado entre otros. Las lámparas hechas con los métodos descritos en el subcapítulo anterior requieren de mas tiempo para producirse, la mano de obra debe estar capacitada y no se puede garantizar la calidad exacta mientras que las tecnologías de corte laser garantizan que todos los modelos sean exactamente iguales garantizando la calidad y generando una ventaja competitiva mucho mayor.

Para elegir los software de diseño 2D, modelado 3D y las maquinarias que se utilizaran se tecnología a utilizar en el proyecto se consideró: precio, capacidad y facilidad de uso. Para elegir nuestro software de modelado paramétrico se consideró también su uso principal. Por ello se descartaron los software Blender, Zbrush, Rhino, Alias y FreeCAD. En relación con la antigüedad del software se descartó AutoCAD y finalmente por temas de precio se eligió Autodesk Inventor como nuestro software de modelado paramétrico $2 \mathrm{D}$ y $3 \mathrm{D}$. 
Para elegir el software de diseño gráfico se tomó la libertad de no optar por la opción más barata pues como este software se comunica directamente con la cortadora láser su óptimo funcionamiento se traduce a ahorro del tiempo que acaba siendo uno de nuestros recursos más valiosos. Por ello se descartaron los software gratuitos y se eligió Adobe Ilustrator por ser el más versátil y fácil de usar para la parte central del negocio.

Finalmente, para seleccionar nuestra cortadora láser se analizaron las opciones y debido a los altos costos de las marcas de alta gama se tomó la decisión de traer una cortadora láser importada de china de calidad media para reducir el costo de la inversión inicial y afinar nuestros consumos. En un futuro se consideraría elegir una cortadora láser de alta gama para mejorar el acabado de los materiales cortados.

\subsubsection{Proceso de producción}

En este subcapítulo se detallará el proceso de producción para fabricar lámparas infantiles domesticas con diseños personalizados detallando las tecnologías que se utilizarán detallando que ocurre en cada parte del proceso de inicio a fin.

\subsubsection{Descripción del proceso}

Diseño: El proceso de producción inicia con nuestro diseñador industrial o especialista de fabricación digital. Se encargará de generar nuevos diseños utilizando el software de Autodesk Inventor que una vez generado se exporta con tipo de archivo .dxf para insertarlo en Adobe Ilustrator como muestra la siguiente figura. Se modifica el espesor de líneas y se vectoriza lo que sea necesario para determinar que líneas serán cortadas y cuáles serán grabadas. A continuación se muestra el proceso paso por paso. 
Figura 5.12

Visualización del diseño en el software Adobe Ilustrator

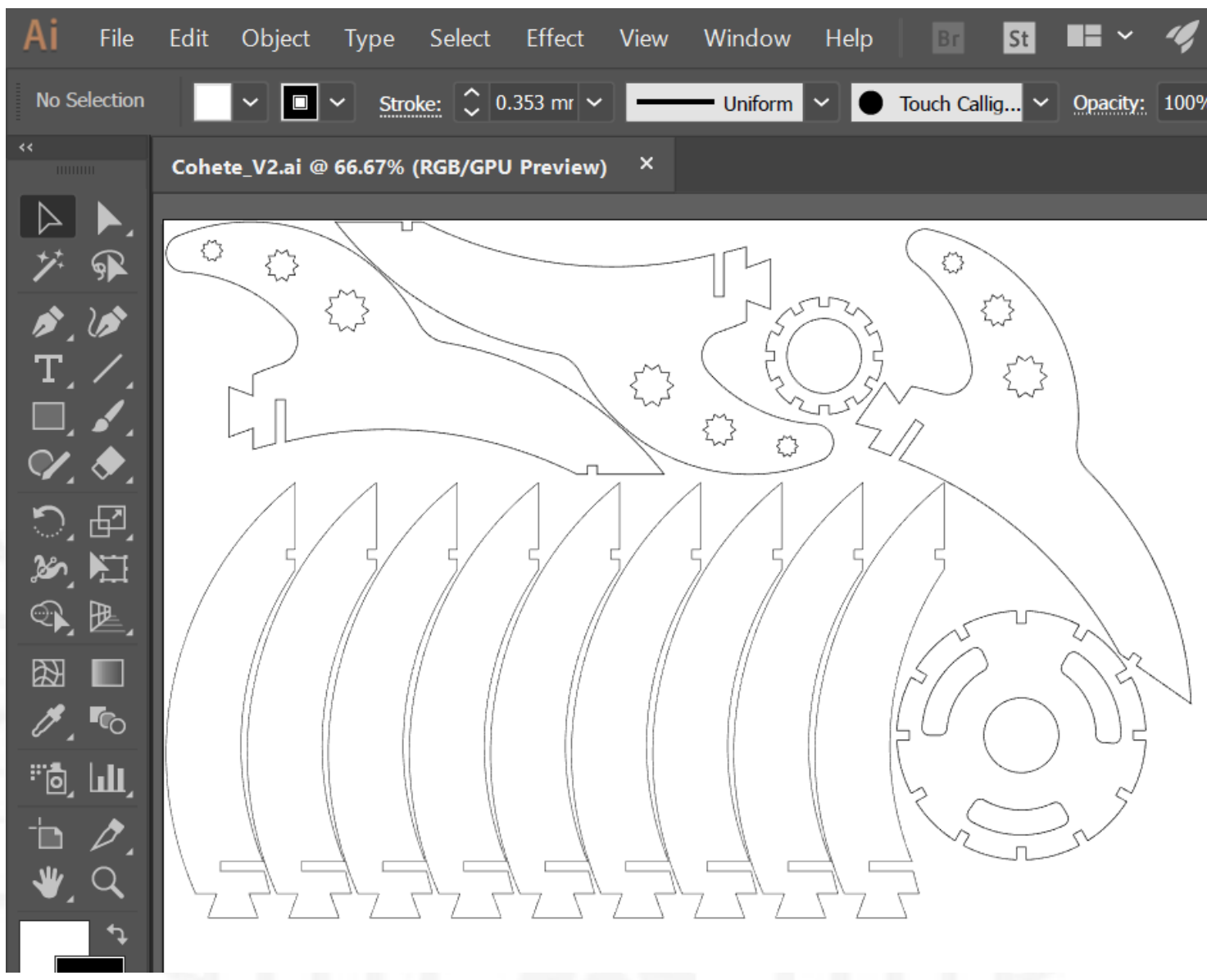

Elaboración propia

Recepción e inspección de materia prima: En relación con la materia prima y materiales a utilizar se inicia con la recepción de las planchas de MDF de 1,3 metros por 0,9 metros, los focos, los soquetes, los enchufes y los rollos de cable mellizo para su posterior inspección de calidad.

Corte láser (maquinado): Luego se utiliza el software de la cortadora láser donde se seleccionan los parámetros de corte como potencia, velocidad, frecuencia y corte, grabado o ambos como muestra la siguiente figura. 
Figura 5.13

Parámetros de corte láser

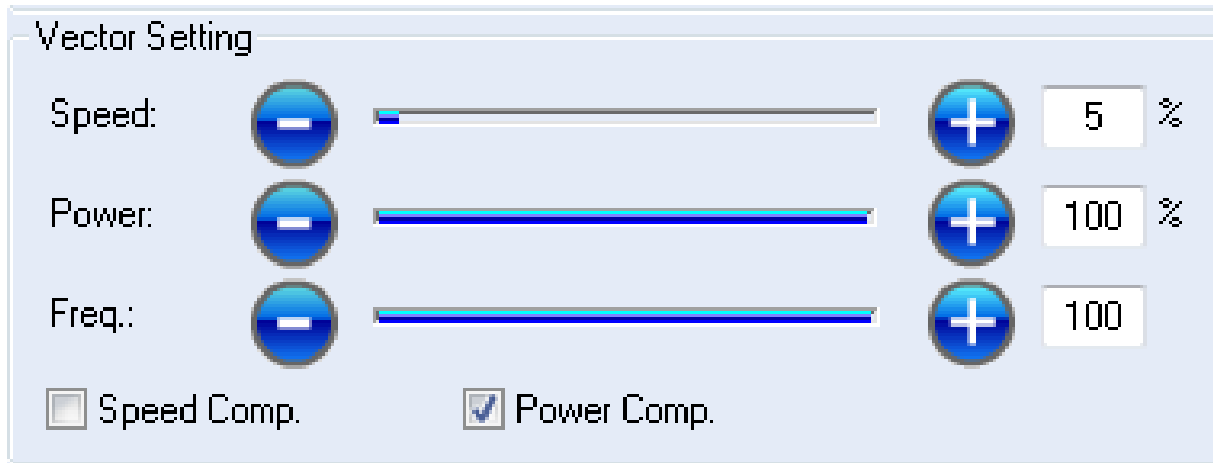

Elaboración propia

Una vez seleccionados todos los parámetros y tomando las medidas de precaución necesarias para reducir riesgos como mascarilla, extractor activado y tubo de $\mathrm{CO}_{2}$ activado se posiciona el material a cortar en la cama de la cortadora láser y se manda el modelo a cortar presionando el botón verde que se muestra en la siguiente figura, en la pantalla se puede visualizar el tiempo que demorará el corte. 
Figura 5.14

Tiempo de corte láser

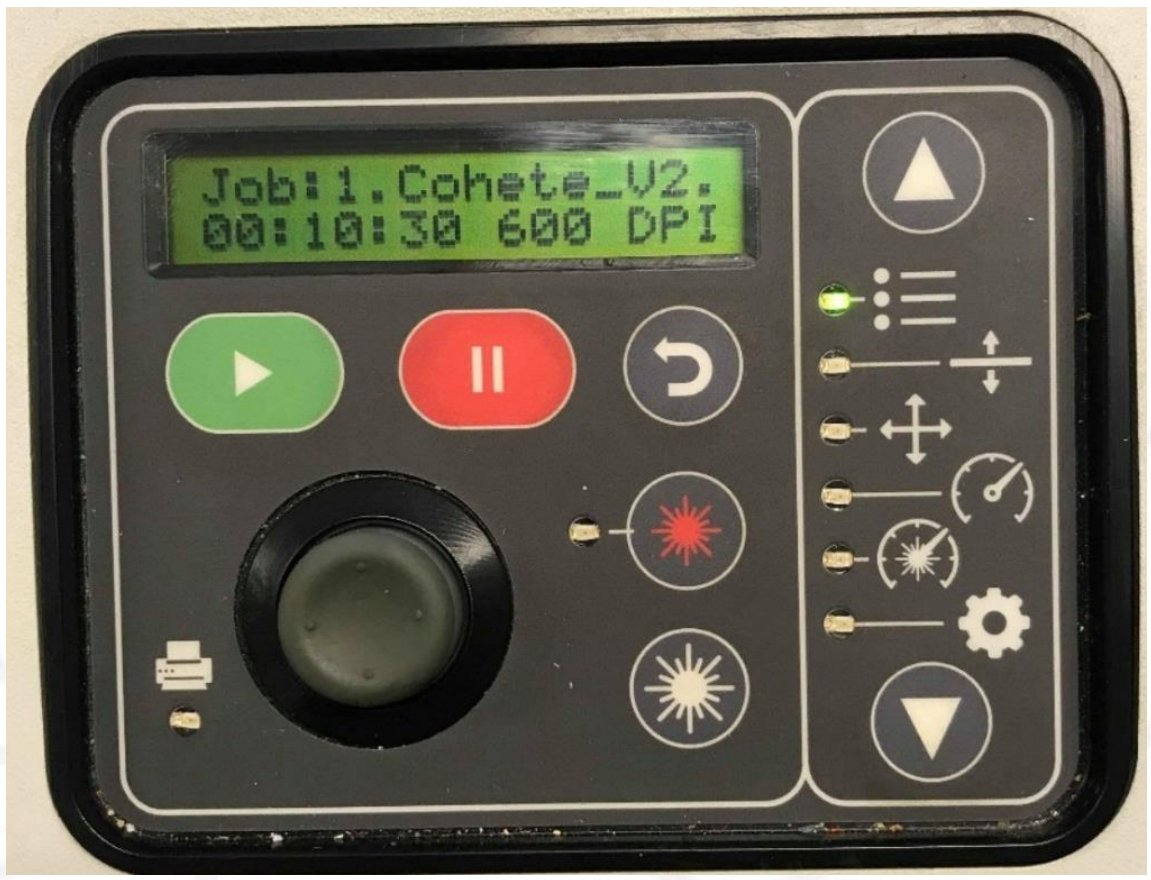

Elaboración propia

Las siguientes figuras muestran cómo se va realizando el corte dentro de la cortadora laser. 
Figura 5.15

Proceso de corte láser 01

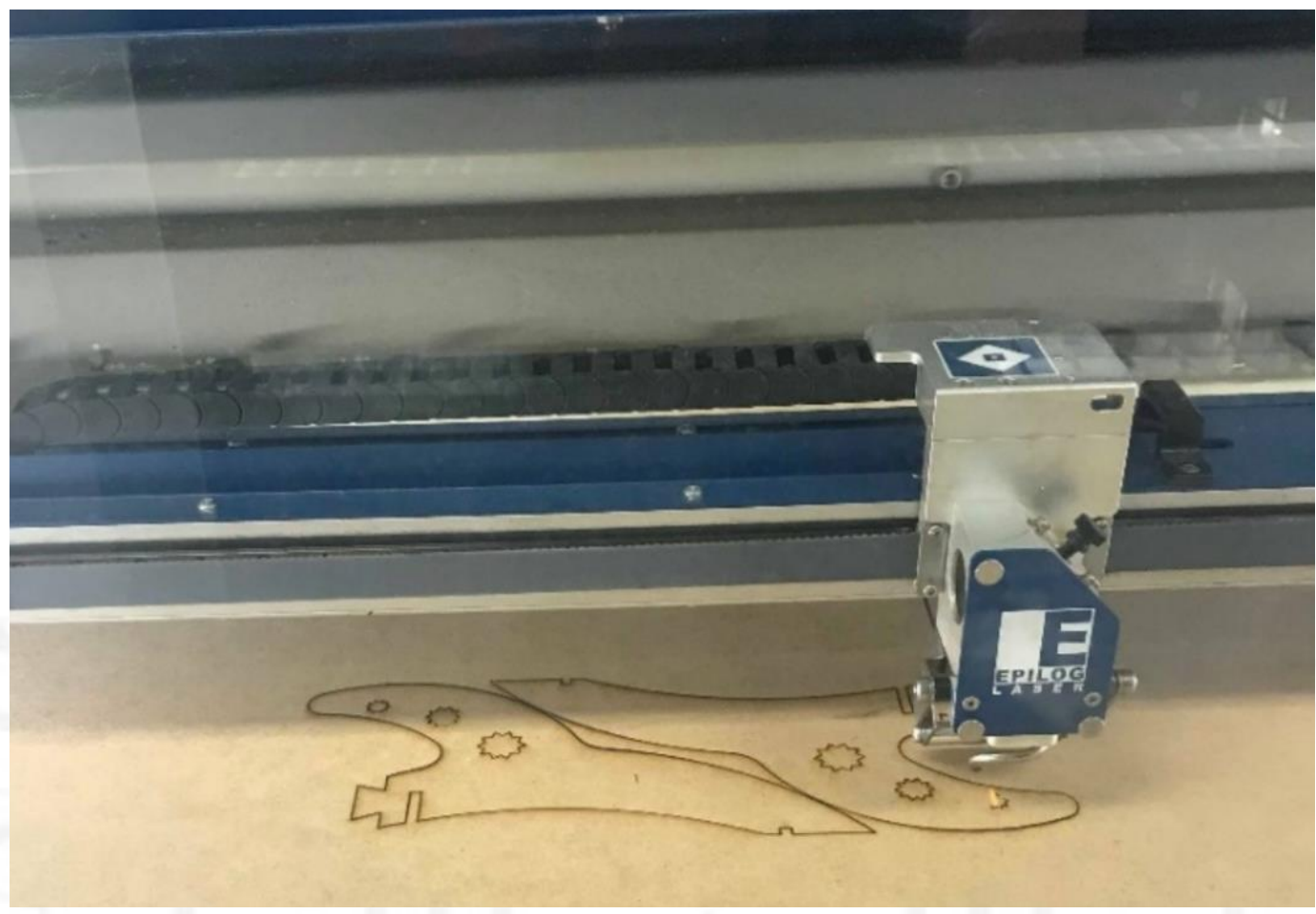

Elaboración propia

Figura 5.16

Proceso de corte láser 02

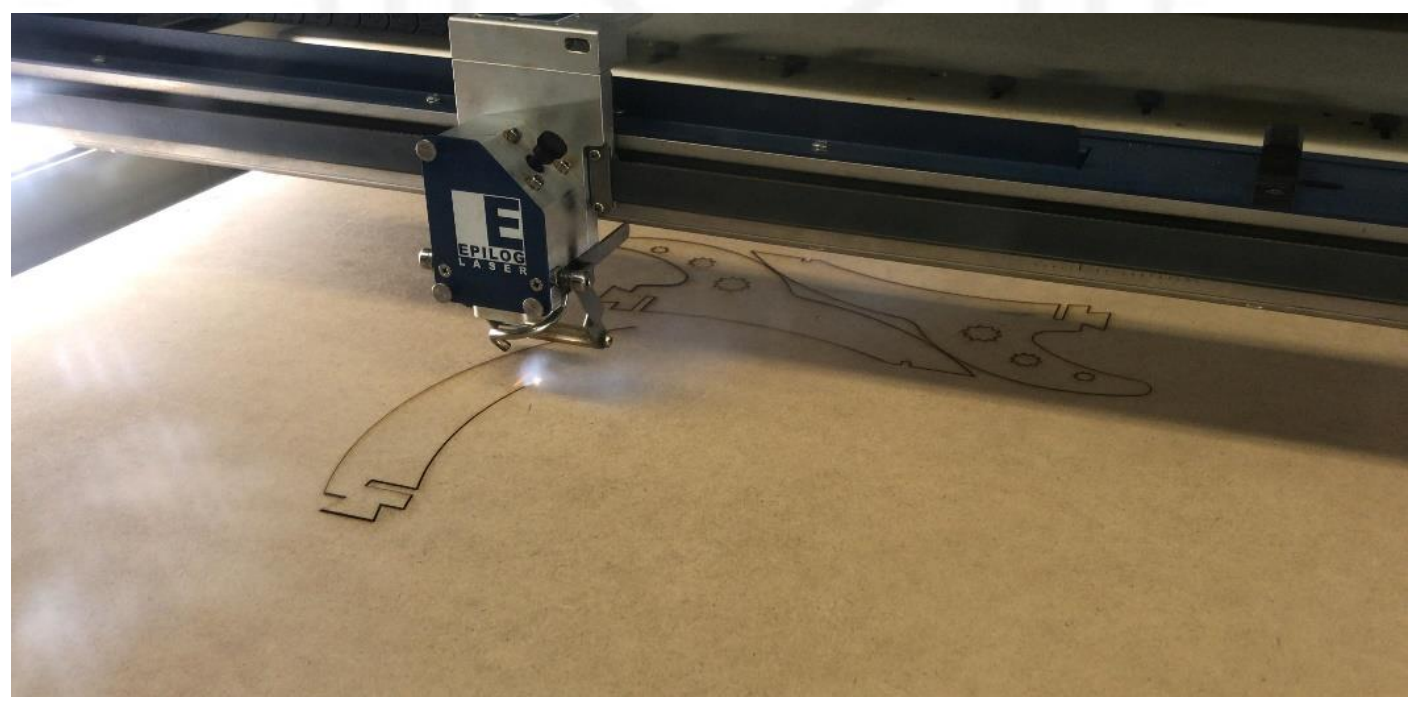

Elaboración propia 
Figura 5.17

Proceso de corte láser 03

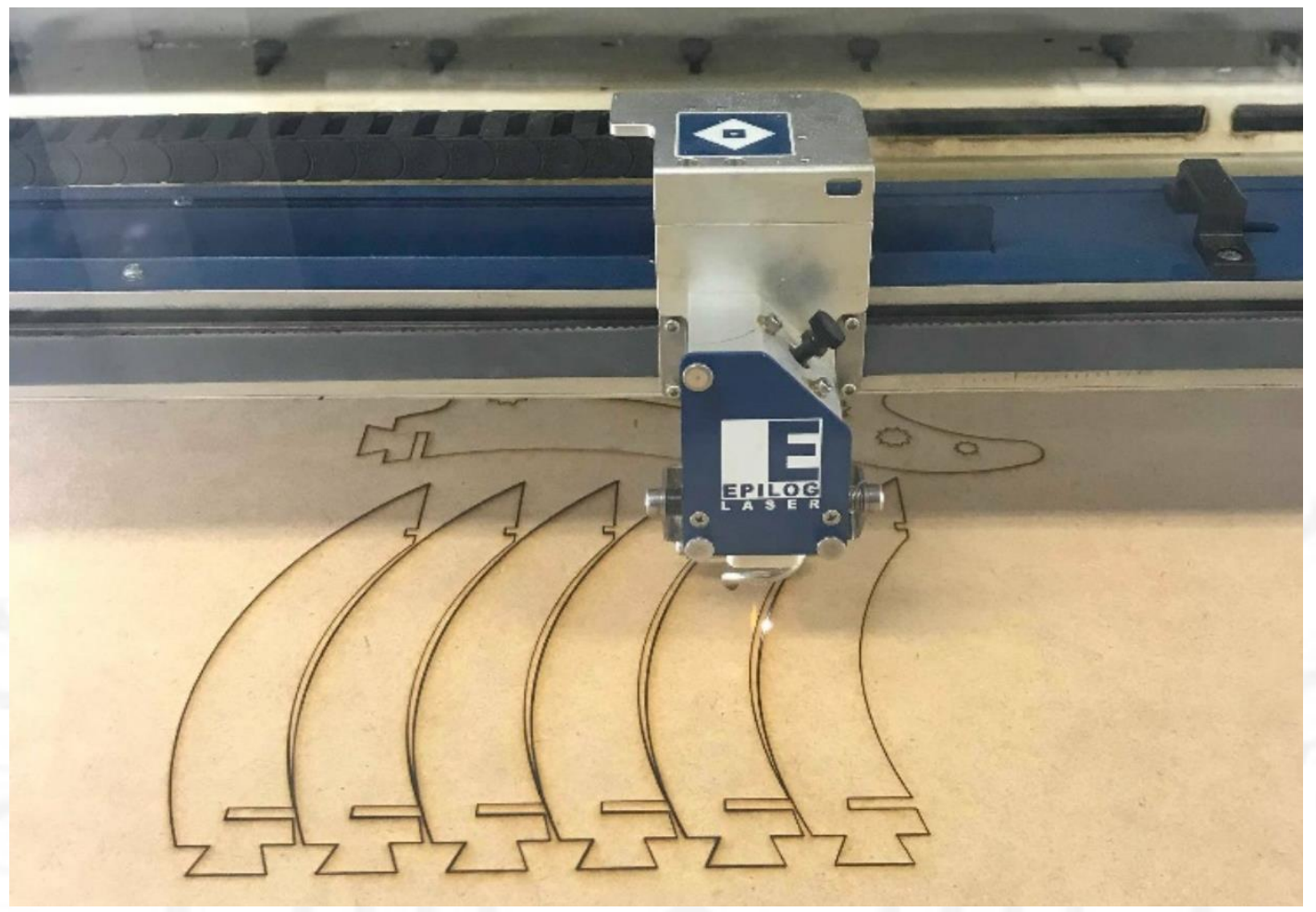

Elaboración propia

Las siguientes operaciones se realizan en paralelo al corte laser ya que al poder cortar suficientes piezas para casi 10 lámparas cada corte demora aproximadamente 100 minutos lo que permite al operario utilizar este tiempo para realizar todas las actividades restantes utilizando las herramientas e insumos que se muestran en la siguiente figura. 
Figura 5.18

Herramientas e insumos para la fabricación de una lámpara

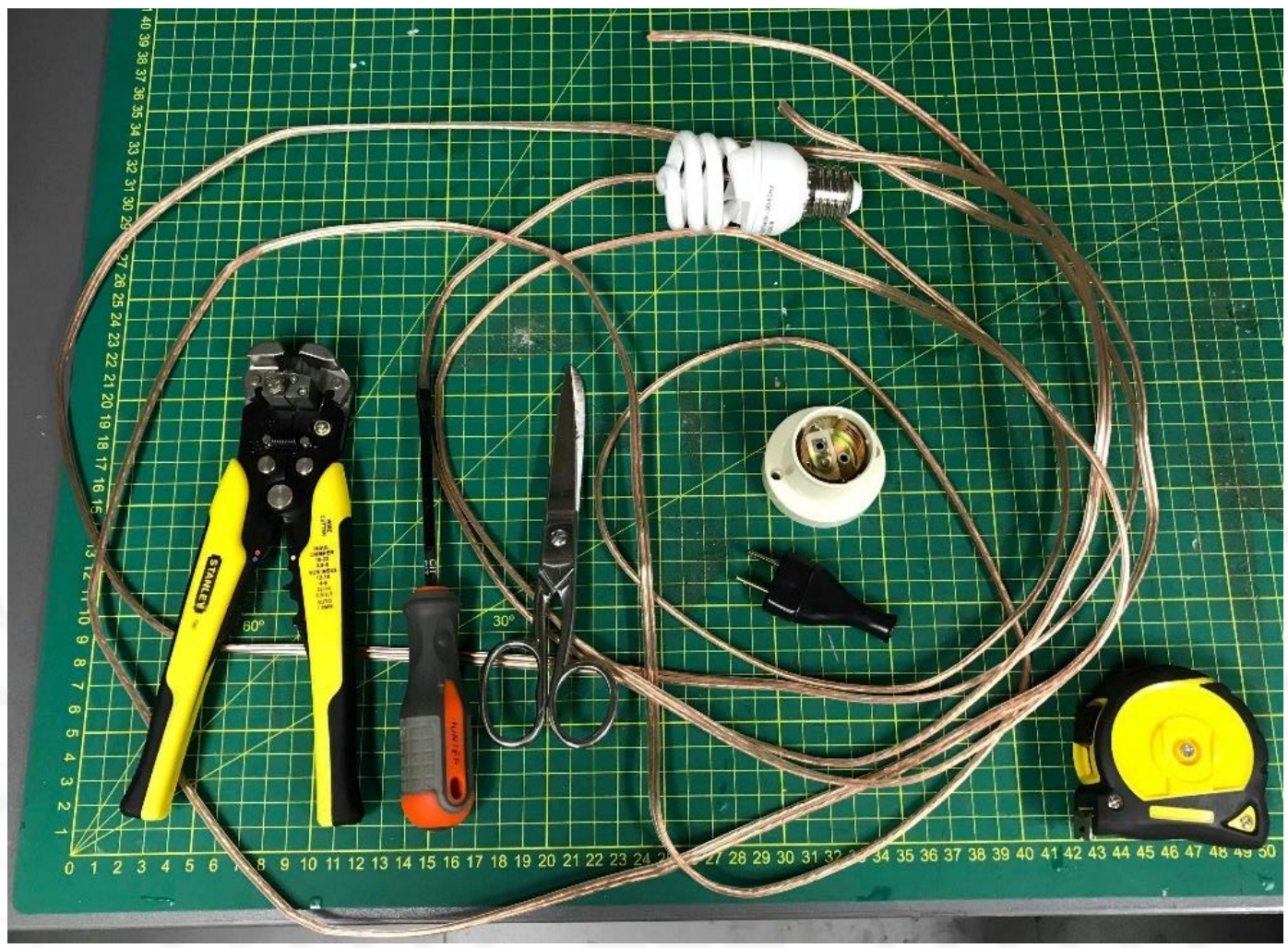

Elaboración propia

Corte de cable mellizo: El operario utilizando una wincha y unas tijeras mide pedazos de 1 metro de longitud de cable mellizo y realiza un corte simple como muestran la siguiente figura. 
Figura 5.19

Corte de cable mellizo

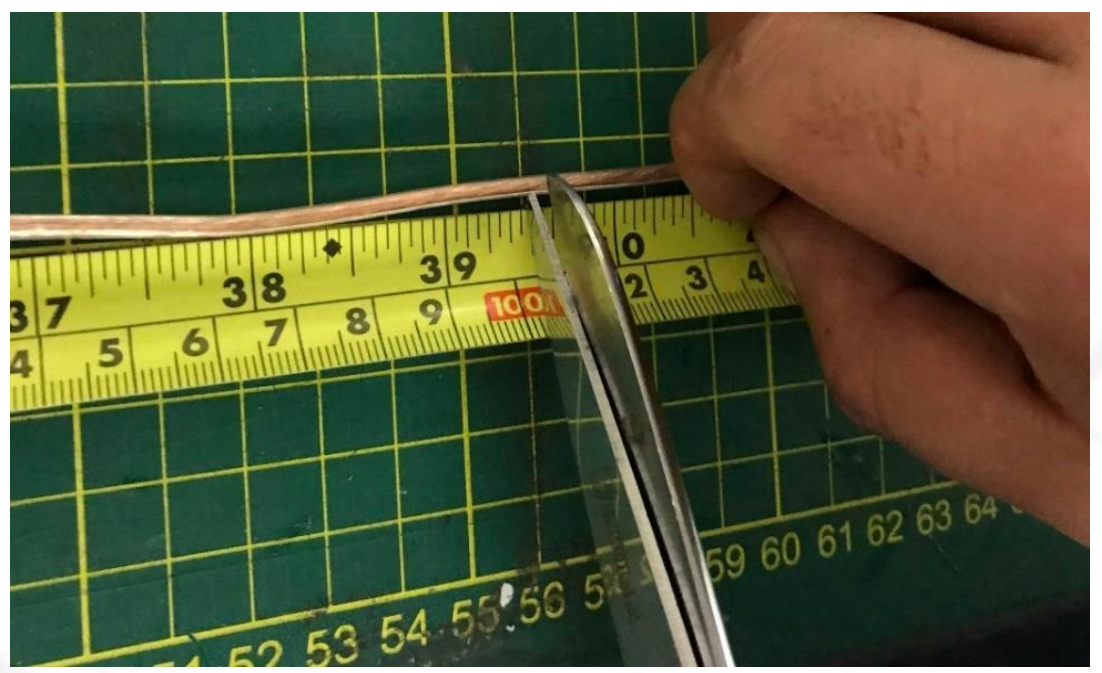

Elaboración propia

Pelado de cable mellizo: Una vez realizado el corte utilizando un alicate pelacables se realiza el pelado del trozo de 1 metro de cable mellizo por ambos lados como lo muestra la siguiente figura.

Figura 5.20

Pelado de cable mellizo

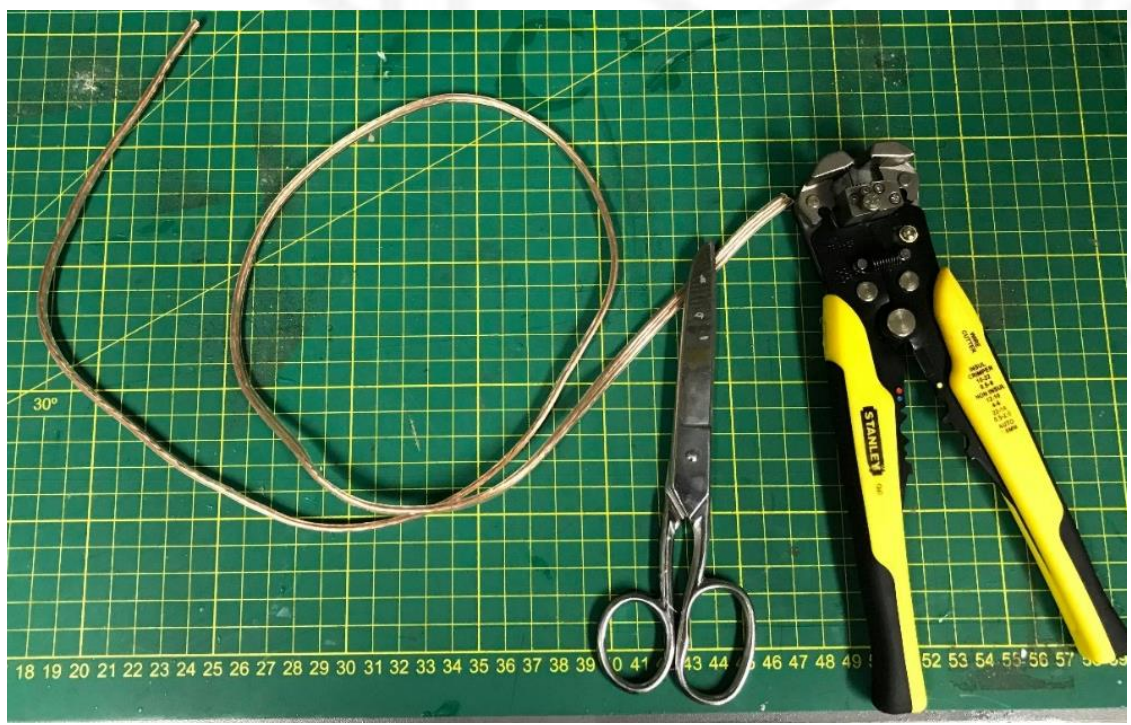

Elaboración propia 
Acoplamiento de cable mellizo a enchufe: Una vez pelados ambos lados del trozo de 1 metro de cable mellizo se realiza el acoplamiento al enchufe utilizando un destornillador y 2 alicates como se muestra en la siguiente figura.

Figura 5.21

Acoplamiento de cable mellizo al enchufe

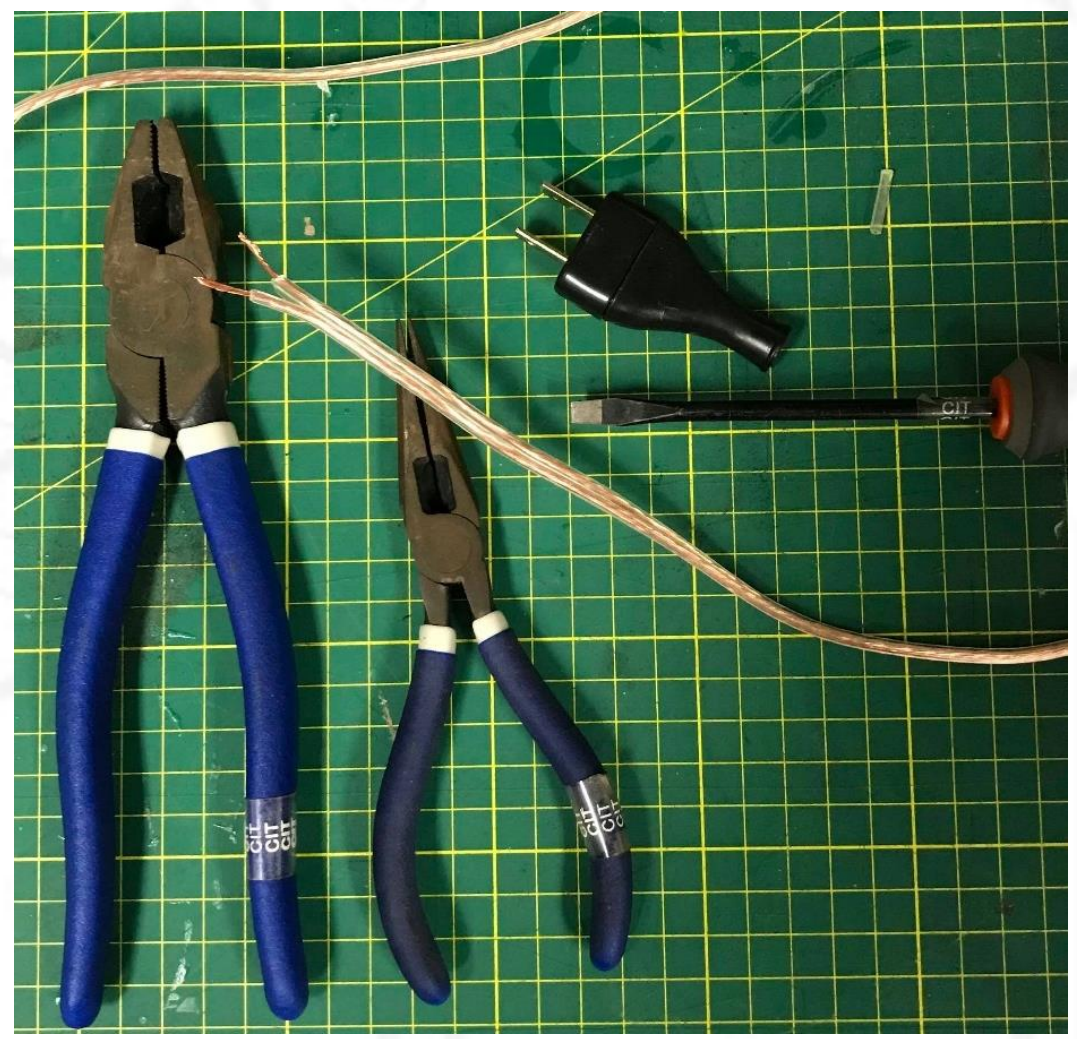

Elaboración propia 
Figura 5.22

Cable mellizo acoplado al enchufe

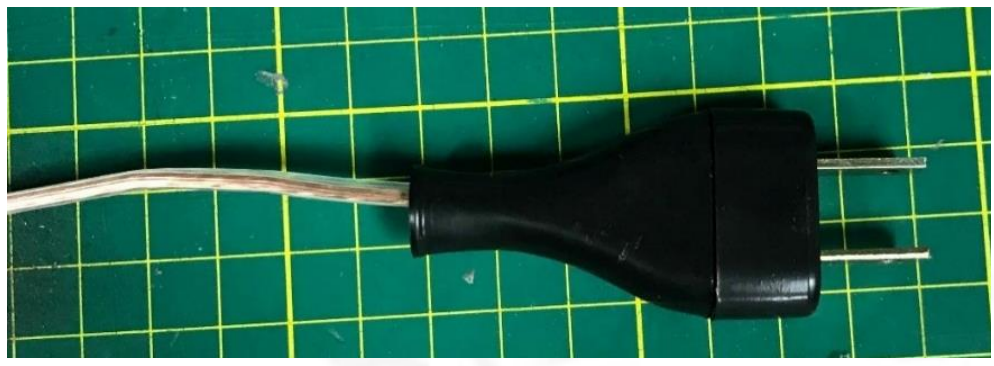

Elaboración propia

Acoplamiento de cable mellizo a soquete: El operario utiliza un destornillador para acoplar el extremo restante del trozo de 1metro de cable mellizo al soquete como lo muestra la siguiente figura.

Figura 5.23

Acoplamiento de cable mellizo al soquete

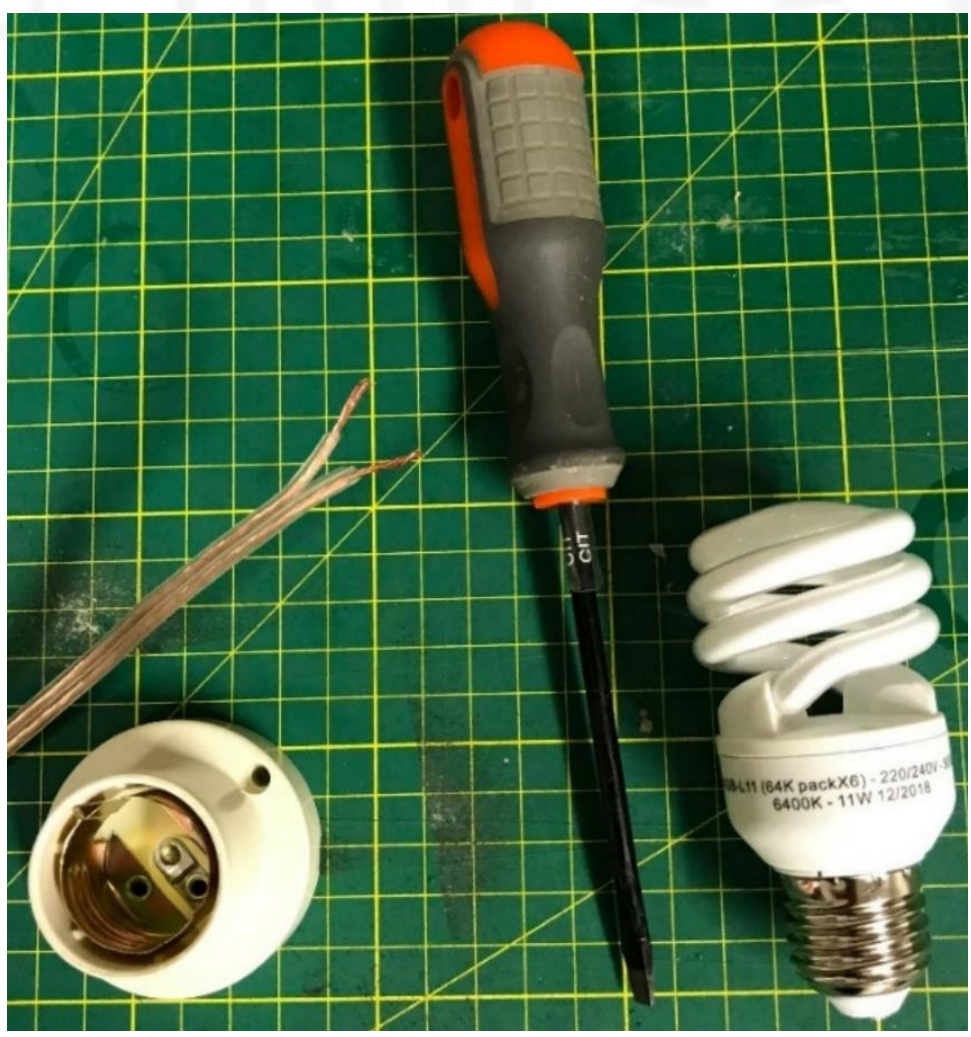

Elaboración propia 
Luego de finalizar el corte se retira el material, se separan las piezas de la merma y se coloca la siguiente plancha.

Figura 5.24

Piezas cortadas

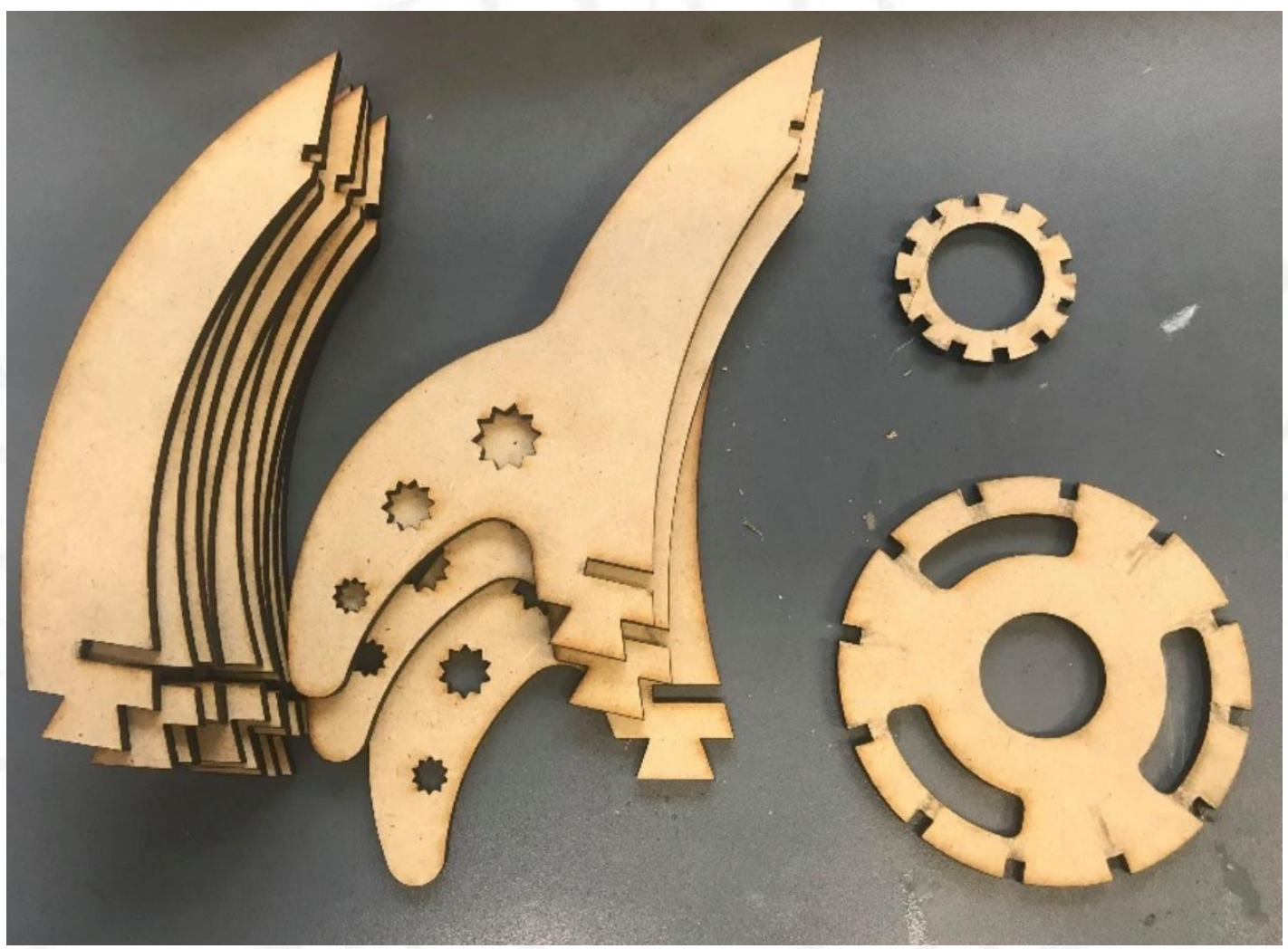

Elaboración propia

Ensamblado e Inspección de Producto Terminado: Posteriormente el soquete es atornillado a la pieza correcta de MDF. Luego se ensamblan las partes de MDF como muestran las siguientes figuras. Esto permite su reparación modular utilizando solo fricción para unirla, sin embargo, cuando es necesario se pueden remover las piezas para cambiar el foco. Finalmente, se realiza una inspección de calidad final al producto terminado para pasar al embalado. 
Figura 5.25

Prototipo ensamblado visto desde arriba

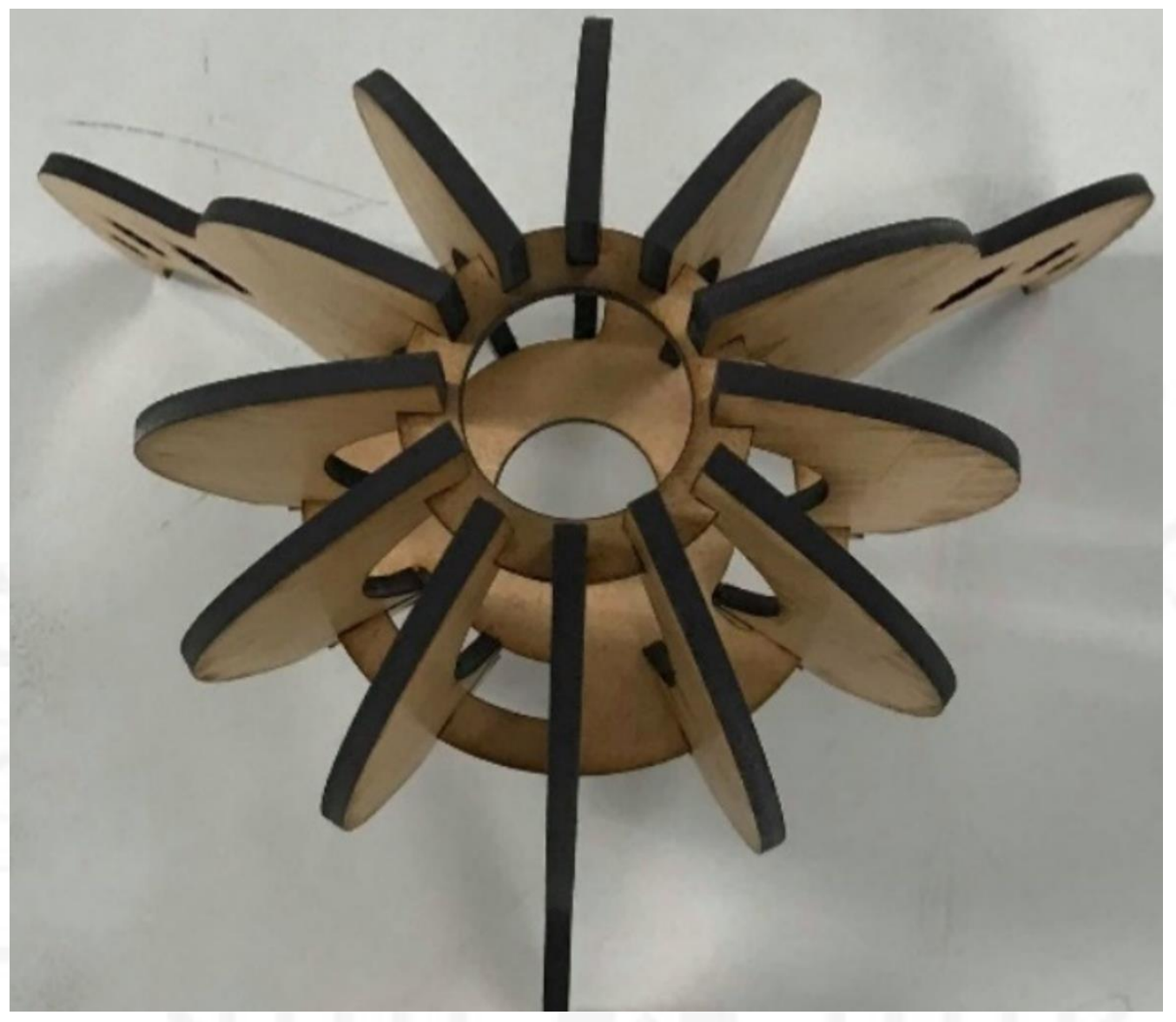

Elaboración propia 
Figura 5.26

Prototipo ensamblado vista isométrica

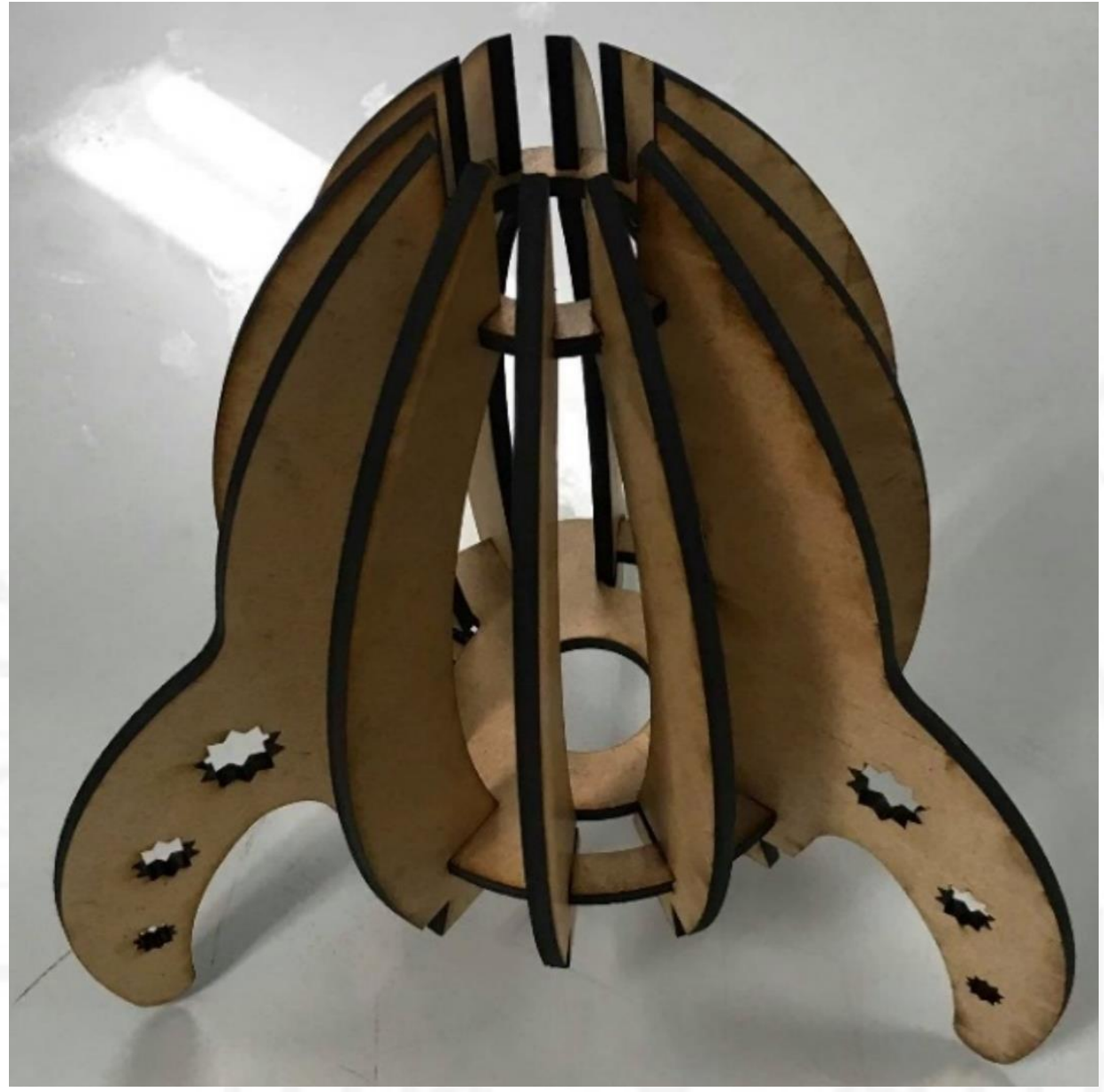

Elaboración propia

Etiquetado: Al producto final se le coloca una etiqueta simple que menciona el voltaje con el que funciona la lámpara, su índice de ahorro según el foco que se utiliza y un código de barra para identificar el producto.

Embalado: El producto terminado es cuidadosamente posicionado dentro de su empaque que será una caja de cartón de $20 \mathrm{~cm}$ x $20 \mathrm{~cm}$ x $20 \mathrm{~cm}$ para su posterior almacenaje en el almacén de productos terminados y su posterior envío a las tiendas de venta al por menor, las cajas llegan etiquetadas para facilitar la logística de los productos terminados. 


\subsubsection{Diagrama de operaciones del proceso: DOP}

La siguiente figura detalla el diagrama de operaciones del proceso que muestra los diferentes materiales que deben ingresar al proceso para producir 1 lámpara y que operaciones son necesarias para transformar los insumos en el producto terminado.

Figura 5.27

Diagrama de operaciones del proceso

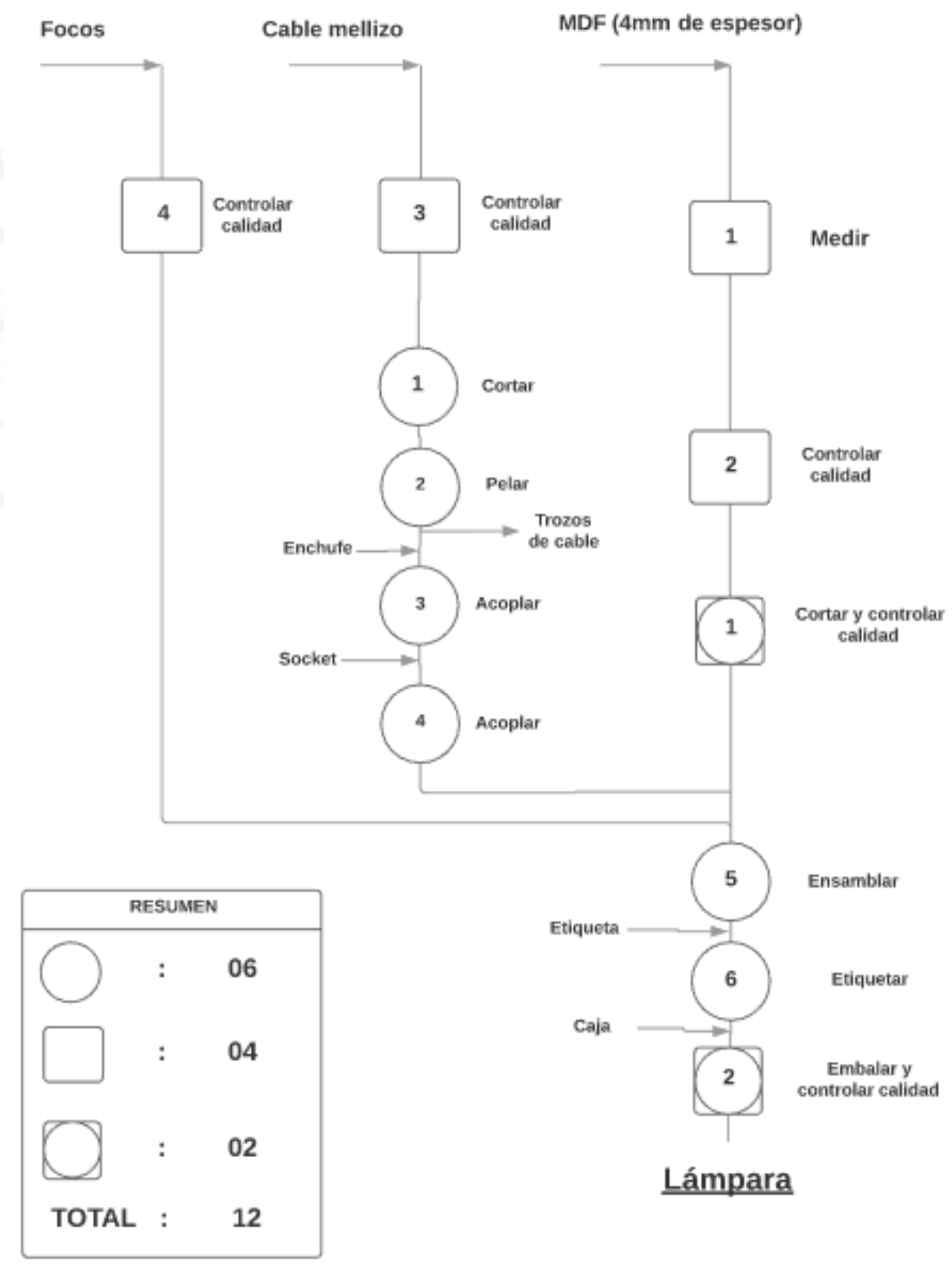

Elaboración propia 


\subsubsection{Balance de materia}

Los materiales involucrados en la producción de nuestro producto final se detallan en la tabla siguiente según las cantidades necesarias para producir una lámpara y sus mermas aproximadas respectivamente.

Tabla 5.5

Balance de materiales

\begin{tabular}{|l|l|l|}
\hline Materiales & $\begin{array}{l}\text { Cantidad } \\
\text { (1 Lámpara) }\end{array}$ & Merma \\
\hline MDF (4mm de espesor) & $0,1218 \mathrm{~m}^{2}$ & $5 \%$ \\
\hline $\begin{array}{l}\text { Foco Marca Daiku 20W } \\
\text { (Luz Fría) }\end{array}$ & 1 & - \\
\hline Cola & $\begin{array}{l}15 \mathrm{ml} \\
\text { (opcional) }\end{array}$ & - \\
\hline Cable mellizo con enchufe & 1 & - \\
\hline $\begin{array}{l}\text { Soquete (Incluye tornillos } \\
\text { para empernar) }\end{array}$ & 1 & - \\
\hline Etiqueta & 1 & - \\
\hline $\begin{array}{l}\text { Caja de cartón }(0,2 \mathrm{~m} \times 0,2 \mathrm{~m} \times \\
0,2 \mathrm{~m})\end{array}$ & 1 & - \\
\hline
\end{tabular}

Elaboración propia

Para expresar a mayor detalle el balance de materia se realizó el siguiente diagrama de balance de materia que detalla el flujo de materiales según sus cantidades para producir 7836 lámparas embaladas en cajas de cartón. 
Figura 5.28

Diagrama de balance de materia parte 1

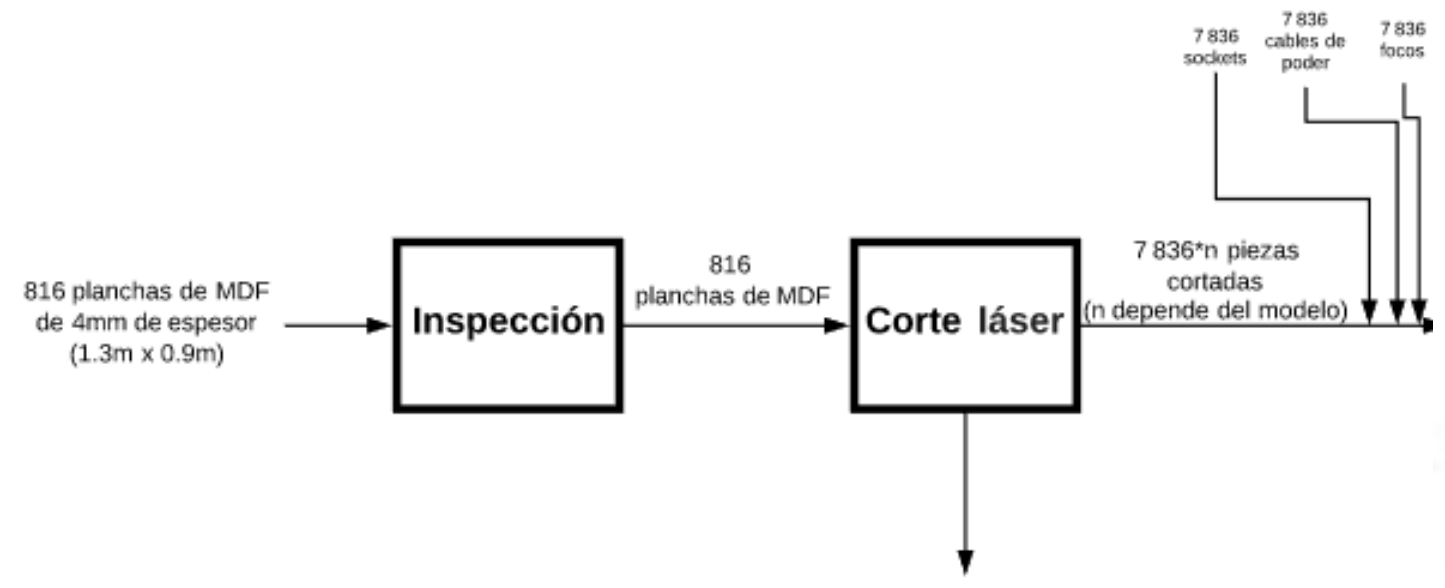

5\% de MDF en trozos

Elaboración propia

Figura 5.29

Diagrama de balance de materia parte 2

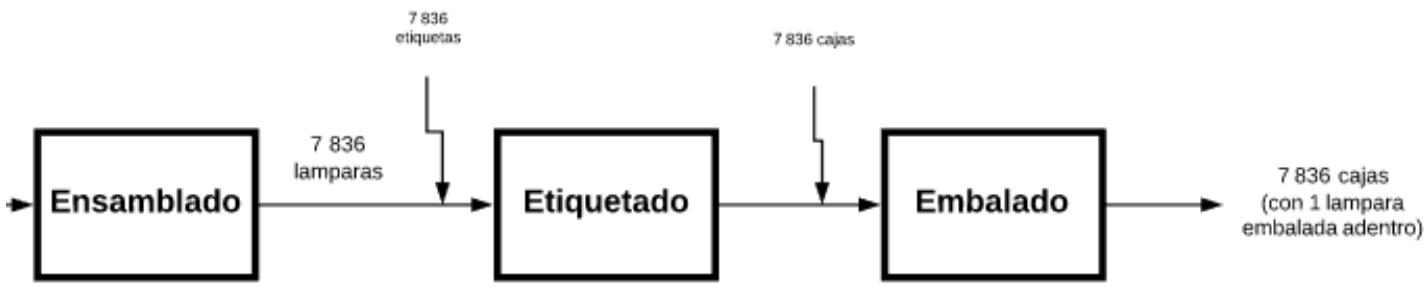

Elaboración propia

\subsection{Características de las instalaciones y equipos}

En este subcapítulo se detallarán las máquinas y equipos necesarios para el emprendimiento contrastando diferentes modelos seguidos por las especificaciones técnicas de estos. 


\subsubsection{Selección de maquinaria y equipos}

A continuación, se listan las máquinas y equipos necesarios:

- Compresor: Lo único indispensable es que pueda alcanzar 1 bar de presión.

- Extractor: Debe ser un extractor especial para cortadora láser cuya compañía opere dentro del Perú para facilitar las reparaciones y repuestos si se necesitaran.

- Computadora desktop: Debe tener características que le permitan manejar de manera apropiada los software a utilizar para el diseño 2D y 3D y el maquinado con corte láser.

- Carretilla hidráulica: No hay requerimientos específicos, pero se buscará que se adecue a los objetos a transportar (Materia prima, piezas cortadas, focos, soquetes, cables y cajas), se buscará la de menor capacidad (2000 kg) en términos de peso para reducir costos por el bajo peso de los objetos a transportar.

- Cortadora láser: Es la maquina principal en nuestro proceso de producción, deberá tener las siguientes características (críticas para la fabricación de nuestros productos de manera industrial):

- Tamaño de cama de corte: Mínimo 1,00 m x 0,60 m

- Potencia: Mínimo $30 \mathrm{~W}$

- Funciones: Grabado y corte láser

- Tipo de láser: $\mathrm{CO}_{2}$

- Velocidad: Mínimo

Para elegir la cortadora láser se analizaron las 3 opciones que se muestran a continuación. 
Tabla 5.6

Características de la cortadora láser modelo RDJ-1390 - Robotek

\begin{tabular}{|l|l|}
\hline Rubros & Características \\
\hline Marca & Robotek \\
\hline Modelo & RDJ-1390 \\
\hline Tamaño de cama de corte & $1300 \mathrm{~mm} * 900 \mathrm{~mm}$ \\
\hline Potencia (Watts/h) & 40 \\
\hline Funciones (Grabado y/o corte láser) & Grabado y corte láser \\
\hline Tipo de láser $\left(\mathrm{CO}_{2}\right.$ o fibra óptica) & $\mathrm{CO}_{2}$ \\
\hline Velocidad de corte & $666 \mathrm{~mm} / \mathrm{seg}$ \\
\hline
\end{tabular}

Fuente: Alibaba, (2019)

Tabla 5.7

Características de la cortadora láser modelo LS-5070 - Láser Edge

\begin{tabular}{|l|l|}
\hline Rubros & Características \\
\hline Marca & LÁSER EDGE \\
\hline Modelo & LS-5070 \\
\hline Tamaño de cama de corte & $500 \mathrm{~mm} * 700 \mathrm{~mm}$ \\
\hline Potencia (Watts/h) & 60 \\
\hline Funciones (Grabado y/o corte láser) & Grabado y corte \\
láser
\end{tabular}

Fuente: Alibaba, (2019)

Tabla 5.8

Características de la cortadora láser modelo Fusion 40 - Epilog

\begin{tabular}{|l|l|}
\hline Rubros & Características \\
\hline Marca & Epilog \\
\hline Modelo & Fusion 40 \\
\hline Tamaño de cama de corte & $1000 \mathrm{~mm} * 700 \mathrm{~mm}$ \\
\hline Potencia (Watts/h) & 30 \\
\hline Funciones (Grabado y/o corte láser) & $\begin{array}{l}\text { Grabado y corte } \\
\text { láser }\end{array}$ \\
\hline Tipo de láser $\left(\mathrm{CO}_{2}\right.$ o fibra óptica) & $\mathrm{CO}_{2}$ \\
\hline Velocidad de corte & $1000 \mathrm{~mm} / \mathrm{seg}$ \\
\hline
\end{tabular}

Fuente: Alibaba, (2019) 
Luego generamos una tabla para contrastar visualmente las diferencias entre las opciones.

Tabla 5.9

Comparación de modelos de cortadora láser

\begin{tabular}{|c|c|c|c|}
\hline Características/ Modelo & Epilog Fusion 40 & LÁSER EDGE-LS5070 & Robotek RDJ-1390 \\
\hline Tamaño de cama & $100 \mathrm{~cm} \mathrm{X} 70 \mathrm{~cm}$ & $50 \mathrm{~cm} \mathrm{X} 70 \mathrm{~cm}$ & $130 \mathrm{~cm} \mathrm{X} 90 \mathrm{~cm}$ \\
\hline Potencia del láser & 30 watts/h & 60 watts/h & 40 watts/h \\
\hline Precio & 27995 & 11500 & 4000 \\
\hline Velocidad máxima del láser & $1000 \mathrm{~mm} / \mathrm{seg}$ & $600 \mathrm{~mm} / \mathrm{seg}$ & $666 \mathrm{~mm} / \mathrm{seg}$ \\
\hline Funcionamiento con raster y vector & SI & SI & SI \\
\hline Funcionamiento a $220 \mathrm{~V}$ y $60 \mathrm{~Hz}$ & $220 \mathrm{~V} \& 60 \mathrm{~Hz}$ & $220 \mathrm{~V} \& 60 \mathrm{~Hz}$ & $220 \mathrm{~V} \& 60 \mathrm{~Hz}$ \\
\hline Consumo & $1,3 \mathrm{KW} / \mathrm{h}$ & $800 \mathrm{~W} / \mathrm{h}$ & $800 \mathrm{~W} / \mathrm{h}$ \\
\hline
\end{tabular}

Elaboración propia

Se selecciono la cortadora láser de marca Robotek modelo RDJ-1390 por cumplir con todos los requerimientos necesarios y tener el más bajo costo de las 3 .

Para elegir las compresoras se buscó el modelo de menor costo económico que este homologado y permita alcanzar como mínimo 1 bar. Para esto se eligieron 3 compresoras vendidas en la página web de SODIMAC y se procedió a compararlas al igual que con las cortadoras láser como se ve a continuación

Tabla 5.10

Características del compresor Pitbull modelo ZBM-25A

\begin{tabular}{|l|l|}
\hline Rubros & Características \\
\hline Marca & Pitbull \\
\hline Modelo & ZBM-25A \\
\hline Potencia (HP) & 2 \\
\hline Capacidad & 24 Litros \\
\hline Presión & 8 bar \\
\hline Precio (soles) & 219,90 \\
\hline
\end{tabular}

Fuente: SODIMAC, (2019) 
Tabla 5.11

Características del compresor Bauker modelo Euro 225

\begin{tabular}{|l|l|}
\hline Rubros & Características \\
\hline Marca & Bauker \\
\hline Modelo & Euro 225 \\
\hline Potencia (HP) & 2 \\
\hline Capacidad & 25 Litros \\
\hline Presión & 8 bar \\
\hline Precio (soles) & 329,90 \\
\hline
\end{tabular}

Fuente: SODIMAC, (2019)

Tabla 5.12

Características del compresor Daewoo modelo DAC 24D

\begin{tabular}{|l|l|}
\hline Rubros & Características \\
\hline Marca & Daewoo \\
\hline Modelo & DAC 24D \\
\hline Potencia (HP) & 2 \\
\hline Capacidad & 24 Litros \\
\hline Presión & 8 bar \\
\hline Precio (soles) & 349,90 \\
\hline
\end{tabular}

Fuente: SODIMAC, (2019)

No hizo falta comparar las compresoras, pues al ser el único requerimiento poder abastecer a la cortadora láser con 1 bar se eligió la opción más barata (Marca Pitbull modelo ZBM-25A) pues las 3 compresoras contaban con la misma capacidad de presión.

Para elegir el extractor se buscó una compañía que opere dentro del Perú y se dedique a proveer artículos relacionados al corte láser para facilitar el mantenimiento del extractor. Solo se encontró la empresa MAQUICORTE y se seleccionó el siguiente extractor. 
Tabla 5.13

Características del extractor marca MAQUICORTE

\begin{tabular}{|c|c|c|}
\hline Rubros & Características & $\prod_{1}^{M}$ \\
\hline Marca & MAQUICORTE & \\
\hline Función & Extractor de humos de corte láser & \\
\hline Voltaje (V) & 220 & \\
\hline Potencia (W) & 550 & \\
\hline Precio (Dólares) & 340 & \\
\hline
\end{tabular}

Fuente: Mercado Libre, (2019)

Para elegir las computadoras desktops se comparó 3 diferentes modelos de desktop de 3 diferentes marcas como se muestra a continuación.

Tabla 5.14

Características de una desktop Dell modelo Optiplex 7010

\begin{tabular}{|l|l|l|}
\hline Rubros & Características \\
\hline Marca & Dell \\
\hline Modelo & Optiplex 7010 \\
\hline Intel Core & i7 \\
\hline RAM & $16 \mathrm{~GB}$ \\
\hline Memoria & 2TB Hard Drive \\
\hline Tarjeta de Video & Intel integrated graphics \\
\hline Tipo de core & Quad-core \\
\hline Sistema operativo & Windows 10 \\
\hline Precio (dólares) & 349 \\
\hline
\end{tabular}

Fuente: Amazon, (2019) 
Tabla 5.15

Características de una desktop HP modelo Elite 8200

\begin{tabular}{|l|l|}
\hline Rubros & Características \\
\hline Marca & HP \\
\hline Modelo & Elite 8200 \\
\hline Intel Core & i7 \\
\hline RAM & $16 \mathrm{~GB}$ \\
\hline Memoria & 2TB Hard Drive \\
\hline Tarjeta de Video & Intel HD graphics \\
\hline Tipo de core & Quad-core \\
\hline Sistema operativo & Windows 10 \\
\hline Precio (dólares) & 298,99 \\
\hline
\end{tabular}

Fuente: Amazon, (2019)

Tabla 5.16

Características de una desktop Lenovo modelo ThinkCenter M92p

\begin{tabular}{|l|l|l|}
\hline Rubros & Características & \multirow{2}{*}{ Wi Fi } \\
\hline Marca & Lenovo & \\
\hline Modelo & ThinkCenter & \\
\hline Intel Core & i7 & \\
\hline RAM & 16 GB & \\
\hline Memoria & $240 \mathrm{~GB}$ SSD \\
\hline Tarjeta de Video & Intel HD graphics & \\
\hline Tipo de core & Quad-core & \\
\hline Sistema operativo & Windows 10 & \\
\hline Precio (dólares) & 300 & \\
\hline
\end{tabular}

Fuente: Amazon, (2019)

Se eligió el modelo Optiplex 7010 por ser de una marca confiable (tienen soporte técnico en todo el mundo), su resistencia y durabilidad (reconocidos a nivel global) y porque cumple con todos los requerimientos necesarios para funcionar de manera apropiada durante los primeros 5 años con los software necesarios para trabajar con la 
cortadora láser tiene un costo sutilmente mayor, pero no escatimaremos en gastos relacionados a la selección de computadoras (mientras sea viable).

Tabla 5.17

Características de una carretilla hidráulica de tipo genérico

\begin{tabular}{|l|l|l|}
\hline Rubros & Características & \\
\hline Marca & Genérico & \\
\hline Tipo de carretilla & Pato & \\
\hline Capacidad & $2000 \mathrm{~kg}$ & \\
\hline Precio (soles) & 1000 & \\
\hline
\end{tabular}

Fuente: Mercado Libre, (2019)

Tabla 5.18

Características de una carretilla hidráulica marca Rhyno

\begin{tabular}{|l|l|l|}
\hline Rubros & Características & \\
\hline Marca & Rhyno & \\
\hline $\begin{array}{l}\text { Tipo de } \\
\text { carretilla }\end{array}$ & Pato & \\
\hline Capacidad & $2000 \mathrm{~kg}$ & \\
\hline Precio (soles) & 1350 & \\
\hline
\end{tabular}

Fuente: Mercado Libre, (2019)

\subsubsection{Especificaciones de la maquinaria}

Las especificaciones de la maquinaria y equipos seleccionados se detallan en las siguientes figuras. 
Figura 5.30

Especificaciones técnicas de una cortadora láser Robotek RDJ-1390

\section{Product Description}

\begin{tabular}{|l|l|}
\hline Item / Model & RDJ-1390 \\
\hline Cutting area & $1300 \times 900 \mathrm{~mm}$ \\
\hline Laser power & $80 \mathrm{~W} / 100 \mathrm{w} / 150 \mathrm{w} / 180 \mathrm{w}$ \\
\hline Laser type & $\mathrm{CO} 2$ sealed laser tube,water-cooled,10.6um \\
\hline Engraving speed & $0-60000 \mathrm{~mm} / \mathrm{min}$ \\
\hline Cutting speed & $0-40000 \mathrm{~mm} / \mathrm{min}$ \\
\hline Laser Output & $1-100 \%$ software setting \\
\hline Resetting positioning & $\leq \pm 0.01 \mathrm{~mm}$ \\
\hline accuracy & $220 \mathrm{~V} / 50 \mathrm{HZ}$ (Optional 110V/60HZ) \\
\hline Power supply & $0-45^{\circ} \mathrm{C}$ \\
\hline Operating temperature & $5-95 \%$ \\
\hline Operating humidity & English $1.0 \times 1.0 \mathrm{~mm}$ \\
\hline Min. shaping character & $\mathrm{BMP}, \mathrm{PLT}, \mathrm{DST}, \mathrm{DXF}, \mathrm{Al}$ \\
\hline Graphic format supported & TAJIMA, CorelDraw, Photoshop, AutoCAD \\
\hline Software supported & stepper motor \\
\hline Driving system & Water-cooling and protection system \\
\hline Cooling mode & $1690 \times 1200 \times 1470 \mathrm{~mm}$ \\
\hline Equipment Dimensions & $1550 \mathrm{~kg}$ \\
\hline Net Weight: & $2090 \times 1500 \times 1570 \mathrm{~mm}$ \\
\hline Shipping Dimensions & Up-down clump, Rotary System, Honeycomb table \\
\hline Optional Spare Parts &
\end{tabular}

Fuente: Alibaba, (2019) 
Figura 5.31

Especificaciones técnicas de un compresor de aire Pitbull ZBM-25A

\begin{tabular}{|c|c|}
\hline Atributo & Detalle \\
\hline Características & Motor de aluminio. Trabajo continuo de 4 a 6 horas \\
\hline Marca & Pitbull \\
\hline Modelo & ZBM 25A \\
\hline Medidas & Ancho: $50 \mathrm{~cm}$. Profundidad: $30 \mathrm{~cm}$. Alto: $62 \mathrm{~cm}$ \\
\hline Potencia & $2 \mathrm{HP}$ \\
\hline Capacidad & $24 \mathrm{~L}$ \\
\hline Caudal de Operación & $7 \mathrm{cfm}$ \\
\hline Voltaje & $220 \mathrm{~V} / 60 \mathrm{~Hz}$ \\
\hline Presión & 8 bar \\
\hline Garantía & 1 año \\
\hline Incluye & Ruedas \\
\hline Uso & Ideal para alimentar múltiples herramientas de aire de alta demanda \\
\hline Procedencia & Importado \\
\hline Recomendaciones & Drenar el tanque diariamente o después de cada uso \\
\hline Tipo & Compresoras \\
\hline Categoria & Comprensoras \\
\hline Promoción vigente hasta & 05/03/2019 \\
\hline Familia & Herramientas y maquinarias \\
\hline
\end{tabular}

Fuente: Alibaba, (2019) 
Figura 5.32

Especificaciones técnicas de una desktop Dell Optiplex-7010

\begin{tabular}{|c|c|}
\hline $\begin{array}{l}\text { Despacho a domicilio y/o } \\
\text { agencia de transporte }\end{array}$ & Sí \\
\hline Marca & Dell \\
\hline Modelo & OptiPlex 7010 \\
\hline Procesador & Intel( Core ${ }^{\mathrm{TM}}$ i7-3770 (8M Cache, hasta $3.90 \mathrm{GHz}$ con Turbo Boost) \\
\hline Placa & DELL \\
\hline Socket & Socket 775 \\
\hline Chipset & Intel Q65 \\
\hline Memoria RAM & 4 GB DDR3 ampliable a 16GB \\
\hline Disco Duro & 500GB 7200RPM \\
\hline Case & Factor de forma pequeño \\
\hline Fuente de poder & $240 \mathrm{~W}$ \\
\hline Monitor & Monitor LED Dell E1914H, 18.5", 1366x768, VGA \\
\hline Unidad óptica & $\mathrm{DVD}+\mathrm{RW}$ \\
\hline Tarjeta de video & Integrada \\
\hline Conectividad & Conexión de red Intel (10/100/1000) integrada \\
\hline Multimedia & Entrada para auriculares estéreo/micrófono \\
\hline Puertos y Ranuras & $\begin{array}{l}\text { VGA } \\
\text { USB } 3.0 \\
\text { Audio in/out }\end{array}$ \\
\hline Teclado \& mouse & DELL incluidos. \\
\hline Características adicionales & Sistema Operativo Windows 7 Professional \\
\hline
\end{tabular}

Fuente: Alibaba, (2019)

\subsection{Capacidad instalada}

En este subcapítulo se realizará el cálculo de la capacidad instalada en base al cálculo previo del número de máquinas y operarios necesarios para cumplir con lo que demanda la producción propuesta del proyecto. 


\subsubsection{Cálculo detallado del número de máquinas y operarios}

Una vez seleccionada la cortadora láser sabiendo que será nuestro cuello de botella por la facilidad de ensamblaje de las lámparas podemos pasar a calcular cuantas se van a necesitar en la planta para satisfacer la demanda percibida de 7836 (punto de equilibrio). Para esto se consideró que cada lámpara demora 10 minutos y 30 segundos en cortar y ensamblar y se consideró un año con 303 días laborables, se tendrá inicialmente solo 1 turno laborable al día de 8 horas y $87,95 \%$ de eficiencia para la cortadora láser considerando que inicialmente no se tendrá mucha experiencia con ella, podría ir reduciéndose a través del tiempo, pero para poder calcular con mayor certeza se mantendrá fijo.

Cálculo de número de máquinas: 7836 lámparas $\times(10,5 \min \div 60$ horas $\times$ lámpara $\div(303$ dias $\times 8$ horas $\div$ dia $\times 0,8795)=0,6432=1$ cortadora láser

Es el número adecuado pues sin considerar el bajo nivel de eficiencia supuesto solo estamos utilizando 1 turno al día permitiendo incrementar la producción hasta en $100 \%$ sin comprar una segunda cortadora láser. Sin embargo, para el cálculo de operarios requeridos solo se necesitarán 2 ya que solo es necesario 1 operario para manejar la cortadora láser y 1 diseñador para generar los diseños y preparar los archivos para utilizar en la cortadora láser mientras se optimiza la producción para reducir mermas y tiempos.

Para corroborar que solo es necesario 1 operario verificaremos si todas las actividades sin considerar el maquinado pueden ser realizadas mientras se realiza el corte laser de las piezas. Para esto se calculó el factor de utilización en base a la relación entre el número de horas productivas desarrolladas (NHP) y el número de horas reales (NHR) que será 8 horas. A continuación, se muestran la tabla del cálculo de NHP y la tabla de tiempos estándar por actividad. 
Tabla 5.19

Lista de tiempos no productivos del operario de corte láser

\begin{tabular}{|l|l|}
\hline Actividades & NHP \\
\hline Uso de servicios higiénicos & $9 \%$ del total \\
\hline Reuniones con su supervisor & $6 \%$ del total \\
\hline Mantenimiento al lente de la laser & 30 minutos \\
\hline Cambio de vestuario y utilización de EPPs & 8 minutos \\
\hline Cambio de plancha a cortar & 40 minutos \\
\hline Inicio de maquina & 10 minutos \\
\hline Total & 160 minutos \\
\hline
\end{tabular}

Elaboración propia

Tabla 5.20

Cálculo de Capacidad diaria por operario/técnico de corte láser

\begin{tabular}{|l|l|l|l|l|}
\hline Actividad de & $\begin{array}{l}\text { Tiempo real } \\
\text { (minutos) }\end{array}$ & $\begin{array}{l}\text { Factor dtilización } \\
\text { Eficiencia }\end{array}$ & Tiempo estándar \\
\hline $\begin{array}{l}\text { Medir y cortar cable } \\
\text { mellizo }\end{array}$ & 0,3128 & 0,67 & 0,95 & 0,491 \\
\hline $\begin{array}{l}\text { Pelado de cable mellizo por } \\
\text { ambos lados }\end{array}$ & 0,65 & 0,67 & 0,95 & 1,021 \\
\hline $\begin{array}{l}\text { Acoplado del cable de } \\
\text { poder al enchufe }\end{array}$ & 1,44 & 0,67 & 0,95 & 2,262 \\
\hline $\begin{array}{l}\text { Acoplado del cable de } \\
\text { poder al soquete }\end{array}$ & 1,314 & 0,67 & 0,95 & 2,064 \\
\hline Entornillado del Soquete & 0,613 & 0,67 & 0,95 & 0,963 \\
\hline Ensamblado de lámpara & 1,4664 & 0,67 & 0,95 & 2,304 \\
\hline Embalado & 0,794 & 0,67 & 0,95 & 1,247 \\
\hline Total & & - & - & 10,354 \\
\hline
\end{tabular}

Elaboración propia

Observando la tabla podemos apreciar que las actividades a realizar mientras se corta 1 lámpara (10 minutos y 30 segundos) demoran considerablemente menos tiempo que el corte convirtiendo a la cortadora láser en nuestro cuello de botella.

\subsubsection{Cálculo de la capacidad instalada}

La capacidad instalada solo se calculará con la capacidad de la cortadora láser por ser la única máquina y seria la producción total de trabajar 8 horas al día 303 días laborables a 
87,95\% de factor de utilización y demorándose 10 minutos y 30 segundos por lampará realizando las otras actividades en paralelo mientras se realiza el corte láser.

Cálculo de la capacidad instalada: $\left(\frac{8 \text { horas }}{\text { dia }} \times 303\right.$ dias $\left.\times 0,8795\right) \div\left(\frac{10,5 \text { min }}{60 \text { horas }} *\right.$ lámpara ) = 12182 lámparas/año

\subsection{Cálculo de la calidad y/o inocuidad del producto}

Para cerciorarnos de la satisfacción de nuestros clientes buscaremos realizar prácticas que le den al producto todas las características de buena calidad. Esto involucra generar un producto que sea seguro para el usuario mientras que satisface la necesidad de este de manera efectiva e innovadora. Para realizar las mejores prácticas se seguirá lo estipulado en la norma ISO 9001:2015 optimizando nuestra gestión de la calidad.

\subsubsection{Calidad de la materia prima, de los insumos, del proceso y del producto}

Proceso de producción: Para garantizar la calidad del proceso de producción se realizarán mantenimientos preventivos esporádicamente según el grado de uso y desgaste de cada máquina o equipo permitiendo que el acabado del corte sea de la calidad esperada por los clientes.

En relación con el almacenado de la materia prima las planchas de MDF de 4mm serán apiladas de manera horizontal una sobre la otra para ahorrar espacio y evitar que se doblen ya que podrían causar que no se pueda ensamblar el producto. También se garantizará una baja humedad en el almacén para evitar el deterioro de las planchas a través de moho y temperatura ambiente (15-30 grados Celsius).

La materia prima (MDF 4mm) tendrá que cumplir con los siguientes estándares:

- Densidad $\left(450 \mathrm{~kg} / \mathrm{m}^{3}\right)$

- Contenido de humedad (4\% - $10 \%)$

- Estabilidad dimensional

- Contenido de formaldehido, etc. 
Para garantizar esto las compras serán realizadas a Sodimac ya que sus proveedores han sido homologados y sus planchas de MDF cumplen con dichos estándares aparte de cortar las planchas de manera gratuita.

Producto Terminado (Lámpara): Para garantizar la calidad de nuestras lámparas se tiene que ir a sus insumos principales (focos, soquetes y cables de poder) y medirlos en base a su funcionamiento. Una vez cortado y acoplado el cable de poder al soquete se probará si su funcionamiento es apropiado según lo esperado de los productos. La prueba consistirá en prender y apagar la lámpara para verificar si su funcionamiento es adecuado. Por otro lado, se manejarán las lámparas con sumo cuidado a la hora del embalaje permitiendo mantener su calidad hasta el usuario final.

\subsection{Estudio de impacto ambiental}

El impacto ambiental que generará nuestro taller/planta será mínimo debido al bajo número de máquinas y operaciones necesarias para la fabricación de nuestros productos. Por otro lado, la energía consumida por la cortadora láser es mínima, la merma se podrá reducir reutilizándola en la medida de lo posible y el polvo liberado al ambiente se podrá controlar con extractores industriales. Sin embargo, es necesario seguir las pautas establecidas por la norma ISO 14001 pues describe de manera general como gestionar de manera apropiada nuestro impacto ambiental.

Para resumir y analizar a mayor detalle el impacto ambiental que generara nuestro emprendimiento se utilizara la matriz de Leopold. Esto nos permitirá seguir la normativa establecida en la Ley No 27446 por el Sistema Nacional de Evaluación de Impacto Ambiental (SEIA), pues es el agente que debe encargarse de identificar, supervisar, controlar y corregir los impactos que pudieran ser negativos para el ambiente de parte del proyecto. A continuación, se muestra la matriz de Leopold. 
Tabla 5.21

Matriz de Leopold

\begin{tabular}{|c|c|c|c|c|c|c|c|c|c|c|}
\hline \multirow{3}{*}{ Etapa } & \multirow{3}{*}{ Actividades del Proyecto } & \multicolumn{9}{|c|}{ Factores Ambientales } \\
\hline & & \multicolumn{3}{|c|}{ Fisicoquímicos } & \multicolumn{4}{|c|}{ Socioeconómicos } & \multicolumn{2}{|c|}{ Biológicos } \\
\hline & & Tierra & Agua & Aire & Estética ambiental & Atmósfera & Salud y seguridad & Nivel de empleo & Flora & Fauna \\
\hline \multirow{6}{*}{ Operaciones } & Recepción & & & & & & & & & \\
\hline & Diseño & & & & & & & & & \\
\hline & Corte láser & & & & & & & & & \\
\hline & Almacenado & & & & & & & & & \\
\hline & Ensamblado & & & & & & & & & \\
\hline & Manejo de residuos & & & & & & & & & \\
\hline
\end{tabular}

\begin{tabular}{|l|l|}
\hline & Impacto positivo alto \\
\hline & Impacto positivo moderado \\
\hline & Impacto positivo ligero \\
\hline & Componente ambiental no alterado \\
\hline & Impacto negativo ligero \\
\hline & Impacto negativo moderado \\
\hline & Impacto negativo alto \\
\hline
\end{tabular}

Elaboración propia 


\subsection{Seguridad y salud ocupacional}

Dentro del taller habrá algunas operaciones de alto riesgo involucrando la cortadora láser y las modificaciones sutiles a los cables. Esto se gestionará minimizando el riesgo manteniendo limpio y ordenado el área de trabajo y utilizando los EPPs necesarios. Asimismo, se tomarán todas las medidas necesarias para cumplir con la Ley 29783 de seguridad y salud en el trabajo para garantizar la seguridad integral de nuestros colaboradores. Por otro lado, también se seguirán las pautas establecidas por la OHSAS 18001 para realizar las mejores prácticas de seguridad y salud en el trabajo como capacitar esporádicamente a los trabajadores concientizándolos de los riesgos e informándolos de cómo prevenirlos garantizando un entorno laborable más seguro.

Se identificaron una serie de peligros en la planta junto con su riesgo, vulnerabilidad, consecuencias y medidas a tomar para prevenir el peligro reduciendo su riesgo como lo muestra la matriz de análisis preliminar de riesgos (APR). 
Tabla 5.22

Matriz de análisis preliminar de riesgos (APR)

\begin{tabular}{|c|c|c|c|c|}
\hline Peligro & Riesgo & Vulnerabilidad & Consecuencia & Medidas \\
\hline $\begin{array}{l}\text { Viruta de } \\
\text { MDF }\end{array}$ & $\begin{array}{l}\text { Probabilidad de } \\
\text { inhalación }\end{array}$ & $\begin{array}{l}\text { La viruta de MDF } \\
\text { que no es absorbida } \\
\text { por el extractor es } \\
\text { emitida al área de } \\
\text { trabajo, el operario } \\
\text { cuenta con } \\
\text { mascarilla y gafas, } \\
\text { pero no los utiliza. }\end{array}$ & $\begin{array}{l}\text { Irritación de las } \\
\text { vías respiratorias, } \\
\text { irritación de los } \\
\text { ojos, cáncer de } \\
\text { pulmón }\end{array}$ & $\begin{array}{l}\text { Elaborar procedimientos } \\
\text { detalladamente } \\
\text { documentados, } \\
\text { capacitaciones esporádicas } \\
\text { al personal para } \\
\text { incrementar el uso de EPPs } \\
\text { en el taller/planta y realizar } \\
\text { mantenimientos } \\
\text { sistemáticos al extractor } \\
\text { para garantizar la máxima } \\
\text { reducción de viruta en el } \\
\text { área de trabajo. }\end{array}$ \\
\hline $\begin{array}{l}\text { Uso de } \\
\text { pegamento } \\
\text { (cola) }\end{array}$ & $\begin{array}{l}\text { Probabilidad de } \\
\text { reacción alérgica } \\
\text { e ingestión de la } \\
\text { sustancia tóxica }\end{array}$ & $\begin{array}{l}\text { Los operarios no } \\
\text { están debidamente } \\
\text { informados sobre la } \\
\text { toxicidad de la } \\
\text { sustancia. }\end{array}$ & $\begin{array}{l}\text { Intoxicación y } \\
\text { reacciones } \\
\text { alérgicas }\end{array}$ & $\begin{array}{l}\text { Señalizar la toxicidad de la } \\
\text { sustancia e informar a los } \\
\text { operarios directamente }\end{array}$ \\
\hline $\begin{array}{l}\text { Elevado } \\
\text { nivel de } \\
\text { Ruido }\end{array}$ & $\begin{array}{l}\text { Probabilidad de } \\
\text { perdida parcial o } \\
\text { total de la } \\
\text { capacidad } \\
\text { auditiva en el } \\
\text { largo plazo }\end{array}$ & $\begin{array}{l}\text { El ruido será casi } \\
\text { constante en el } \\
\text { taller debido al uso } \\
\text { de la cortadora } \\
\text { láser, los operarios } \\
\text { no utilizan de } \\
\text { manera apropiada } \\
\text { sus EPPs para la } \\
\text { reducción del ruido. }\end{array}$ & $\begin{array}{l}\text { Sordera parcial o } \\
\text { total }\end{array}$ & $\begin{array}{l}\text { Elaborar procedimientos } \\
\text { detalladamente } \\
\text { documentados, } \\
\text { capacitaciones esporádicas } \\
\text { al personal para } \\
\text { incrementar el uso de EPPs } \\
\text { en el taller/planta y adquirir } \\
\text { dispositivos que reduzcan } \\
\text { el ruido que genera la } \\
\text { cortadora láser. }\end{array}$ \\
\hline
\end{tabular}

Elaboración propia

\subsection{Sistema de mantenimiento}

Para lograr la mayor eficiencia de parte de nuestra cortadora láser se realizarán mantenimientos preventivos esporádicos definiendo su frecuencia. Por otro lado, también se tendrán en cuenta los mantenimientos reactivos para estar preparados en caso de una falla. También existen recomendaciones que se seguirán para reducir los tiempos de parada de máquina que se representa anualmente como tiempo promedio por fallas (MTTR) del año. La principal recomendación será tener repuestos para el lente de la 
cortadora láser, pues es el consumible de mayor rotación. A continuación, se muestra la tabla de Actividades de Mantenimiento.

Tabla 5.23

Mantenimiento preventivo y reactivo

\begin{tabular}{|l|l|l|l|}
\hline $\begin{array}{l}\text { Tipo de } \\
\text { Mantenimiento }\end{array}$ & Máquina/Equipo & $\begin{array}{l}\text { Actividades de } \\
\text { mantenimiento }\end{array}$ & Frecuencia \\
\hline & & Inspección general & Semanal \\
\cline { 3 - 4 } & & Revisión del lente del láser & 3 veces por dia \\
\cline { 3 - 4 } $\begin{array}{l}\text { Mantenimiento } \\
\text { Preventivo }\end{array}$ & \multirow{5}{*}{$\begin{array}{l}\text { Cimpieza de viruta } \\
\text { acumulada }\end{array}$} & Semanal \\
\cline { 3 - 4 } & & Engrasar ejes $(\mathrm{X}, \mathrm{Y} \mathrm{Z})$ & Semanal \\
\cline { 3 - 4 } & & $\begin{array}{l}\text { Revisión y limpieza de } \\
\text { sensores }\end{array}$ & Mensual \\
\cline { 3 - 4 } & & Cambio de Tubo CO $\mathrm{CO}_{2}$ & Anual \\
\cline { 3 - 4 } $\begin{array}{l}\text { Mantenimiento } \\
\text { Reactivo }\end{array}$ & & Calibración de Sensores & Cuando sea necesario \\
\cline { 3 - 4 } & & Cambio de lente de láser & Cuando sea necesario \\
\hline
\end{tabular}

Elaboración propia

\subsection{Diseño de la cadena de suministro}

La cadena de suministro en relación con la materia prima que ingresa será simple ya que son solo 6 componentes que conforman el producto final. El principal insumo para considerar será el MDF por su dificultad de traslado y necesidad de corte previo al envío. Por ello se consideró a Sodimac y Castor, pero optando por tener un mayor poder de negociación en relación con el escalamiento de costos se eligió a Sodimac ya que se le comprarían todos los insumos necesarios para las lámparas.

Por otro lado, para el transporte de las lámparas a los puntos de venta finales (tiendas al por menor) se tercerizará un servicio de transporte. Este recogerá los productos desde la planta y los transportará hasta las tiendas al por menor asegurando su calidad mediante contratos debidamente estipulados. De esta manera el foco del negocio se concentrará en los diseños y el maquinado optimizando costos y mejorando la calidad de los productos constantemente. 


\subsection{Programa de producción}

Para realizar el programa de producción se considerará un stock de seguridad de 7 días en relación a las ventas anuales. A continuación, se muestra el programa de producción para los 5 años del proyecto.

Tabla 5.24

Programa de producción 2019 - 2023 (cajas)

\begin{tabular}{|l|l|l|l|l|l|}
\hline $\begin{array}{l}\text { Número total de } \\
\text { lámparas embaladas }\end{array}$ & 2019 & 2020 & 2021 & 2022 & 2023 \\
\hline Inventario Inicial & - & 161 & 177 & 193 & 209 \\
\hline Producción & 7097 & 7646 & 8339 & 9033 & 9726 \\
\hline Venta & 6936 & 7630 & 8323 & 9017 & 9710 \\
\hline Inventario final & 161 & 177 & 209 & 209 & 225 \\
\hline
\end{tabular}

Elaboración propia

\subsection{Requerimiento de insumos, servicios y personal indirecto}

En este subcapítulo se detallarán los requerimientos de materias primas, servicios y personal indirecto para el emprendimiento.

\subsubsection{Materia prima, insumos y otros materiales}

A continuación, se describen los materiales necesarios para fabricar una lámpara. 
Tabla 5.25

Balance de materiales

\begin{tabular}{|l|l|}
\hline Materiales & Cantidad (1 Lámpara) \\
\hline MDF (4mm de espesor) & 0,1218 metros cuadrados \\
\hline Foco ahorrador (Daiku) & 1 \\
\hline Cola & $15 \mathrm{ml}$ (opcional) \\
\hline Cable mellizo & 1 metro \\
\hline Enchufe simple & 1 \\
\hline Soquete (Incluye tornillos para empernar) & 1 \\
\hline Etiqueta & 1 \\
\hline Caja de cartón $(0,2 \mathrm{~m} x 0,2 \mathrm{~m} x 0,4 \mathrm{~m})$ & 1 \\
\hline
\end{tabular}

Elaboración propia

Tabla 5.26

Requerimiento de materiales

\begin{tabular}{|l|l|l|l|l|l|l|l|}
\hline Año & $\begin{array}{l}\text { Planchas de } \\
\text { MDF de 4mm } \\
(1,3 \mathrm{~m} \times 0,9 \mathrm{~m})\end{array}$ & $\begin{array}{l}\text { Focos } \\
\text { (6-pack) }\end{array}$ & Soquetes & $\begin{array}{l}\text { Cable mellizo } \\
\text { (en metros) }\end{array}$ & Enchufe & Etiquetas & Cajas \\
\hline 2019 & 739 & 1183 & 7097 & 7097 & 7097 & 7097 & 7097 \\
\hline 2020 & 796 & 1244 & 7646 & 7646 & 7646 & 7646 & 7646 \\
\hline 2021 & 868 & 1390 & 8339 & 8339 & 8339 & 8339 & 8339 \\
\hline 2022 & 940 & 1506 & 9033 & 9033 & 9033 & 9033 & 9033 \\
\hline 2023 & 1014 & 1622 & 9726 & 9726 & 9726 & 9726 & 9726 \\
\hline
\end{tabular}

Elaboración propia

Entre los insumos encontraremos los consumibles de la cortadora láser: lentes del láser, malla de corte y tubo de $\mathrm{CO}_{2}$.

Entre otros materiales encontraremos: EPPs (mascarillas, tapones de reducción sonora, lentes de seguridad, etc.), artículos de limpieza, herramientas (para realizar mantenimiento), herramientas (para ensamblado), agua (para beber), 


\subsubsection{Servicios: energía eléctrica, agua, vapor, combustible, etc.}

Entre los demás servicios que necesitará la empresa se encuentran los servicios de:

- Telecomunicaciones (teléfono) e internet: Se contratará a Movistar para que nos proporcione línea telefónica e internet.

- Agua: Sera provista por SEDAPAL.

- Energía eléctrica: Sera provista por Luz del Sur cuyo precio es casi despreciable, pues la cortadora láser consume muy poca energía $(1,5 \mathrm{~kW} / \mathrm{h})$ volviendo el costo de la energía eléctrica casi despreciable (aproximadamente 85 soles mensuales por cortadora).

A continuación, se muestra el cálculo de la energía eléctrica que demandara el proyecto.

Tabla 5.27

Consumo eléctrico por máquina / equipo

\begin{tabular}{|l|l|l|l|l|l|}
\hline Máquina & $\begin{array}{l}\text { Consumo } \\
(\mathrm{kW}-\mathrm{h})\end{array}$ & $\begin{array}{l}\text { Número de } \\
\text { máquinas/equipos }\end{array}$ & $\begin{array}{l}\text { Número } \\
\text { de Horas }\end{array}$ & Consumo (kW-d) & Consumo (kW-mes) \\
\hline Compresora & 1,5 & 1 & 8 & 12 & 288 \\
\hline Extractor & 0,5 & 1 & 8 & 4 & 96 \\
\hline Cortadora láser & 1,5 & 1 & 8 & 12 & 288 \\
\hline Computadora & 0,1 & 4 & 8 & 3,2 & 76,8 \\
\hline Focos & 0,1 & 8 & 8 & 6,4 & 153,6 \\
\hline Total & & & & 37,6 & 902,4 \\
\hline
\end{tabular}

Elaboración propia

\subsubsection{Determinación del número de trabajadores indirectos}

No hay necesidad de calcular el número de trabajadores indirectos pues la cantidad de actividades a cumplir son sumamente reducidas, nuestros trabajadores indirectos serán: el gerente general quien se encargará de negociar todas las tercerizaciones y alianzas necesarias para la empresa y nuestro jefe de ventas que negociara junto con el gerente los contratos de ventas con las tiendas al por menor mientras busca nuevos clientes potenciales. 


\subsubsection{Servicios de terceros}

Para entrar en funcionamiento la empresa deberá tercerizar los siguientes servicios:

- Telefonía e Internet: Se trabajará con la empresa Movistar del Perú y se optará por el paquete que cumpla con nuestros requerimientos al menor costo.

- Capacitaciones: Se trabajará con el emprendimiento Zolid para realizar capacitaciones esporádicas sobre corte láser y diseño y con otras empresas para las capacitaciones necesarias (seguridad, salud, ética, trabajo en equipo, etc.).

- Mantenimiento: El mantenimiento anual de la cortadora láser se realizará con un técnico tercerizado. Las computadoras en el taller también recibirán mantenimientos de manera mensual por un técnico tercerizado.

- Transporte: Se tercerizará el transporte de los productos terminados hacia los puntos de venta (tiendas al por menor).

\subsection{Disposición de planta}

En este subcapítulo se detallará la disposición de planta para el emprendimiento.

\subsubsection{Características físicas del proyecto}

Las características físicas del proyecto serán descritas mediante el factor edificio y el factor servicio. Mientras que el factor edificio normalmente habla de la construcción nos servirá para describir las características imprescindibles del local que alquilaremos. El factor servicio determinara las necesidades básicas de nuestros trabajadores en relación con las instalaciones sanitarias, equipos de protección personal (EPPs), vías de acceso, iluminación, ventilación, alimentación y atención medica entre otros.

Factor Edificio: Primeramente, en relación con el estudio de suelos se optó por suelos residuales, pues garantiza una cimentación más optima del local. Por otro lado, se decidió que el local a rentar tuviera un solo piso y suelo de concreto para el área administrativa y concreto armado para el área de operaciones ya que tiene mayor resistencia y durabilidad. Por estar conformada únicamente por 2 espacios (almacén de productos terminados y área de producción) se optó por no tener pasillos. Se considero 
que se utilizaran carretillas hidráulicas y los desniveles deben ser compensados por rampas hechas con placas de metal abrasivo. Finalmente, el techo deberá ser en forma de arco de flecha por su alto nivel de estabilidad y una altura de por lo menos 2,7 metros desde el nivel del suelo y as ventanas estarán posicionadas a $90 \mathrm{~cm}$ sobre el suelo. Todas estas características junto con las señalizaciones apropiadas (estipuladas por la NTP 399.010-1:2004) tendrán que ser garantizadas para permitir el correcto funcionamiento de la planta.

Factor Servicio: En relación con el factor servicio será necesario el abastecimiento de equipos de protección personal (EPPs) para nuestros operarios, así como casilleros donde puedan dejar sus pertenencias. La iluminación y ventilación deben ser óptimas para mejorar el desempeño de nuestros colaboradores. Por otro lado, se deberá contar con un comedor como área de alimentación. Finalmente, se deberá contar con un botiquín de primeros auxilios y capacitaciones para su uso apropiado.

\subsubsection{Determinación de las zonas físicas requeridas}

Área administrativa: En esta área podremos encontrar las oficinas de la gerencia general, el jefe de ventas y el diseñador industrial/especialista en fabricación digital junto con el área de circulación (pasillos). En esta área también estarán los baños para hombres y mujeres por separado que contarán con todo lo necesario para el uso higiénico de las instalaciones que permitirá la limpieza personal apropiada a nuestros colaboradores y espacio suficiente para cambiarse de vestuario. Asimismo, en el área administrativa también se encontrará el área de descanso donde podrán almorzar los trabajadores y almacenar sus productos alimenticios aparte de acceder a hervidoras de agua para cafés e infusiones y refrigeradora para refrigerar lo que lo requiera.

Área de operaciones: En esta área se realizará el maquinado del MDF con la cortadora láser y todas las operaciones necesarias realizadas por el operario para convertir las materias primas en un producto terminado siendo estas, corte y pelado de cables, acoplamiento de cable a soquete y enchufe, ensamblado, etiquetado y embalado.

Patio de maniobras y área de almacenaje: En esta área se realizarán las actividades de traslado de materiales, recepción de materias primas y recojo de productos terminados. Por otro lado, para mayor eficiencia a la hora de la recepción de materia prima y envió 
de productos terminados los almacenes de materia prima y productos terminados estarán posicionados de manera ordenada en el área del patio de maniobras. Este tendrá una puerta de 3 metros de ancho para que una camioneta pueda entrar en forma de retroceso y agilizar el proceso.

En referencia a las materias primas se almacenarán en 1 parihuela y un estante vertical (para las planchas de MDF): enchufes, soquetes, rollos de cable mellizo, 6 packs de focos, etiquetas, cajas y planchas de MDF de 4 milímetros. Por otro lado, se almacenarán las lámparas ensambladas, etiquetadas y embaladas en 2 parihuelas de 1,2 metros por 1 metro posicionadas una al lado de la otra y movilizadas con un pato hidráulico. El área se mantendrá a una temperatura ambiente de 15-30 grados Celsius para mantener en buen estado los productos y materias primas.

\subsubsection{Cálculo de áreas para cada zona}

A continuación, se muestran los cálculos para definir el tamaño del local a alquilar y como estará distribuido dicho espacio (área administrativa, área de operaciones y baños).

Área de Operaciones: Luego de calcular las medidas necesarias para las máquinas y equipos se realizó el método de guerchet para tomar en consideración el espacio de gravitación y el espacio de evolución de los elementos móviles y estáticos como se demuestra a continuación y así llegar a las dimensiones reales del área de operaciones o área de corte láser. 
Tabla 5.28

Método de Guerchet (elementos estáticos)

\begin{tabular}{|l|l|l|l|l|l|l|l|l|l|l|l|}
\hline \multicolumn{10}{|c|}{ Zona de Corte Láser } \\
\hline Nombre & $\mathrm{n}$ & $\mathrm{N}$ & $\mathrm{L}$ & $\mathrm{A}$ & $\mathrm{h}$ & $\mathrm{SS}$ & $\mathrm{Sg}$ & $\mathrm{Se}$ & $\mathrm{St}$ & $\mathrm{SS} \times \mathrm{n}$ & $\mathrm{SS} \times \mathrm{n} \times \mathrm{h}$ \\
\hline Cortadora Láser & 1 & 1 & 1,69 & 1,2 & 1,47 & 2,028 & 2,028 & 17,811 & 58,371 & 2,028 & 29,812 \\
\hline Compresor & 1 & 1 & 0,5 & 0,3 & 0,62 & 0,15 & - & 0,1317 & 0,2817 & 0,15 & 0,093 \\
\hline Mesa de trabajo & 2 & 1 & 1,8 & 0,8 & 1,2 & 1,44 & 2,88 & 18,970 & 62,170 & 2,88 & 3,456 \\
\hline
\end{tabular}

Elaboración propia

\section{Tabla 5.29}

Método de Guerchet (elementos móviles)

\begin{tabular}{|l|l|l|l|l|l|l|l|l|}
\hline Elementos Móviles & $\mathrm{n}$ & $\mathrm{N}$ & $\mathrm{L}$ & $\mathrm{A}$ & $\mathrm{h}$ & $\mathrm{SS}$ & SS x n & SS $\mathrm{n} \times \mathrm{h}$ \\
\hline Carretilla hidráulica & 1 & 1 & 1,55 & 0,53 & 1,2 & 0,8215 & 0,8215 & 0,9858 \\
\hline Operarios (incluye diseñador) & 2 & - & - & - & 1,65 & 0,5 & 1 & 1,65 \\
\hline
\end{tabular}

Elaboración propia 
Tabla 5.30

Método de Guerchet (cálculo de área total)

\begin{tabular}{|l|l|l|l|}
\hline & Ss*n total & Ss*n*h total & hee/hem \\
\hline Elementos Estáticos & 6,498 & 8,2582 & 1,2709 \\
\hline Elementos Móviles & 1,8215 & 2,6358 & 1,4470 \\
\hline K: & 0,4391 & \multicolumn{3}{|l}{} \\
\hline Área Total: & 15,7297 & \multicolumn{2}{|l}{} \\
\hline
\end{tabular}

Elaboración propia

Gracias al método de Guerchet y la próxima tabla se puede demostrar la necesidad de espacio para los almacenes y se determinó que el mínimo número de parihuelas de 1,2 metros x 1 metro será 1 para el área de almacenaje de materia prima pues los insumos se podrán posicionar dentro de cajas para aprovechar el espacio vertical evitando tenerlos apilados de manera desordenada y sin necesidad de un segundo nivel, por otro lado también se tendrá un estante de 30 centímetros de ancho por 1,2 metros de largo para almacenar las planchas de MDF de manera vertical (estilo estante para vidrios o espejos) optimizando el espacio. Por otro lado, se necesitarán 2 parihuelas para el área de productos terminados pues en cada una se podrán apilar 4 niveles de 30 cajas cada uno y el almacenaje necesario es de 225 cajas. Como resultado el espacio mínimo necesario para que el operario maniobre deja un espacio de pasillo será de 3,1 metros como lo demuestra la figura 5.32 . 
Tabla 5.31

Área de almacén de materias primas

\begin{tabular}{|c|c|c|c|c|c|}
\hline $\begin{array}{l}\text { Almacén de } \\
\text { Materias Primas }\end{array}$ & $\begin{array}{l}\text { Planchas de MDF } \\
(1,3 \mathrm{~m} \times 0,9 \mathrm{~m})\end{array}$ & $\begin{array}{l}\text { Focos Daiku } \\
(6-P a c k) \\
\left(0,075 \mathrm{~m}^{2}\right)\end{array}$ & $\begin{array}{l}\text { Soquetes } \\
\left(0,003 \mathrm{~m}^{2}\right)\end{array}$ & $\begin{array}{l}\text { Enchufe } \\
\left(0,002 \mathrm{~m}^{2}\right)\end{array}$ & $\begin{array}{l}\text { Cajas de Cartón } \\
(20 \mathrm{~cm} \times 20 \mathrm{~cm} \times 20 \mathrm{~cm}) \\
\text { Apilables en sets de } 20\end{array}$ \\
\hline Unidades al año & 1014 & 1625 & 9726 & 9726 & 9726 \\
\hline Días laborables & 303 & 303 & 303 & 303 & 303 \\
\hline $\begin{array}{|lr|}\text { Días } & \text { de } \\
\text { almacenamiento }\end{array}$ & 7 & 7 & 7 & 7 & 7 \\
\hline $\begin{array}{|ll|}\text { Unidades } & \text { para } \\
\text { almacenar } & \\
\end{array}$ & 24 & 38 & 225 & 225 & 225 \\
\hline $\begin{array}{|ll|}\text { Unidades } & \text { por } \\
\text { carretilla } & \\
\text { hidráulica } & \\
\end{array}$ & 50 & 50 & 250 & 250 & 300 \\
\hline $\begin{array}{l}\text { Espacio } \\
\text { necesario }\left(\mathrm{m}^{2}\right)\end{array}$ & $0,09 \mathrm{~m}^{2}$ & $\begin{array}{ll}0,7125 & (20 \\
\text { cm de altura) }\end{array}$ & 0,675 & 0,40 & 0,45 \\
\hline $\begin{array}{lll}\# & \text { de } & \text { parihuelas } \\
\text { de } & 1 & \text { metro por } \\
1,2 & \text { metros }\end{array}$ & $\begin{array}{l}\text { Irán en un estante } \\
\text { de } 30 \mathrm{~cm} \text { de ancho } \\
\text { por } 1,5 \text { metros de } \\
\text { alto y } 1,2 \text { metros } \\
\text { de largo }\end{array}$ & 1 & 1 & 1 & 1 \\
\hline
\end{tabular}

Elaboración propia

El área administrativa se ve dividida entre las áreas mostradas en la siguiente tabla que detalla el área total que ocupara.

Tabla 5.32

Área administrativa

\begin{tabular}{|l|l|l|}
\hline \multicolumn{3}{|c|}{ Área Administrativa } \\
\hline Requerimientos & Medidas & Área $\left(\mathrm{m}^{2}\right)$ \\
\hline G. General & $2,9 \mathrm{~m} \times 4,2 \mathrm{~m}$ & 12,18 \\
\hline J. de Ventas & $2 \mathrm{~m} \times 3 \mathrm{~m}$ & 6 \\
\hline Diseñador & $2 \mathrm{~m} \times 3 \mathrm{~m}$ & 6 \\
\hline Área de descanso & $2 \mathrm{~m} \times 4 \mathrm{~m}$ & 8 \\
\hline Baño de hombres & $1,5 \mathrm{~m} \times 2 \mathrm{~m}$ & 3 \\
\hline Baño de mujeres & $1,5 \mathrm{~m} \times 2 \mathrm{~m}$ & 3 \\
\hline $\begin{array}{l}\text { Área de circulación } \\
\text { y paredes }\end{array}$ & 3 personas & 11,52 \\
\hline Área Total $\left(\mathrm{m}^{2}\right)$ & \multicolumn{2}{|c|}{49,7} \\
\hline
\end{tabular}

Elaboración propia 
Figura 5.33

Dimensiones para la movilidad de la carretilla hidráulica

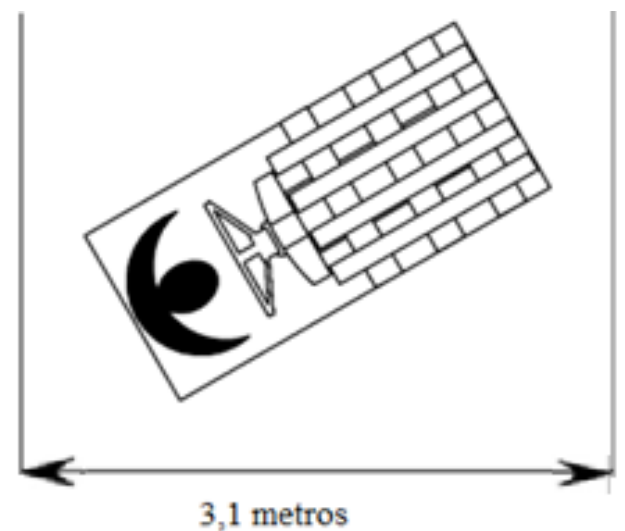

Elaboración propia

Tabla 5.33

Superficie por área

\begin{tabular}{|l|l|}
\hline Área & Superficie $\left(\mathrm{m}^{2}\right)$ \\
\hline Área administrativa & 49,7 \\
\hline Área de operaciones & 23 \\
\hline Área de patio de maniobras & 16,3 \\
\hline Total & 90 \\
\hline
\end{tabular}

Elaboración Propia

\subsubsection{Dispositivos de seguridad industrial y señalización}

La planta estará equipada con detectores de humo y señalizaciones de seguridad adecuadas para garantizar la seguridad de los trabajadores tanto durante sus labores como en caso de emergencia como sismos. Entre las señales de seguridad como lo indica el reglamento nacional de edificaciones (2013) norma A.120 artículo 23. Se ubicarán señales color rojo de prohibición como la señal de prohibido fumar y la señalización de donde se ubicarán los extinguidores. Por otro lado, también se ubicarán señales amarillas de atención de riesgo eléctrico en el área de operaciones. Asimismo, se posicionarán adecuadamente señales color verde como salidas, primeros auxilios y direcciones hacia las salidas. 
Figura 5.34

Plano de seguridad

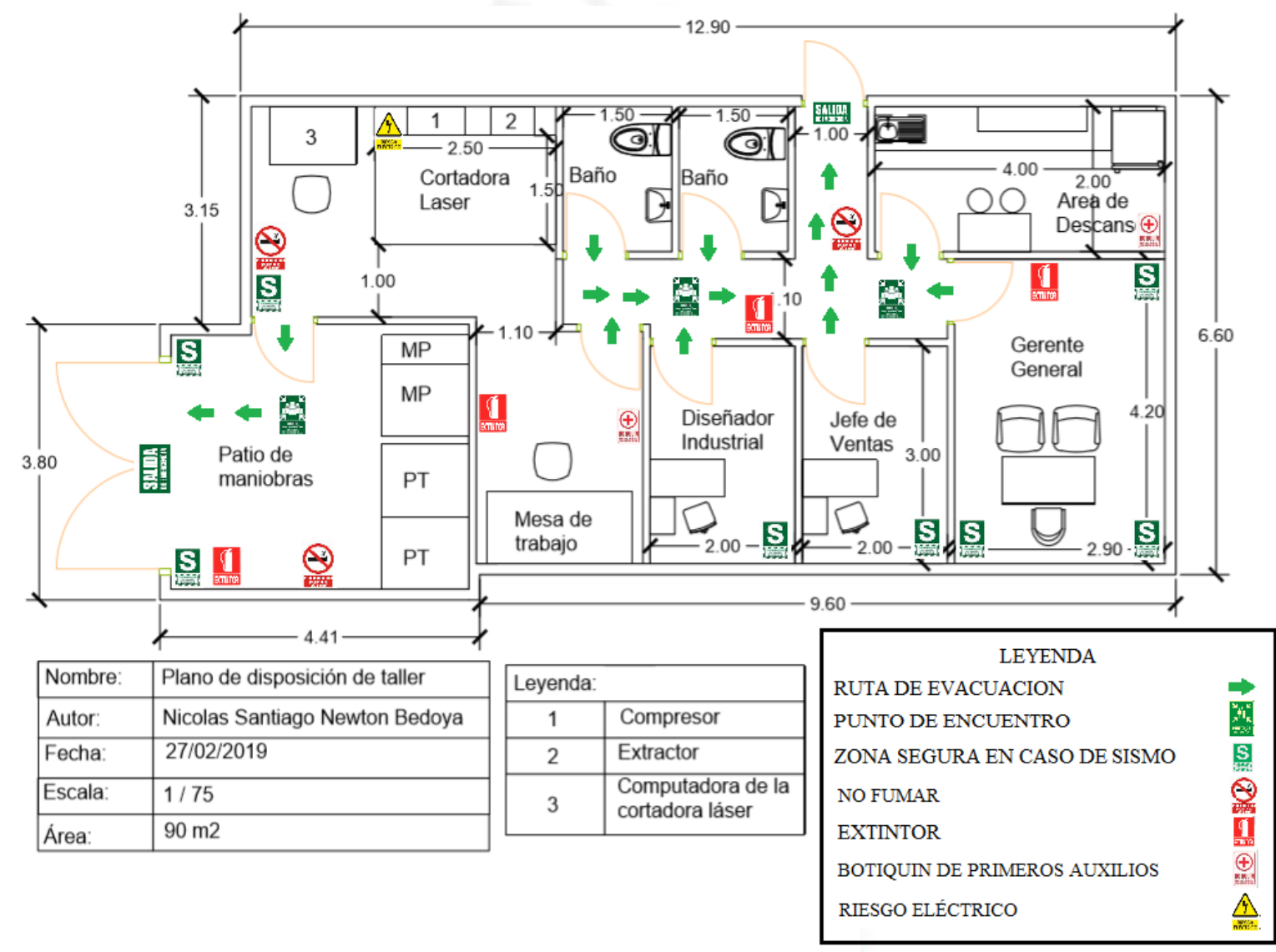

Elaboración propia

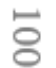




\subsubsection{Disposición de detalle de la zona productiva}

En la siguiente figura se detalla el plano de disposición del taller de corte laser acotado debidamente para la visualización de la distribución de las áreas. El taller medirá 90 metros cuadrados en su totalidad con paredes externas de 0,15 metros y paredes internas de 0,10 metros. Tiene 2 entradas, 1 hacia el área administrativa y 1 para vehículos de transporte en el patio de maniobras que también actuará como área de almacenaje esta entrada estará posicionada estratégicamente para facilitar la carga y descarga de productos terminados y materias primas respectivamente. La escala del plano será de 1/75 para una adecuada visualización de este.

El área administrativa estará dividida en oficinas para el gerente general de 4,2 metros por 2,9 metros y 2 oficinas de 2 metros por 3 metros una para el jefe de ventas adyacente a la oficina del gerente general y un diseñador industrial adyacente al área de operaciones para optimizar sus movimientos. Por otro lado, también se tendrán áreas de circulación en forma de pasillos de un mínimo de 1 metro de ancho, 2 baños de 1,5 metros por 2 metros para hombres y mujeres y un área de descanso de 2 metros por 4 metros.

En el área de operaciones se tendrá una mesa de trabajo donde el operario realizara todas las labores explicadas previamente en paralelo al corte laser, una mesa junto a la cortadora laser donde ira la computadora necesaria para manejarla y un compresor y un extractor atrás de la cortadora laser pegado a la pared para expulsar los humos que se generan al utilizar la cortadora. El área de operaciones medirá 23 metros cuadrados en su totalidad.

Finalmente, se tendrá junto al área de operaciones un patio de maniobras donde ingresaran de retroceso las camionetas que realizaran el transporte de los productos y materias primas, una carretilla hidráulica y el área de almacenaje dividido como lo muestra el plano, 1 estante vertical de 0,4 metros por 1,2 metros y 1 parihuela de 1 metro por 1,2 metros donde se posicionarán cajas o jabas para optimizar el almacenaje de las materias primas (MP) y 2 parihuelas de 1 metro por 1,2 metros para almacenar las cajas con los productos terminados (PT) apiladas hasta en 4 niveles (capacidad 240 cajas). 
Figura 5.35

Plano de disposición de taller

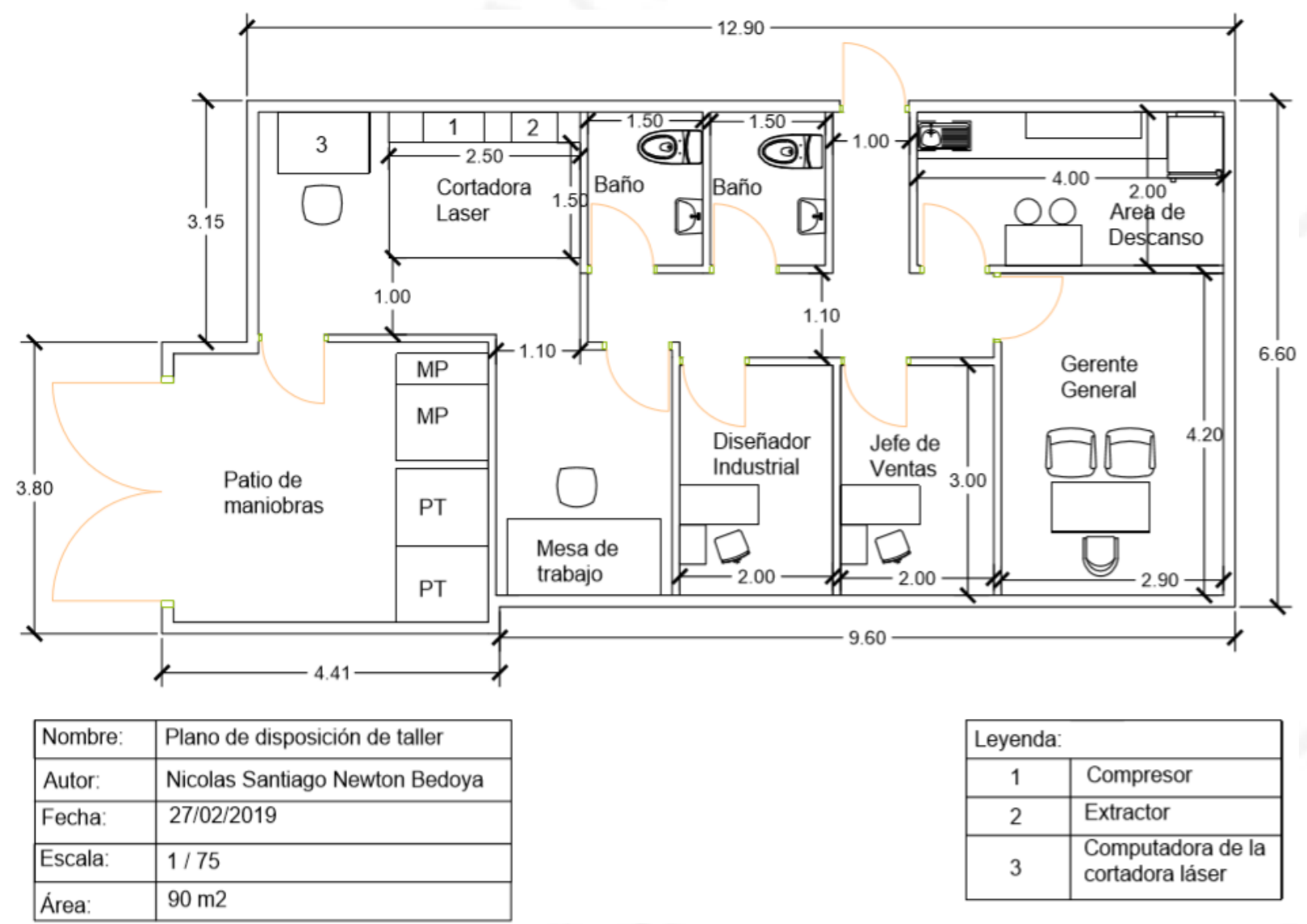

Elaboración propia

옹 


\subsubsection{Disposición general}

Las figuras siguientes demuestran la relación entre las áreas existentes en el taller y como las prioridades del emprendimiento generan la distribución de estas de la manera propuesta para optimizar el funcionamiento del emprendimiento. En la primera figura podemos ver que tan deseable es que las distintas áreas estén próximas una a la otra. Por otro lado, la segunda figura muestra dicha relación de manera gráfica.

Figura 5.36

Diagrama relacional

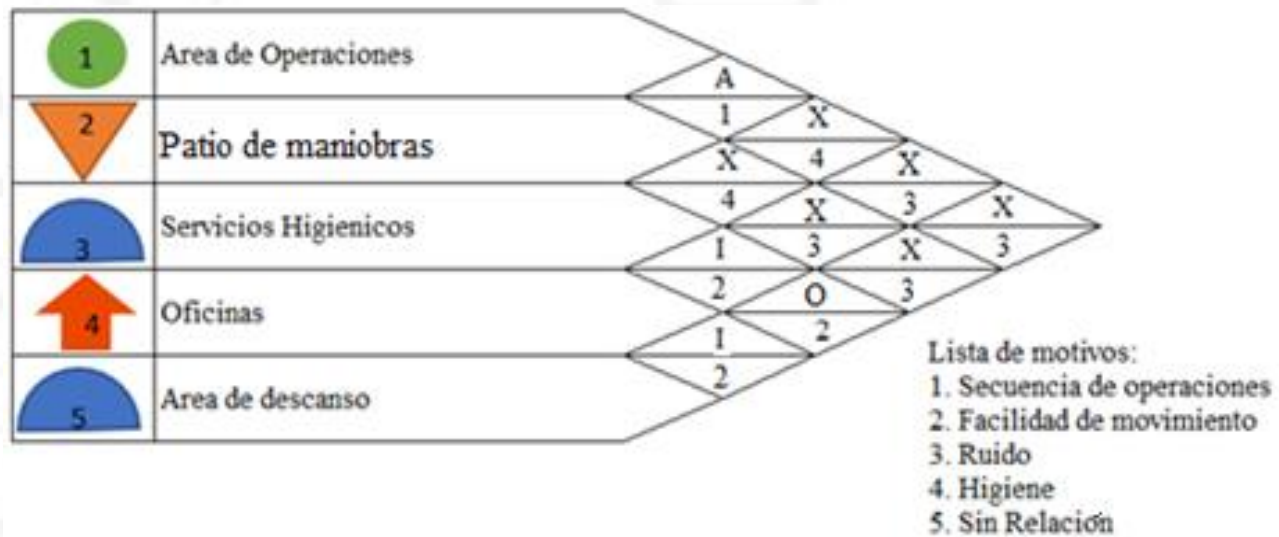

Elaboración propia

Figura 5.37

Diagrama relacional de actividades

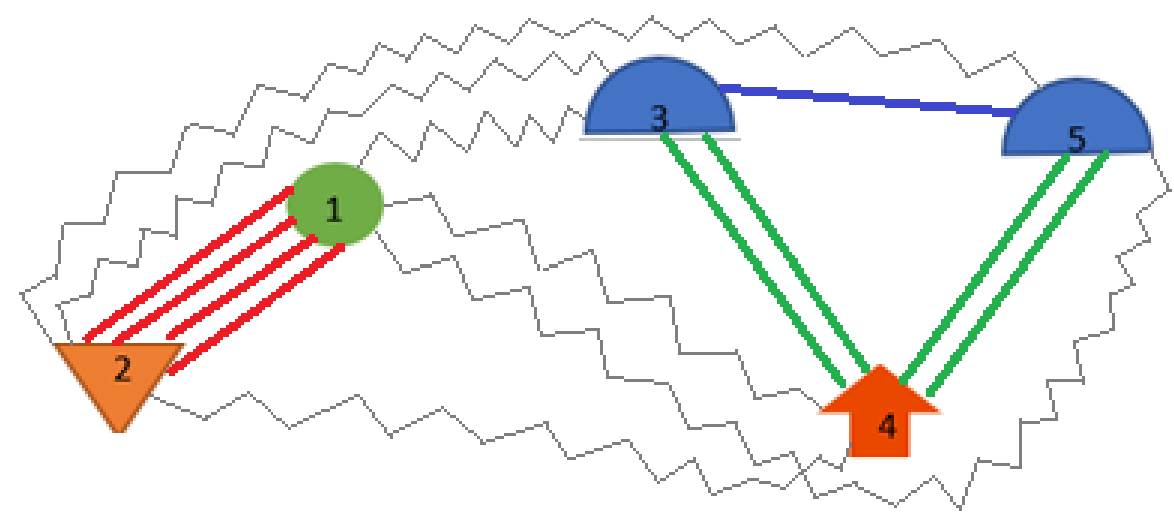

Elaboración propia 


\subsection{Cronograma de implementación del proyecto}

Para realizar la implementación del proyecto se consideraron 6 diferentes actividades a realizar en un tiempo total de ciento diez (110) días.

Tabla 5.34

Cronograma del proyecto

\begin{tabular}{|l|l|l|l|}
\hline Etapas & $\begin{array}{l}\text { Duración } \\
\text { (Días) }\end{array}$ & Comienzo & Fin \\
\hline Constituir la empresa & 20 & 01.04 .2019 & 20.04 .2019 \\
\hline Buscar y alquilar local & 20 & 21.04 .2019 & 09.05 .2019 \\
\hline $\begin{array}{l}\text { Buscar y contratar empleados } \\
\text { (Incluye Terceros y Outsourcing) }\end{array}$ & 20 & 21.04 .2019 & 30.05 .2019 \\
\hline Comprar Activos & 30 & 10.05 .2019 & 09.06 .2019 \\
\hline Acondicionamiento de Local & 30 & 10.05 .2019 & 19.06 .2019 \\
\hline Puesta en marcha & 10 & 10.06 .2019 & 19.06 .2019 \\
\hline
\end{tabular}

Elaboración Propia 
Tabla 5.35

Diagrama de Gantt

\begin{tabular}{|l|l|l|l|l|l|l|l|l|}
\hline Actividad/Fechas & $01.04-10.04$ & $11.04-20.04$ & $21.04-30.04$ & $01.04-10.05$ & $11.05-20.05$ & $21.05-30.05$ & $31.05-09.06$ & $10.06-19.06$ \\
\hline Constituir la empresa & & & & & & & & \\
\hline Buscar y alquilar local & & & & & & & & \\
\hline Buscar y contratar empleados & & & & & & & & \\
\hline Comprar Activos & & & & & & & & \\
\hline Acondicionamiento de Local & & & & & & & & \\
\hline Puesta en marcha & & & & & & & & \\
\hline
\end{tabular}

Elaboración Propia 


\section{CAPÍTULO VI: ORGANIZACIÓN Y ADMINISTRACION}

\subsection{Formación de la organización empresarial}

Se opto por crear una Sociedad Anónima Cerrada (SAC) cuyo nombre será MUMMU PERU SAC y estará constituida por 2 socios (personas naturales) quienes darán inicio a la empresa constituyéndola con un $51 \%$ de acciones para el creador del proyecto y $49 \%$ para el financiamiento vía smart money, pues se verá involucrado en el planeamiento y gestión del emprendimiento como miembro estratégico del directorio. Para crear la empresa se seguirán las siguientes pautas.

1. Reserva del nombre propuesto: Se procede a través de Registros públicos de manera presencial o vía on-line y asegura que el nombre no lo tome otra empresa.

2. Capital social: Este se refiere al aporte de los accionistas y consta de efectivo y/o bienes del propietario.

3. Socios: Una empresa debe tener como mínimo 2 socios, requerimiento con el que cumplimos.

4. Asignación de Gerencia general: Para realizar la constitución se debe nombrar al gerente general y establecer cuáles serán sus facultades.

5. Registros públicos: Se tendrá que seguir el procedimiento apropiado para elevar los datos necesarios a los registros públicos.

Una vez constituida nuestra empresa se deberá definir y generar la cultura organizacional que permitirá la comunicación horizontal entre los colaboradores permitiendo su desarrollo profesional y personal.

- Misión: MUMMU PERU SAC es una empresa productora y comercializadora de lámparas infantiles modernas de estilo modular fabricadas con tecnologías de corte láser y fabricación digital (diseño 2D y 3D) que se dedicara al rubro de la mobiliaria infantil de una manera práctica y segura. 
- Visión: Ser empresa pionera y reconocida a nivel nacional por su constante innovación que se caracterice por sus prácticas de mejora continua, la calidad de sus productos y su apropiada gestión de impacto ambiental, así como el desarrollo de nuevos diseños que permitan potenciar el crecimiento de la fabricación digital en el Perú.

- Políticas: Hemos definido los siguientes 4 pilares principales que marcaran las políticas de la empresa.

- Responsabilidad social: Se generarán proyectos de apoyo a la sociedad utilizando parte de la rentabilidad para desarrollar programas de capacitación sobre fabricación digital en colegios de bajos recursos.

- Mejora continua: Para garantizar la calidad y seguridad de nuestros procesos y productos guiándonos por programas de gestión como las $5 \mathrm{~S}$ y las pautas estipuladas por las ISO:9001.

- Trabajo en equipo: Se alinearán los colaboradores a las metas de la empresa a través de una gestión apropiada y la delegación de tareas permitiendo el crecimiento personal y profesional de nuestros colaboradores mediante la autonomía en sus labores.

- Transparencia: Se trabajará de manera totalmente transparente con nuestros colaboradores y clientes generando confianza en la marca y lealtad de parte de los trabajadores.

\subsection{Requerimientos de personal directivo, administrativo y de servicios; $y$ funciones generales de los principales puestos}

Es necesario definir las características esenciales que deben tener nuestros colaboradores para realizar las labores de sus puestos de manera apropiada. A continuación, se detalla cuales serán dichas características para cada puesto de la organización.

Gerente General: Se encargará de la gestión de la empresa tomando decisiones estratégicas en relación con la dirección que tomará la empresa en su rubro. También se encargará de gestionar las finanzas de la empresa y de las relaciones estratégicas como alianzas corporativas y negociaciones con proveedores y clientes. Por otro lado, será el 
representante legal de la empresa y también tendrá como labor el planeamiento del futuro de la empresa en relación con expansiones, alteraciones al mercado objetivo, etc.

Será imprescindible una persona con altas capacidades de liderazgo, un mínimo de 3 años de experiencia en el rubro o un rubro similar. También deberá tener mínimo una carrera universitaria y preferiblemente una maestría y/o doctorado en ingeniería industrial o administración de empresas. Finalmente, será necesario que posea habilidades que le permitan negociar con facilidad con nuestros proveedores y clientes.

Jefe de Ventas: Él nos representará ante las tiendas de venta al por menor con los que se negociará la comercialización de nuestros productos (ellos nos comprarán productos terminados y revenderán los productos en sus puntos de venta). Su labor también incluirá observar posibles mejoras en la presentación del producto y definir nuevos clientes potenciales y posibles alianzas comerciales con entidades que puedan beneficiar al negocio en términos de publicidad y reducción de gastos en distribución.

Será necesario tener un mínimo de 2 años de experiencia en el rubro y una carrera universitaria. Sera importante que tenga una personalidad carismática y proactiva, facilidad para las negociaciones y cualidades de líder.

Diseñador: Sera el encargado de generar nuevos modelos de lámparas para la empresa. También tendrá como labor optimizar los modelos en términos de uso de material, velocidad de producción y reducción de mermas durante el corte láser. Por otro lado, sus labores diarias involucraran apoyar al operario en relación con el uso del software para el maquinado, capacitándolo y generando los archivos que estén listos para el corte. Finalmente, sus responsabilidades también incluyen realizar las revisiones (mantenimiento preventivo) de la cortadora láser para indicarle al operario (técnico de corte láser) cuando realizarlas o cuando llamar a un tercero para que las realice.

Debe ser una persona con experiencia en el rubro de por lo menos 1 año y experiencia utilizando los software (Autodesk Inventor, Autodesk Fusion 360 y Adobe Ilustrator) y cortadoras láser de por lo menos 3 años. Debe tener una personalidad creativa y ser proactivo a la hora de indagar las mejores prácticas para su puesto, pues se espera que busque una mejora continua.

Técnico de Corte láser (Operario de producción): Sus funciones serán encargarse de los procesos de producción como lo serán: el corte láser, almacenaje de materias 
primas, piezas cortadas y productos terminados, el corte y acoplado de los cables de poder a los soquetes, ensamblado, embalado y mantenimientos preventivos.

Deberá ser una persona con capacidades para el aprendizaje relacionado a las máquinas y será preferible que tenga educación técnica sobre electrónica.

El requerimiento de personal tercerizado como lo será: el personal de limpieza, el contador, la seguridad, los transportistas, el asesor jurídico y el servicio de mantenimiento de computadoras, equipos y maquinaria serán tercerizados por grupo Eulen, Liderman, Kunaq, entre otros.

\section{Tabla 6.1}

Requerimiento de servicio de terceros

\begin{tabular}{|l|l|}
\hline Personal & Cantidad \\
\hline Limpieza & 1 \\
\hline Asesor Jurídico & 1 \\
\hline Contador & 1 \\
\hline Vigilante & 1 \\
\hline Transportista & 1 \\
\hline Técnico de Mantenimiento & 1 \\
\hline Total & 6 \\
\hline
\end{tabular}

Elaboración propia

\subsection{Esquema de la estructura organizacional}

Es sumamente importante tener en cuenta al personal preoperativo del proyecto para calcular adecuadamente los costos reales de la inversión. A continuación, se detalla en un organigrama preoperativo. 
Figura 6.1

Organigrama preoperativo del proyecto

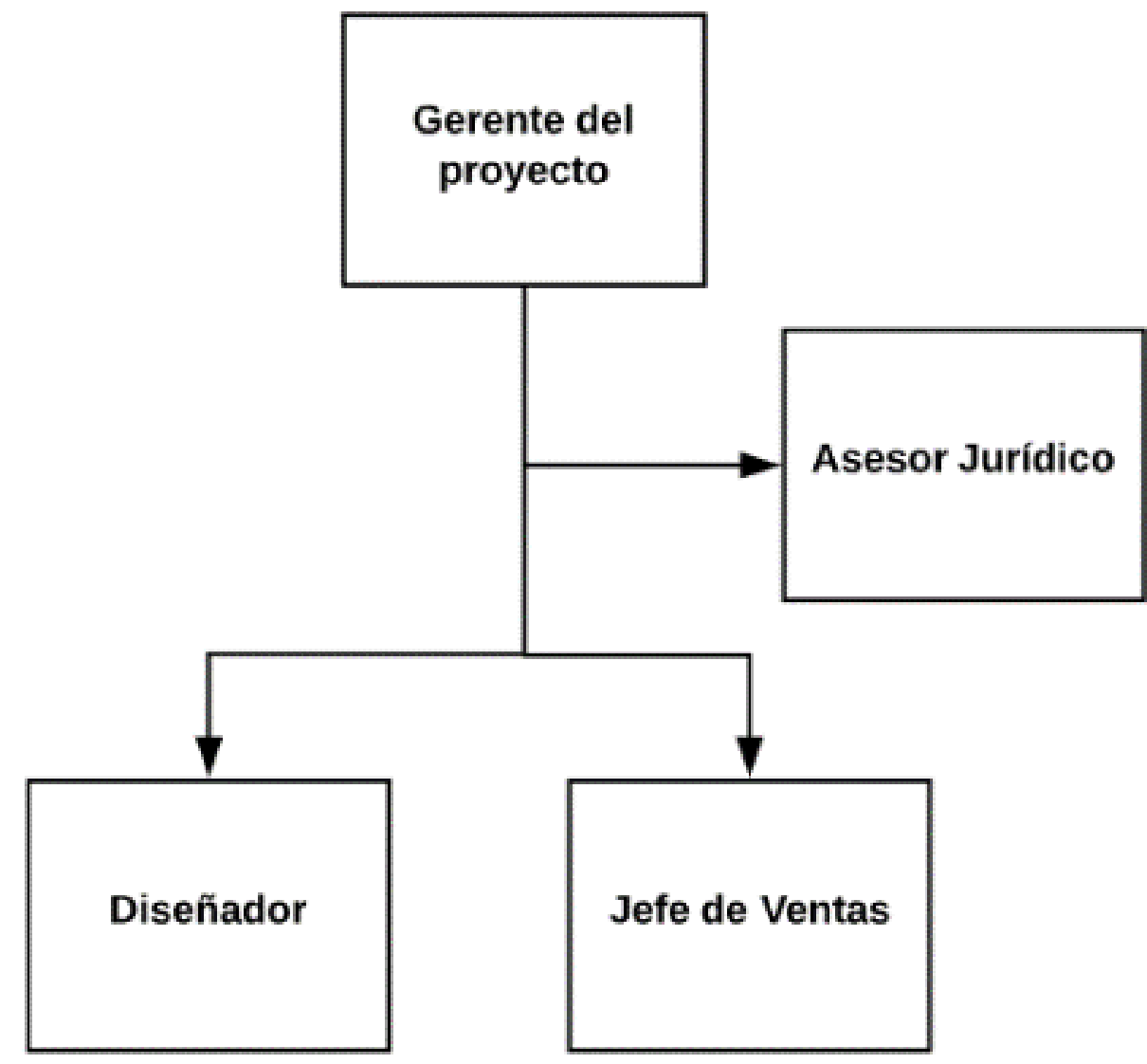

Elaboración propia

El presupuesto requerido para ello sería:

- El asesor jurídico quien recibirá S/ 1500 soles mediante recibo por honorarios por sus asesorías.

- El jefe de ventas quien recibirá S/2 000 soles para gestionar las negociaciones iniciales y así poder comenzar a producir con nuestros puntos de venta iniciales (tiendas de venta al por menor) bien definidos.

- No se necesitará un ingeniero supervisor ya que se rentará el local a utilizar y nuestro gerente general tendrá las capacidades necesarias para supervisar la instalación de los equipos y la aclimatación del local.

Una vez superada la etapa preoperativa la empresa se constituirá de la siguiente manera. 
Figura 6.2

Organigrama de la empresa

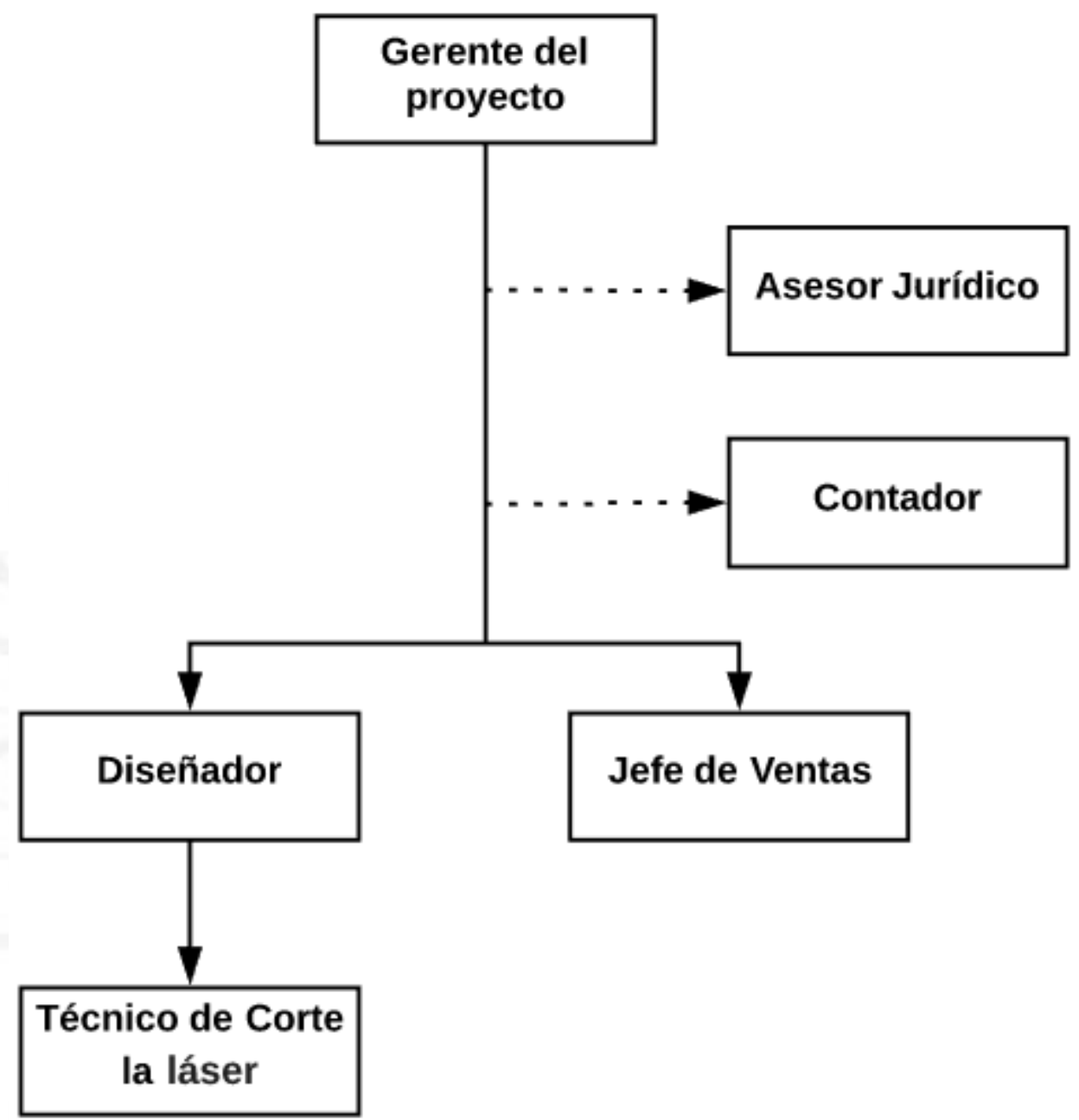

Elaboración propia 


\section{CAPÍTULO VII: ASPECTOS ECONÓMICOS Y FINANCIEROS}

\subsection{Inversiones}

El tipo de cambio a utilizar será de S/3,33 por dólar (enero, 2019).

\subsubsection{Estimación de las inversiones de largo plazo (tangibles e intangibles)}

La inversión a largo plazo se ha dividido en activos tangibles e intangibles. La oficina que se rentará viene parcialmente equipada y el aire acondicionado se tercerizará.

\section{Tabla 7.1}

Inversión fija tangible e intangible

\begin{tabular}{|l|l|l|}
\hline Inversión & Rubro & Soles (S/) \\
\hline \multirow{5}{*}{ Activos Tangibles } & Equipos y maquinaria & 16919,20 \\
\cline { 2 - 3 } & Mobiliario de planta & 1260,00 \\
\cline { 2 - 3 } & Equipos y mobiliario de oficina & 7347,00 \\
\cline { 2 - 3 } & Modificaciones del local & 15000,00 \\
\cline { 2 - 3 } & Imprevistos & 1021,05 \\
\cline { 2 - 3 } & Total Inversión Tangible & 41547,25 \\
\hline \multirow{5}{*}{$\begin{array}{l}\text { Intivos } \\
\text { Intangibles }\end{array}$} & Estudios previos & 15000,00 \\
\cline { 2 - 3 } & Constitución de la empresa & 500,00 \\
\cline { 2 - 3 } & Permisos para modificaciones & 2500,00 \\
\cline { 2 - 3 } & Puesta en marcha & 8705,00 \\
\cline { 2 - 3 } & Adquisición de licencia de funcionamiento & 620,41 \\
\cline { 2 - 3 } & Reclutamiento, selección y capacitación & 5000,00 \\
\cline { 2 - 3 } & Licencia de Autodesk Inventor & 6443,55 \\
\cline { 2 - 3 } & Licencia de Autodesk Fusion 360 & 1998,00 \\
\cline { 2 - 3 } & Licencia de Adobe Ilustrator & 799,20 \\
\cline { 2 - 3 } & Total Inversión Intangible & 41566,16 \\
\hline
\end{tabular}

Elaboración propia 


\subsubsection{Estimación de las inversiones de corto plazo}

La inversión a corto plazo será el capital de trabajo que va con relación al tiempo necesario para iniciar operaciones antes de generar ingresos (normalmente se realiza por los primeros 3 meses luego de iniciada la producción).

Se utilizó el método de déficit acumulado máximo para calcular el capital de trabajo. Considerando que del $100 \%$ de las ventas, $20 \%$ son al contado, $30 \%$ son con crédito a 30 días, $30 \%$ son con crédito a 60 días y el $20 \%$ faltante son con crédito a 90 días. Por otro lado, el $80 \%$ de las compras son al contado y $20 \%$ a crédito a 30 días calendario. 
Tabla 7.2

Capital de trabajo

\begin{tabular}{|c|c|c|c|}
\hline \multicolumn{4}{|c|}{ PRIMER AÑO DE OPERACIÓN } \\
\hline Mes & 1 & 2 & 3 \\
\hline Precio & 42,64 & 42,64 & 42,64 \\
\hline Unidades Vendidas & 578 & 578 & 578 \\
\hline S/ Ventas & 24645,92 & 24645,92 & 24645,92 \\
\hline \multicolumn{4}{|c|}{ Presupuesto de Ingresos } \\
\hline & MES 01 & MES 02 & MES 03 \\
\hline $20 \%$ al contado & 4929,18 & 4929,18 & 4929,18 \\
\hline $30 \%$ a 30 días & & 7393,78 & 7393,78 \\
\hline $30 \%$ a 60 días & & & 7393,78 \\
\hline \multicolumn{4}{|l|}{$20 \%$ a 90 días } \\
\hline Ingreso Mensual & 4929,18 & 12322,96 & 19716,74 \\
\hline Total Und Vendidas & 578 & 578 & 578 \\
\hline Inv. Inicial & 0 & 161 & 161 \\
\hline Inv. Final & 161 & 161 & 161 \\
\hline Plan de Producción & 739 & 578 & 578 \\
\hline Costo de Materia Prima & 7633,87 & 5970,74 & 5970,74 \\
\hline Mat directo al contado $(80 \%)$ & 6107,1 & 4776,59 & 4776,59 \\
\hline Mat directo a 30 días (20\%) & & 1194,15 & 1194,15 \\
\hline M.O Directa & 4248,5 & 4248,5 & 4248,5 \\
\hline Costos Indirectos & 9655,25 & 9655,25 & 9655,25 \\
\hline Egresos de Fabricación & 20010,85 & 19874,49 & 19874,49 \\
\hline Gastos de Adm y de Ventas & 8064,75 & 8064,75 & 8064,75 \\
\hline Tributos por pagar & 1454,11 & 3635,27 & 5816,44 \\
\hline Interés & 1453,3 & 1453,3 & 1453,3 \\
\hline Egreso Mensual & 30983,01 & 33027,81 & 35208,98 \\
\hline Ingreso Mensual & 4929,18 & 12322,96 & \begin{tabular}{|l|}
19716,74 \\
\end{tabular} \\
\hline Egreso Mensual & 30983,01 & 33027,81 & 35208,98 \\
\hline Saldo Mensual & $-26053,83$ & $-20704,85$ & $-15492,24$ \\
\hline Caja inicial & 0 & $-26053,83$ & $-46758,68$ \\
\hline Caja final & $-26053,83$ & $-46758,68$ & $-62250,92$ \\
\hline
\end{tabular}

Elaboración propia

La inversión a corto plazo será el capital de trabajo por 3 meses que es el periodo promedio utilizado para calcular el capital de trabajo necesario para que un negocio 
comience a ser rentable. Este monto asciende a 62 250,92 soles así que para asegurar la vida del proyecto se considerara 75 mil soles por si hubiera imprevistos.

Tabla 7.3

Inversión total

\begin{tabular}{|l|l|}
\hline Inversión Tangible & 41547,25 \\
\hline Inversión Intangible & 41566,16 \\
\hline Capital de Trabajo & 75000,00 \\
\hline Total & 158113,41 \\
\hline
\end{tabular}

Elaboración Propia

Para adquirir la inversión necesaria se adquirirá un préstamo de $100 \mathbf{0 0 0 , 0 0}$ $\mathbf{( 6 3 , 2 5 \% )}$ ) al Banco de Crédito, en soles, con una TEA de 18,2\% (por ser una microempresa) por un periodo de 5 años con un periodo de gracia de un semestre para poder generar rentabilidad antes de comenzar a pagar las cuotas. El resto de la inversión $\mathbf{5 8} 113,41$ soles $\mathbf{( 3 6 , 7 5 \%}$ ) será financiado con capital propio con un costo de oportunidad de $17,42 \%$ calculado utilizando el modelo de valorización de activos financieros o CAPM como lo muestra la siguiente tabla.

Tabla 7.4

Modelo de valorización de activos financieros

\begin{tabular}{|l|l|l|}
\hline CAPM & KLR $+($ Km - KLR $) *$ Beta & 17,42 \\
\hline KLR & $4,696 \%$ & \\
\hline Km & $10,445 \%$ & \\
\hline Beta & 2,213 & \\
\hline
\end{tabular}

Elaboración propia 


\subsection{Costos de producción}

En este subcapítulo se detallarán los costos de producción incluyendo los costos de las materias primas, los costos de mano de obra directa y los costos indirectos de fabricación (CIF).

\subsubsection{Costos de las materias primas}

A continuación, se detallan los costos relacionados a las materias primas necesarias para la producción con la proyección hasta el año 2023.

Tabla 7.5

Costos de materia prima, insumos y materiales proyectados

\begin{tabular}{|l|l|l|l|l|l|l|}
\hline Detalle & Precio unitario (Soles) & 2019 & 2020 & 2021 & 2022 & 2023 \\
\hline MDF 4 mm & 0,89 & 6173,04 & 6790,7 & 7407,47 & 8025,13 & 8641,9 \\
\hline Foco & 4,99 & 34610,64 & 38073,7 & 41531,77 & 44994,83 & 48452,9 \\
\hline Soquete & 1,50 & 10404 & 11445 & 12484,5 & 13525,5 & 14565 \\
\hline Enchufe & 0,90 & 8323,2 & 9156 & 9987,6 & 10820,4 & 11652 \\
\hline Etiqueta & 0,30 & 2774,4 & 3052 & 3329,2 & 3606,8 & 3884 \\
\hline Cable Mellizo & 1,20 & 8323,2 & 9156 & 9987,6 & 10820,4 & 11652 \\
\hline Cajas & 0,55 & 3814,88 & 4196,5 & 4577,65 & 4959,35 & 5340,5 \\
\hline Total & 71648,88 & 78817,9 & 85976,59 & 93145,61 & 100304,3 \\
\hline
\end{tabular}

Elaboración propia

\subsubsection{Costos de la mano de obra directa}

Se calculan 15 sueldos al año: 12 sueldos, CTS y 2 gratificaciones para los 2 técnicos de corte láser y el diseñador industrial. 
Table 7.6

Costos de la mano de obra directa

\begin{tabular}{|l|l|l|l|l|l|l|l|}
\hline Cargo & Cantidad & $\begin{array}{l}\text { Sueldo } \\
\text { Mensual (S/) }\end{array}$ & $\begin{array}{l}\text { CTS } \\
(1 \text { sueldo })\end{array}$ & $\begin{array}{l}\text { Gratificaciones } \\
(2 \text { sueldos })\end{array}$ & $\begin{array}{l}\text { ESSALUD } \\
9 \%\end{array}$ & $\begin{array}{l}\text { SENATI } \\
0,75 \%\end{array}$ & $\begin{array}{l}\text { Total } \\
\text { Anual (S/) }\end{array}$ \\
\hline Operario & 1 & 930,00 & 930,00 & 1860,00 & 83,70 & 6,98 & 14040,68 \\
\hline $\begin{array}{l}\text { Diseñador } \\
\text { Industrial }\end{array}$ & 1 & 2000,00 & 2000,00 & 4000,00 & 180,00 & 15 & 30195,00 \\
\hline \multicolumn{8}{|c|}{ Costo de Mano de Obra Directa Anual } \\
\hline
\end{tabular}

Elaboración propia

\subsubsection{Costos indirectos de fabricación}

La empresa no contará con mano de obra indirecta pues el técnico de corte láser tendrá tiempo suficiente para actuar como auxiliar de almacén y ejecutará las labores de mantenimiento preventivo de la maquinaria y equipos.

Para calcular el costo de los servicios se calculó el consumo eléctrico de las maquinarias que es de $902,4 \mathrm{~kW}$-h por mes en tarifa BTB5 con la empresa Luz del Sur costando S/. 503,85 mensual. El consumo de agua se calculó en 9,65 metros cúbicos mensuales costando S/. 70,00 mensuales. De estos servicios se le asignara el 80\% al costo de indirecto de fabricación.

Tabla 7.7

Costos de servicios indirectos

\begin{tabular}{|l|l|l|l|l|l|l|l|}
\hline Detalle & $\begin{array}{l}\text { Costo Mensual } \\
\text { (S/) }\end{array}$ & $\begin{array}{l}\text { \% Asignación } \\
(\mathrm{a} \text { CIF) }\end{array}$ & 2019 & 2020 & 2021 & 2022 & 2023 \\
\hline Transporte & 1200 & $0 \%$ & 0 & 0 & 0 & 0 & 0 \\
\hline Luz y Agua & 573,85 & $80 \%$ & 5508,96 & 5508,96 & 5508,96 & 5508,96 & 5508,96 \\
\hline Seguridad & 1200 & $60 \%$ & 8640 & 8640 & 8640 & 8640 & 8640 \\
\hline Mantenimiento & 200 & $80 \%$ & 1920 & 1920 & 1920 & 1920 & 1920 \\
\hline Limpieza & 1200 & $60 \%$ & 8640 & 8640 & 8640 & 8640 & 8640 \\
\hline
\end{tabular}

Elaboración propia

El transporte se asignará a gastos de ventas en un $100 \%$ al este ser solo utilizado para realizar la entrega de los productos terminados. El resto del costo mensual de los servicios se asignará a los gastos de administración y ventas. 


\subsection{Presupuesto operativo}

En este subcapítulo se detallará el presupuesto operativo del emprendimiento.

\subsubsection{Presupuesto de ingresos por ventas}

Para el siguiente cálculo se utilizó la demanda proyectada en los capítulos anteriores.

Tabla 7.8

Presupuesto de ingreso por ventas

\begin{tabular}{|l|l|l|l|l|l|l|}
\hline \multirow{2}{*}{ RUBRO } & \multirow{2}{*}{ UNIDAD } & \multicolumn{5}{|c|}{ AÑO } \\
\cline { 3 - 7 } & & 2019 & 2020 & 2021 & 2022 & 5 \\
\hline Ventas & TPA & 6936 & 7630 & 8323 & 9017 & 9710 \\
\hline Precio & Soles $x \mathrm{~T}$ & 42,64 & 42,64 & 42,64 & 42,64 & 42,64 \\
\hline Ventas & Soles & 295751,04 & 325326,14 & 354901,25 & 384476,35 & 414051,46 \\
\hline
\end{tabular}

Elaboración propia

\subsubsection{Presupuesto operativo de costos}

Tabla 7.9

Costos de materia prima, insumos y materiales proyectados

\begin{tabular}{|l|l|l|l|l|l|l|}
\hline Detalle & Precio unitario (Soles) & 2019 & 2020 & 2021 & 2022 & 2023 \\
\hline MDF 4 mm & 0,89 & 6173,04 & 6790,7 & 7407,47 & 8025,13 & 8641,9 \\
\hline Foco & 4,99 & 34610,64 & 38073,7 & 41531,77 & 44994,83 & 48452,9 \\
\hline Soquete & 1,50 & 10404 & 11445 & 12484,5 & 13525,5 & 14565 \\
\hline Enchufe & 0,90 & 8323,2 & 9156 & 9987,6 & 10820,4 & 11652 \\
\hline Etiqueta & 0,30 & 2774,4 & 3052 & 3329,2 & 3606,8 & 3884 \\
\hline Cable Mellizo & 1,20 & 8323,2 & 9156 & 9987,6 & 10820,4 & 11652 \\
\hline Cajas & 0,55 & 3814,88 & 4196,5 & 4577,65 & 4959,35 & 5340,5 \\
\hline Total & & 71648,88 & 78817,9 & 85976,59 & 93145,61 & 100304,3 \\
\hline
\end{tabular}

Elaboración propia 
Tabla 7.10

Presupuesto de depreciación y amortización

\begin{tabular}{|c|c|c|c|c|c|c|c|c|c|c|}
\hline \multirow{2}{*}{$\begin{array}{l}\text { ACTIVO FIJO } \\
\text { TANGIBLE }\end{array}$} & \multirow{2}{*}{$\begin{array}{l}\text { IMPORTE } \\
\text { Soles }\end{array}$} & \multirow{2}{*}{$\%$ DEP. } & & & AÑO & & & & \multirow{2}{*}{ DEPRECIACION TOTAL } & \multirow{2}{*}{$\begin{array}{l}\text { VALOR } \\
\text { RESIDUAL }\end{array}$} \\
\hline & & & 1 & 2 & 3 & 4 & \multicolumn{2}{|l|}{5} & & \\
\hline Terreno & 0 & $0,00 \%$ & 0 & 0 & 0 & 0 & \multicolumn{2}{|l|}{0} & 0 & 0 \\
\hline $\begin{array}{l}\text { Modificaciones } \\
\text { planta }\end{array}$ & 9000,00 & $5,00 \%$ & 450 & 450 & 450 & 450 & \multicolumn{2}{|l|}{450} & 2250 & 0 \\
\hline $\begin{array}{l}\text { Modificaciones } \\
\text { oficinas admin. }\end{array}$ & 6000,00 & $5,00 \%$ & 300 & 300 & 300 & 300 & \multicolumn{2}{|l|}{300} & 1500 & 0 \\
\hline Maquinaria y equipo & 16919,20 & $10,00 \%$ & 1692 & 1692 & 1692 & 1692 & \multicolumn{2}{|l|}{1692} & 8460 & 8460 \\
\hline Muebles de planta & 1260,00 & $10,00 \%$ & 126 & 126 & 126 & 126 & \multicolumn{2}{|l|}{126} & 630 & 630 \\
\hline Muebles de oficina & 7347,00 & $10,00 \%$ & 735 & 735 & 735 & 735 & \multicolumn{2}{|l|}{735} & 3674 & 3674 \\
\hline Imprevistos fabriles & 727,17 & $10,00 \%$ & 73 & 73 & 73 & 73 & \multicolumn{2}{|l|}{73} & 364 & 0 \\
\hline $\begin{array}{l}\text { Imprevistos no } \\
\text { fabriles }\end{array}$ & 293,88 & $10,00 \%$ & 29 & 29 & 29 & 29 & \multicolumn{2}{|l|}{29} & 147 & 0 \\
\hline Total & 41547,25 & & 3405 & 3405 & 3405 & 3405 & \multicolumn{2}{|l|}{3405} & 17024 & 6382 \\
\hline Deprec. Fabril & & & 2341 & 2341 & 2341 & 2341 & \multicolumn{2}{|l|}{2341} & 11703 & \\
\hline \multirow[t]{3}{*}{ Deprec. No Fabril } & & & 1064 & 1064 & 1064 & 1064 & \multicolumn{2}{|l|}{1064} & 5320 & \\
\hline & & & & & & & & $\begin{array}{l}\text { VALOR DE } \\
\text { MERCADO } \\
(\%)\end{array}$ & & $50,00 \%$ \\
\hline & & & & & & & & $\begin{array}{l}\text { VALOR } \\
\text { RESIDUAL }\end{array}$ & & 6382 \\
\hline
\end{tabular}

Elaboración propia 
Tabla 7.11

Amortización de activos fijos intangibles

\begin{tabular}{|c|c|c|c|c|c|c|c|c|c|}
\hline \multirow{2}{*}{ ACTIVO FIJO INTANGIBLE } & \multirow{2}{*}{$\begin{array}{l}\text { IMPORTE } \\
\text { Soles }\end{array}$} & \multirow{2}{*}{$\%$ DEP } & & & AÑO & & & \multirow{2}{*}{$\begin{array}{l}\text { DEPRECIACIÓN } \\
\text { TOTAL }\end{array}$} & \multirow{2}{*}{$\begin{array}{l}\text { VALOR } \\
\text { RESIDUAL }\end{array}$} \\
\hline & & & 1 & 2 & 3 & 4 & 5 & & \\
\hline Estudios previos & 15000,00 & $20,00 \%$ & 3000 & 3000 & 3000 & 3000 & 3000 & 15000 & 0 \\
\hline Licencia de Software & 9240,75 & $100,00 \%$ & 9241 & 0 & 0 & 0 & 0 & 9241 & 0 \\
\hline Constitución de la empresa & 500 & $20,00 \%$ & 100 & 100 & 100 & 100 & 100 & 500 & 0 \\
\hline Permisos de construcción & 2500,00 & $20,00 \%$ & 500 & 500 & 500 & 500 & 500 & 2500 & 0 \\
\hline Gastos puestos en marcha & 8705,00 & $20,00 \%$ & 1741 & 1741 & 1741 & 1741 & 1741 & 8705 & 0 \\
\hline $\begin{array}{l}\text { Reclutamiento, Selección y } \\
\text { capacitación }\end{array}$ & 5000,00 & $20,00 \%$ & 1000 & 1000 & 1000 & 1000 & 1000 & 5000 & 0 \\
\hline Licencia de Funcionamiento & 620,41 & $20,00 \%$ & 124 & 124 & 124 & 124 & 124 & 620 & 0 \\
\hline \multirow[t]{3}{*}{ Total } & 41566,16 & & 4206 & 4965 & 4965 & 4965 & 4965 & 34066 & 0 \\
\hline & & & & & & & $\begin{array}{l}\text { VALOR DE } \\
\text { MERCADO } \\
(\%)\end{array}$ & & $0,00 \%$ \\
\hline & & & & & & & \begin{tabular}{|l|} 
VALOR \\
RESIDUAL \\
\end{tabular} & & 0 \\
\hline
\end{tabular}

Elaboración propia 
Tabla 7.12

Presupuesto CIF

\begin{tabular}{|l|l|l|l|l|l|l|l|}
\hline Detalle & $\begin{array}{l}\text { Costo } \\
\text { Mensual } \\
(\mathrm{S} /)\end{array}$ & Asignación & 2019 & 2020 & 2021 & 2022 & 2023 \\
\hline Transporte & 1200 & $0 \%$ & 0 & 0 & 0 & 0 & 0 \\
\hline $\begin{array}{l}\text { Luz y } \\
\text { Agua }\end{array}$ & 573,85 & $80 \%$ & 5508,96 & 5508,96 & 5508,96 & 5508,96 & 5508,96 \\
\hline Seguridad & 1200 & $60 \%$ & 8640 & 8640 & 8640 & 8640 & 8640 \\
\hline Mtto & 200 & $80 \%$ & 1920 & 1920 & 1920 & 1920 & 1920 \\
\hline Limpieza & 1200 & $60 \%$ & 8640 & 8640 & 8640 & 8640 & 8640 \\
\hline Mano de Obra Indirecta & & 0 & 0 & 0 & 0 & 0 \\
\hline Depreciación fabril & & 2341 & 2341 & 2341 & 2341 & 2341 \\
\hline \multicolumn{2}{|l}{ Total CIF } \\
\hline
\end{tabular}

Elaboración propia

Tabla 7.13

Presupuesto de costos de producción

\begin{tabular}{|l|l|l|l|l|l|}
\hline Detalle & 2019 & 2020 & 2021 & 2022 & 2023 \\
\hline Materia Prima & 71648,88 & 78817,9 & 85976,59 & 93145,61 & 100304,3 \\
\hline MOD & 44235,68 & 44235,68 & 44235,68 & 44235,68 & 44235,68 \\
\hline CIF & 26599,96 & 26599,96 & 26599,96 & 26599,96 & 26599,96 \\
\hline TOTAL & 142484,16 & 149649,04 & 156813,93 & 163978,82 & 171143,81 \\
\hline
\end{tabular}

Elaboración propia

\subsubsection{Presupuesto operativo de gastos}

Tabla 7.14

Presupuesto de gastos generales

\begin{tabular}{|l|l|l|l|l|l|}
\hline Detalle & 2019 & 2020 & 2021 & 2022 & 2023 \\
\hline $\begin{array}{l}\text { Gastos de adm y } \\
\text { ventas }\end{array}$ & 96777,24 & 96777,24 & 96777,24 & 96777,24 & 96777,24 \\
\hline $\begin{array}{l}\text { Depreciación no } \\
\text { fabril }\end{array}$ & 1064,09 & 1064,09 & 1064,09 & 1064,09 & 1064,09 \\
\hline $\begin{array}{l}\text { Amortización de } \\
\text { Intangibles }\end{array}$ & 15705,83 & 6465,08 & 6465,08 & 6465,08 & 6465,08 \\
\hline TOTAL & 113547,16 & 104306,41 & 104306,41 & 104306,41 & 104306,41 \\
\hline
\end{tabular}

Elaboración propia 


\subsection{Presupuesto financiero}

En este subcapítulo se detallará el presupuesto financiero del emprendimiento.

\subsubsection{Presupuesto de servicio de deuda}

Se optó por elegir un financiamiento de 100 mil soles que representa el 63,25\% de la inversión total. El cronograma de pagos de la deuda se elaboró con una TEA de 18,20\% con cuota fija y periodo de gracia parcial de 1 semestre en un plazo de 5 años con cuotas semestrales.

Tabla 7.15

Cronograma de pagos del financiamiento (en soles)

\begin{tabular}{|c|c|c|c|c|c|}
\hline AÑO & & $\begin{array}{l}\text { DEUDA } \\
\text { CAPITAL }\end{array}$ & $\begin{array}{l}\text { AMORTIZACION } \\
\text { (*) PRINCIPAL }\end{array}$ & INTERESES & SALDO \\
\hline \multirow[t]{2}{*}{ AÑO 1} & 1 & 100000,00 & 0,00 & 8719,82 & 100000,00 \\
\hline & 2 & 100000,00 & 11111,11 & 8719,82 & 88888,89 \\
\hline \multirow[t]{2}{*}{ AÑO 2} & 3 & 88888,89 & 11111,11 & 7750,95 & 77777,78 \\
\hline & 4 & 77777,78 & 11111,11 & 6782,08 & 66666,67 \\
\hline \multirow[t]{2}{*}{ AÑO 3} & 5 & 66666,67 & 11111,11 & 5813,22 & 55555,56 \\
\hline & 6 & 55555,56 & 11111,11 & 4844,35 & 44444,44 \\
\hline \multirow[t]{2}{*}{ AÑO 4} & 7 & 44444,44 & 11111,11 & 3875,48 & 33333,33 \\
\hline & 8 & 33333,33 & 11111,11 & 2906,61 & 22222,22 \\
\hline \multirow[t]{2}{*}{ AÑO 5} & 9 & 22222,22 & 11111,11 & 1937,74 & 11111,11 \\
\hline & 10 & 11111,11 & 11111,11 & 968,87 & 0,00 \\
\hline TOTAL & & & 100000,00 & 52318,94 & \\
\hline
\end{tabular}

Elaboración propia

\subsubsection{Presupuesto de estado de resultados}

Para el siguiente Estado de Resultados no se consideró participaciones (0\%), esto va de acuerdo con lo establecido en el Decreto Legislativo Nro. 892 que estipula que una empresa no requiere repartir utilidades si cuenta con menos de 20 trabajadores contratados. 
Tabla 7.16

Estado de resultados (en soles)

\begin{tabular}{|l|l|l|l|l|l|}
\hline RUBRO & 2019 & 2020 & 2021 & 2022 & 2023 \\
\hline INGRESO POR VENTAS & 295751,04 & 325326,14 & 354901,25 & 384476,35 & 414051,46 \\
\hline$(-)$ COSTO DE PRODUCCION & 142484,16 & 149649,04 & 156813,93 & 163978,82 & 171143,71 \\
\hline$(=)$ UTILIDAD BRUTA & 153266,88 & 175677,10 & 198087,32 & 220497,53 & 242907,75 \\
\hline$(-)$ GASTOS GENERALES & 113547,16 & 104306,41 & 104306,41 & 104306,41 & 104306,41 \\
\hline$(-)$ GASTOS FINANCIEROS & 17439,65 & 14533,04 & 10657,56 & 6782,08 & 2906,61 \\
\hline$(+)$ VENTA DE ACT TANGIBLE MERCADO & & & & & 6381,55 \\
\hline$(-)$ VALOR RESIDUAL LIBRO A TANGIBLE & & & & & 12763,10 \\
\hline$(=)$ UTILIDAD ANTES DE IMP. & 22280,08 & 56837,65 & 83123,34 & 109409,04 & 135694,73 \\
\hline$(-)$ IMPUESTO A LA RENTA (29,5\%) & 6572,62 & 16767,11 & 24521,39 & 32275,67 & 40029,95 \\
\hline$(=)$ UTILIDAD ANTES DE RESERVA LEGAL & 15707,45 & 40070,54 & 58601,96 & 77133,37 & 95664,78 \\
\hline$(-)$ RESERVA LEGAL (HASTA 10\%) & 1570,75 & 4007,05 & 5860,20 & 185,00 & \\
\hline$(=)$ UTILIDAD DISPONIBLE & 14136,71 & 36063,49 & 52741,76 & 76948,37 & 95664,78 \\
\hline
\end{tabular}

Elaboración propia 


\subsubsection{Presupuesto de estado de situación financiera}

La siguiente tabla demuestra la relación entre activos, pasivos y patrimonio que tendrá el emprendimiento a través del estado de situación financiera.

Tabla 7.17

Estado de situación financiera

\begin{tabular}{|c|c|c|c|}
\hline \multicolumn{4}{|c|}{ Estado de Situación Financiera } \\
\hline Rubro & & & \\
\hline \multirow{8}{*}{ Activo } & \multirow{4}{*}{ Corriente } & Efectivo y equivalentes & S/. 75000,00 \\
\hline & & Cuentas por cobrar & \\
\hline & & Inventarios & \\
\hline & & Total Activo Corriente & S/. 75000,00 \\
\hline & \multirow{3}{*}{$\begin{array}{l}\text { No } \\
\text { Corriente }\end{array}$} & Inversión Fija Tangible & S/. 41547,25 \\
\hline & & Inversión Fija Intangible & S/. 41566,16 \\
\hline & & Total Activo No Corriente & S/. 83113,41 \\
\hline & $\begin{array}{l}\text { Total } \\
\text { Activo } \\
\end{array}$ & Total Activo & $\mathrm{S} / .158$ 113,41 \\
\hline \multirow{6}{*}{ Pasivo } & \multirow{3}{*}{ Corriente } & Cuentas por pagar & \\
\hline & & Impuesto por pagar & \\
\hline & & Total Pasivo Corriente & - \\
\hline & \multirow{2}{*}{$\begin{array}{l}\text { No } \\
\text { Corriente }\end{array}$} & Deudas de Largo Plazo & S/. 100000,00 \\
\hline & & Total Pasivo No Corriente & S/. 100000,00 \\
\hline & \begin{tabular}{|l} 
Total \\
Pasivo
\end{tabular} & Total Pasivo & S/. 100000,00 \\
\hline \multirow{3}{*}{ Total } & \multirow{3}{*}{$\begin{array}{l}\text { Total } \\
\text { Pasivo y } \\
\text { Patrimonio }\end{array}$} & Capital & S/. 58113,41 \\
\hline & & Total Patrimonio & S/. 58113,41 \\
\hline & & Total Pasivo y Patrimonio & S/. 158 113,41 \\
\hline
\end{tabular}

Elaboración Propia 


\subsubsection{Flujo de fondos netos}

En este subcapítulo se expresarán los flujos de fondos económicos y financieros a través de tablas, en el segundo amortizando el préstamo que se realizó al banco mostrando una idea más real de los flujos del emprendimiento.

\subsubsection{Flujo de fondos económicos}

Tabla 7.18

Flujo de fondos económicos (en soles)

\begin{tabular}{|l|l|l|l|l|l|l|}
\hline \multicolumn{1}{|c|}{ RUBRO } & $\mathbf{0}$ & $\mathbf{2 0 1 9}$ & $\mathbf{2 0 2 0}$ & $\mathbf{2 0 2 1}$ & $\mathbf{2 0 2 2}$ & $\mathbf{2 0 2 3}$ \\
\hline $\begin{array}{l}\text { INVERSION TOTAL } \\
\text { UTILIDAD NETA } \\
\text { (+) AMORTIZACION DE }\end{array}$ INTANGIBLES & $(158113,41)$ & & & & & \\
(+) DEPRECIACION FABRIL & & 15707,45 & 40070,54 & 58601,96 & 77133,37 & 95664,78 \\
(+) DEPRECIACION NO FABRIL & & 14705,83 & 5465,08 & 5465,08 & 5465,08 & 5465,08 \\
(+) GASTOS FINANCIEROS * (1 - 0.295) & & 2340,64 & 2340,64 & 2340,64 & 2340,64 & 2340,64 \\
(+) RECUP DE CAPITAL DE TRABAJO & & 1064,09 & 1064,09 & 1064,09 & 1064,09 & 1064,09 \\
(+) VALOR RESIDUAL & 12294,95 & 10245,79 & 7513,58 & 4781,37 & 2049,16 \\
\hline $\begin{array}{l}\text { FLUJO NETO DE FONDOS } \\
\text { ECONOMICO }\end{array}$ & & & & & & 75000,00 \\
\hline
\end{tabular}

Elaboración propia 
7.4.4.2 Flujo de fondos financieros

Tabla 7.19

Flujo de fondos financieros (en soles)

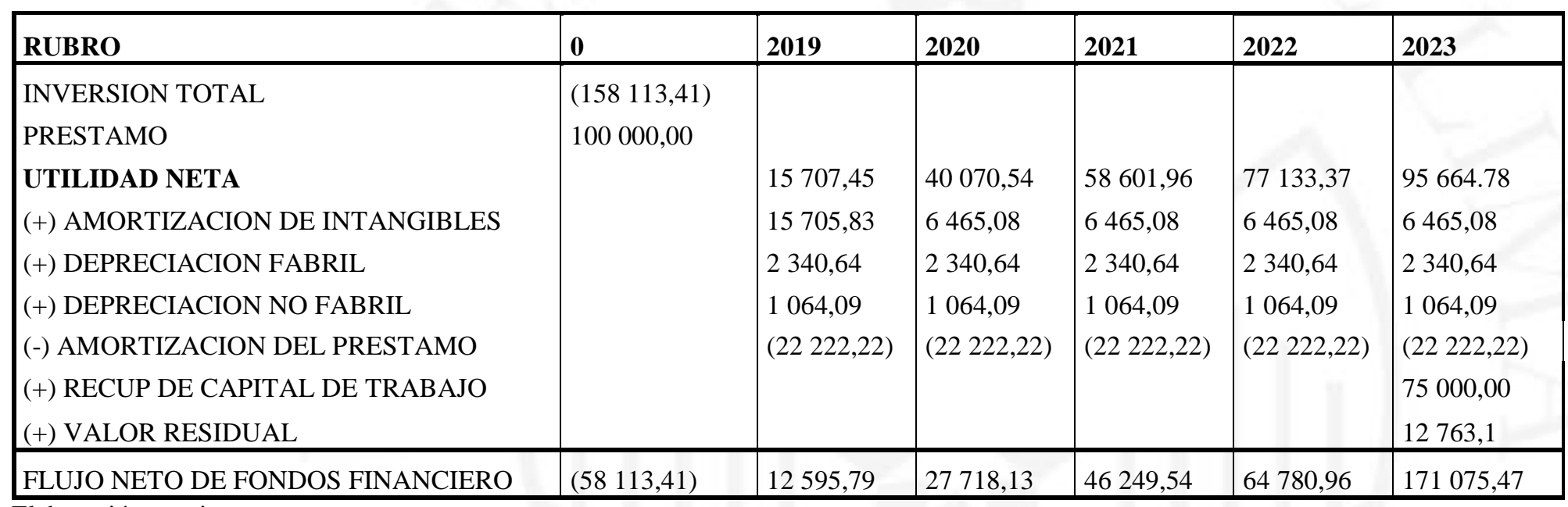

Elaboración propia 


\subsection{Evaluación económica y financiera}

A continuación, se detalla el cálculo del CCPP, se eligió la tasa del Banco de Crédito para microempresas por préstamos de más de 1 año de 18,20\% pero luego de aplicarle el impuesto a la renta es $12,83 \%$ y un Cok de $17,42 \%$ como el costo de oportunidad de los accionistas calculado con el método de valoración de activos financieros.

Tabla 7.20

Cálculo del CCPP del proyecto

\begin{tabular}{|l|l|l|l|l|}
\hline RUBRO & IMPORTE (S/.) & $\%$ PARTICP. & INTERES & "TASA DE DCTO." \\
\hline & & & & \\
ACCIONISTAS & 58113,41 & $36,75 \%$ & $17,42 \%$ & $6,402 \%$ \\
PRESTAMO & 100000 & $63,25 \%$ & $12.83 \%$ & $8.115 \%$ \\
& & & & \\
\hline TOTAL & 158113,41 & $100,00 \%$ & & $14,52 \%$ \\
\hline \multicolumn{2}{|l|}{ C.C.P.P. del Proyecto= } & $14,52 \%$ & & \\
\cline { 1 - 2 }
\end{tabular}

Elaboración propia

\subsubsection{Evaluación económica}

A continuación, se detallan los indicadores económicos VAN, TIR, relación B/C y periodo de recupero.

Tabla 7.21

Evaluación económica

\begin{tabular}{|l|l|}
\hline VAN ECONOMICO & 105238,99 \\
\hline RELACION B/C & 1,67 \\
\hline TASA INTERNA DE RETORNO ECONOMICO & $37,65 \%$ \\
\hline PERIODO DE RECUPERACION (AÑOS) & 3,62 años \\
\hline
\end{tabular}

Elaboración propia

\subsubsection{Evaluación financiera}

A continuación, se detallan los indicadores financieros VAN, TIR, relación B/C y periodo de recupero. 
Tabla 7.22

Evaluación financiera

\begin{tabular}{|l|l|}
\hline VAN FINANCIERO & 112013,51 \\
\hline RELACION B / C & 2,927 \\
\hline TASA INTERNA DE RETORNO FINANCIERA & $58,37 \%$ \\
\hline PERIODO DE RECUPERACION (AÑOS) & 2,95 \\
\hline
\end{tabular}

Elaboración propia

\subsubsection{Análisis de ratios}

Se observa que según los indicadores obtenidos el proyecto es económica y financieramente viable. Esto es debido a que su Valor Activo Neto (VAN) es positivo y la Tasa Interna de Retorno es superior a la tasa de descuento o Costo de Oportunidad.

Por otro lado, la evaluación económica muestra un periodo de recuperación de 3,62 años mientras que la evaluación financiera muestra un periodo de recupero más rápido de 2,95 años. Asimismo, la evaluación económica demuestra ser un poco menos atractiva teniendo una relación beneficio costo menor que la evaluación financiera $(1,67$ $<2,927)$.

\subsubsection{Análisis de sensibilidad del proyecto}

El siguiente análisis nos permitirá ver que tan sensible es el proyecto a los cambios en el entorno y cuánto podría verse beneficiado o perjudicado en casi se alteraran las variables que lo afectan como el precio de venta del producto y la demanda.

Escenario Pesimista: Se considero que la demanda del proyecto disminuyo en un $20 \%$ y para contrarrestar esta baja se disminuirá el precio del producto en $10 \%$ manteniéndose constante el costo de oportunidad y las demás cuentas de los estados financieros. Este escenario tiene una probabilidad de ocurrencia del 17,5\%. 


\section{Tabla 7.23}

Análisis de sensibilidad del escenario pesimista (FCF)

\begin{tabular}{|l|l|}
\hline VAN FINANCIERO & 34827,60 \\
\hline RELACION B / C & 1,599 \\
\hline TASA INTERNA DE RETORNO FINANCIERO & $29,73 \%$ \\
\hline PERIODO DE RECUPERACION (AÑOS) & 4,45 \\
\hline
\end{tabular}

Elaboración propia

Se puede observar que mientras va variando el precio del producto (10\% menos) los indicadores de rentabilidad se mantienen positivos. No obstante, el periodo de recupero incrementa en $400 \%$. El resto de los indicadores también se ven drásticamente afectados, pero se mantienen positivos, inclusive la TIR se mantiene por encima del CPPC.

Escenario Moderado: Se considero que las ventas y el precio se mantuvieron como se habían proyectado en el presente estudio. Este escenario es el más probable con una probabilidad de $70 \%$. Los resultados serán los mismos mostrados previamente en el análisis financiero.

Tabla 7.24

Análisis de sensibilidad escenario moderado (FCF)

\begin{tabular}{|l|l|}
\hline VAN FINANCIERO & 119240,64 \\
\hline RELACION B / C & 3,052 \\
\hline TASA INTERNA DE RETORNO FINANCIERA & $59,38 \%$ \\
\hline PERIODO DE RECUPERACION (AÑOS) & 3,41 años \\
\hline
\end{tabular}

Elaboración propia

Escenario Optimista: Se considero que la demanda incremento en $10 \%$ por lo que el precio se mantendrá constante al igual que el costo de oportunidad. Este escenario es el menos probable con una probabilidad de $12,5 \%$. 
Tabla 7.25

Análisis de sensibilidad escenario optimista (FCF)

\begin{tabular}{|l|l|}
\hline VAN FINANCIERO & 170500,30 \\
\hline RELACION B / C & 3,934 \\
\hline TASA INTERNA DE RETORNO FINANCIERO & $81,27 \%$ \\
\hline PERIODO DE RECUPERACION (AÑOS) & 2,03 \\
\hline
\end{tabular}

Elaboración propia

Podemos observar cómo los indicadores de rentabilidad se ven afectados positivamente y cabe recalcar que en dicho escenario se recuperara la inversión inicial en 2,03 años.

Evaluación financiera ponderada: A continuación, se detallan los flujos financieros del proyecto en las siguientes tablas.

\section{Tabla 7.26}

Evaluación financiera ponderada (FCF)

\begin{tabular}{|l|l|l|l|l|l|l|l|}
\hline & 2018 & 2019 & 2020 & 2021 & 2022 & 2023 & Prob. \\
\hline Pesimista & & $(8254,66)$ & 4782,63 & $21,229.00$ & 37675,37 & 141884,84 & 0,175 \\
\hline Moderado & & 12595,79 & 27718,13 & 46249,54 & 64780,96 & 171075,47 & 0,7 \\
\hline Optimista & & 28394,99 & 45097,25 & 65208,58 & 85319,92 & 193194,35 & 0,125 \\
\cline { 1 - 6 } Ponderado & $-58113,41$ & 10921,86 & 25876,81 & 44240,83 & 62604,85 & 168731,97 & \multicolumn{1}{|c}{} \\
\cline { 1 - 5 } & & & &
\end{tabular}

Elaboración propia

Tomando en consideración el escenario ponderado los indicadores de rentabilidad del proyecto son: 
Tabla 7.27

Análisis de la evaluación financiera ponderada (FCF)

\begin{tabular}{|l|l|}
\hline VAN FINANCIERO & 110875,82 \\
\hline RELACION B / C & 2,91 \\
\hline $\begin{array}{l}\text { TASA INTERNA DE RETORNO } \\
\text { FINANCIERO }\end{array}$ & $56,93 \%$ \\
\hline $\begin{array}{l}\text { PERIODO DE RECUPERACION } \\
\text { (AÑOS) }\end{array}$ & 3,42 \\
\hline
\end{tabular}

Elaboración propia

Con estos resultados, se confirma la rentabilidad del proyecto en los 3 escenarios aunque se muestra una imagen más clara al visualizar escenario ponderado según la probabilidad de ocurrencia de cada escenario demostrando que es un proyecto rentable con buen índice de beneficios y un periodo de recupero dentro del tiempo de vida del proyecto. 


\section{CAPÍTULO VIII: EVALUACIÓN SOCIAL DEL PROYECTO}

\subsection{Indicadores sociales}

Esta evaluación pretende conocer la contribución del proyecto al crecimiento económico del país: por ello, se hace uso de los siguientes indicadores e índices macroeconómicos.

Valor agregado: Este es el aporte que se le genera a los insumos y materias primas para la transformación e incluye: sueldos, salarios, intereses, depreciación, utilidades e impuestos.

Se utilizó un CPPC de 14,52\% para este proyecto y en base a la siguiente proyección podemos apreciar que el valor agregado acumulado a lo largo de la vida útil del proyecto traído a su valor actual utilizando la tasa más agresiva para el proyecto $(17,42 \%)$ es 605123,84 soles, dato que será utilizado para otros indicadores.

\section{Tabla 8.1}

Proyección del valor agregado del proyecto

\begin{tabular}{|l|l|l|l|l|l|}
\cline { 2 - 6 } \multicolumn{1}{c|}{} & 2019 & 2020 & 2021 & 2022 & 2023 \\
\hline Ventas & 295751,04 & 325326,14 & 354901,25 & 384476,35 & 414051,46 \\
\hline Costos primos & 142484,16 & 149649,04 & 156813,93 & 163978,82 & 171143,71 \\
\hline & & & & & \\
\hline Valor Agregado & 153266,88 & 175677,1 & 198087,32 & 220497,53 & 242907,75 \\
\hline $\begin{array}{l}\text { Valor Agregado } \\
\text { Actual }\end{array}$ & 130528,77 & 127418,06 & 122357,46 & 115993,97 & 108825,58 \\
\hline $\begin{array}{l}\text { Valor Agregado } \\
\text { Acumulado }\end{array}$ & 130528,77 & 257946,83 & 380304,29 & 496298,26 & 605123,84 \\
\hline
\end{tabular}

Elaboración propia

- Densidad de capital: Este indicador se utiliza para relacionar la inversión total con la cantidad de personal ocupado, esto nos ayuda a estimar la cantidad de inversión necesaria para crear un puesto de trabajo. La relación obtenida es 39 528,35 soles por puesto de trabajo generado como se demuestra a continuación. 
Densidad de Capital $=\frac{158 \text { 113,41(inversión total })}{4 \text { (número de empleados })}=39528,35$

- Intensidad de capital: Este indicador se utiliza regularmente para medir el grado de aporte del proyecto mediante el nivel de inversión, para generar valor agregado en relación con los insumos. En este caso, el aporte del proyecto con relación a la inversión es 0,26 y es aceptable, pues se genera 4 veces más valor del que se invierte.

$$
\text { Intensidad de Capital }=\frac{158 \text { 113,41(Inversión total })}{605123,84(\text { valor agregado })}=0,26
$$

- Relación Producto-Capital: Este indicador se utiliza para medir la relación entre el valor agregado que genera un proyecto y la inversión total. En este caso podemos decir que el valor agregado al proyecto es mucho mayor que la inversión total como se demuestra a continuación.

Producto - Capital $=\frac{605123,84(\text { valor agregado })}{158113,41(\text { inversión total })}=3,83$ 


\section{CONCLUSIONES}

- El estudio de mercado realizado revelo la existencia de una demanda para el producto, la cual para el 2019 será de 6936 lámparas infantiles con una proyección al año 2023 de 9710 lámparas infantiles. Esta fue calculada en base a la segmentación del publico de nivel socioeconómico C y D con hijos recién nacidos de 0-5 años e interés por tener una decoración más personalizada de sus espacios.

- Este trabajo de investigación determino que Surco fuera elegido como mejor opción de macro localización debido a la cantidad de Universidades y negocios que utilizan las tecnologías de corte láser en el distrito y del movimiento demográfico que ocurre cada día dentro de Surco. Por otro lado, realizando el ranking de factores para la micro localización se determinó que Monterrico sería la mejor zona para alquilar el local del proyecto.

- El tamaño de planta fue determinado en base al tamaño - tecnología determinando un máximo de producción de 12182 lámparas infantiles innovadoras producidas con tecnologías de corte láser al año.

- El costo unitario promedio del producto es de 10,33 soles y asignándole un precio de 42,64 soles por lámpara (según el estudio de mercado) se obtiene una utilidad neta sobre la venta de $16,18 \%$.

- La inversión total para el proyecto es de S/ 158 113,41 dividida entre el capital de trabajo de S/ 75 000,00, la inversión fija tangible de S/ 41 547,25 y la inversión fija intangible de S/ 41 566,16.

- Los indicadores económicos y financieros obtenidos afirman la rentabilidad del proyecto. Un VANE de 105 238,99 y VANF de 112 013,51 indican una alta rentabilidad ya que no solo son positivos sino que son mayores a la inversión total. Por otro lado, el TIRE de $37,65 \%$ y el TIRF de $58,37 \%$ son sumamente 
positivos ya que ambos se encuentran muy por encima del costo de oportunidad de nuestros accionistas, así se concluye la rentabilidad del proyecto.

- El proyecto será viable y sostenible debido a lo demostrado por los indicadores de rentabilidad que son mucho más altos de lo necesario. Gracias a esto se puede afirmar que el proyecto será generador de ingresos y contribuirá al bienestar y progreso de la sociedad. 


\section{RECOMENDACIONES}

- Se recomienda verificar la viabilidad económica de un proyecto buscando casos similares en el ámbito internacional. Es importante recalcar que esto debe ser tomado como referencia y se deben considerar las diferencias entre los mercados que se busca abastecer para que la información sea válida.

- Para generar un servicio de calidad en el mercado actual se recomienda considerar la tecnología más avanzada en los campos que se relacionen con el centro del negocio a implementar. Puede que esto incremente el periodo de recupero del proyecto, pero apoyara a conseguir la participación de mercado que es vital para todo negocio.

- A la hora de definir los puestos necesarios para que una empresa funcione se recomienda considerar contratar a colaboradores más capacitados que puedan realizar múltiples labores y aumentar la productividad de la empresa reduciendo la probabilidad de duplicidad de tareas e incrementando la productividad por trabajador.

- Una recomendación para el estado peruano seria que los ministerios seleccionen proyectos que podrían incrementar la calidad de vida de nuestros compatriotas y se genere el crecimiento de nuevas industrias y la adopción y desarrollo de nuevas tecnologías.

- Se recomienda incursionar en el mercado del corte láser y la fabricación digital mientras este es joven en el Perú para tener una mayor probabilidad de éxito. 


\section{REFERENCIAS}

Carranza Llerena, A. J., (1988) Estudio tecnológico para la elaboración de muebles de madera no ensamblados "kits". Lima: Universidad de Lima.

Compañía peruana dedicada a la investigación, estudios de mercados y opinión pública. (2017). Recuperado de CPI.PE:

http://cpi.pe/images/upload/paginaweb/archivo/26/mr_poblacion_peru_2017.pd $\mathrm{p}$

Eglo. (2019). Recuperado de EGLO.COM.PE:

http://www.eglo.com.pe/

Instituto Nacional de Estadística e Informática. (junio de 1995). Recuperado de

INEI.GOB.PE:

https://www.inei.gob.pe/media/MenuRecursivo/publicaciones_digitales/Est/Lib 0001/N53/anexo031.htm

Instituto Nacional de Estadística e Informática. (septiembre de 2016). Recuperado de INEI.GOB.PE:

https://www.inei.gob.pe/

Instituto Nacional de Estadística e Informática. (2017). Recuperado de INEI.GOB.PE:

https://www.inei.gob.pe/media/MenuRecursivo/publicaciones_digitales/Est/Lib 1530/libro.pdf

Instituto Nacional de Estadística e Informática. (2019). Recuperado de INEI.GOB.PE: https://www.inei.gob.pe/estadisticas/indice-tematico/economia/

ISOTOOLS. (2019). Recuperado de ISOTOOLS.ORG:

https://www.isotools.org/normas/calidad/iso-9001/

Klima Haidinger, P. E., (1990). Proyecto de prefactibilidad para la creación de una empresa dedicada a la fabricación de muebles de madera: línea de oficina. Lima: Universidad de Lima. 
Lloyd's Register. (2018). Recuperado de www.lr.org/es-es/

http:// www.lr.org/es-es/iso-14001/

Municipalidad de Santiago de Surco. (2018). Recuperado de MUNISURCO.GOB.PE: http://www.munisurco.gob.pe/municipio/surcoSeguro/planDistritalSeguridadCi udadana/plan_distrital_seguridad_ciudadana_2018.pdf

Pipoli Velarde, F. (1989). Estudio tecnológico: fabricación de artículos de madera para uso doméstico. Lima: Universidad de Lima.

Sandoval Palacios, C. (1988). Estudio tecnológico para la elaboración de muebles de oficina de madera. Lima: Universidad de Lima.

Vega Menéndez, M. H., (1985)Estudio preliminar para la implementación de una pequeña fábrica de muebles modulares de madera (línea juvenil). Lima: Universidad de Lima. 


\section{BIBLIOGRAFÍA}

Alibaba. (2019). Recuperado de Alibaba.com:

https://www.alibaba.com/

Aliexpress. (2019). Recuperado de Aliexpress.com:

https://www.aliexpress.com/

ALMACO. (2018). Recuperado de ALMACOPERU.COM:

https://www.almacoperu.com/

Congreso de la República del Perú. (2011). Ley 29783, Ley de Seguridad y Salud en el Trabajo. Lima

Congreso de la República del Perú. (2014). Ley 30222, que modifica la Ley 29783, Ley de Seguridad y Salud en el Trabajo. Lima

Córdova, K. (18 de Enero de 2018). Urbania. Recuperado de Urbania.pe: https://urbania.pe/blog/mercado-inmobiliario-2/san-borja-y-surco-los-preciosmas-bajos/

Criollo Pérez, P. X. (2015). Diseño y producción de mobiliario mediante técnicas Cad/Cam, Diseño tecnológico y materialidad(Bachelor's thesis, Universidad del Azuay).

Díaz Garay, B., Noriega, M. T., (2018). Manual para el diseño de instalaciones manufactureras y de servicios (2.a ed.). Lima, Perú: Fondo Editorial de la Universidad de Lima.

Guerrero García, M. S. (2014). Desechos pulverizados de MDF para la construcción de complementos decorativos de hogar(Bachelor's thesis, Pontificia Universidad Católica del Ecuador Sede Ambato).

Limitada, D. P. R., \& Emprendimiento, M. G. M. (2011). GT2P: diseño personalizado de muebles de vanguardia. 
Lohr Rodríguez, C. (2011). Mejoramiento de la calidad del borde cortado en PMMA por láser de $\mathrm{CO} 2$.

Mercado Libre. (2019). Recuperado de Mercadolibre.com.pe:

https://www.mercadolibre.com.pe/

Muñoz, P. (2013). Diseño Basado en Investigación. In CONGRESO DE LA SOCIEDAD IBEROAMERICANA DE GRÁFICA DIGITAL (Vol. 17, pp. 435438).

Muñoz, P., Coronel, J. L., Sequeira, A., \& Magnasco, I. R. (2011). Fabricación digital y morfología: la flexibilidad en la generación de formas. In SIGraDI, XV Congreso de la Sociedad Iberoamericana de Gráfica Digital.[on line] Santa Fe, Argentina(p. 368).

PHILIPS. (2019). Recuperado de PHILIPS.COM.PE:

https://www.philips.com.pe/

RAMON, L., \& ALEXIS, R. (2018). Diseño y construcción de una máquina de corte y grabado láser en materiales de baja densidad para un centro de diseño gráfico (Bachelor's thesis, Quito).

Sesnic Humeres, D. (2013). Diseño paramétrico y mimbre.

Sodimac. (2019). Recuperado de sodimac.com.pe: https://www.sodimac.com.pe/sodimac-pe/

Urbania. (2017). Recuperado de Urbania.pe:

https://urbania.pe/indice_m2/ 


\section{ANEXOS}

Anexo 1.

Encuesta realizada: sección 1

\section{Encuesta: Tesis}

Se realizaran una serie de preguntas para generar una base de datos la cual sera utilizada como fuente primaria en un estudio de mercado realizado para sustentar una tesis de Ingeniería Industrial en la universidad de Lima. Es por ello que se pide sinceridad a la hora de contestar

Edad $^{*}$

Texto de respuesta corta

Genero *

Masculino

Femenino

Otra...

¿Usted tiene un/a hijo/a de 0 a 5 años de edad ? *

Sí

No

Elaboración propia 
Anexo 2.

Encuesta realizada: sección 2

Sección 2 de 3

\section{Intención de Compra}

Se medirá si el cliente compraría la lámpara.

¿Cuantos años tiene su hijo? *

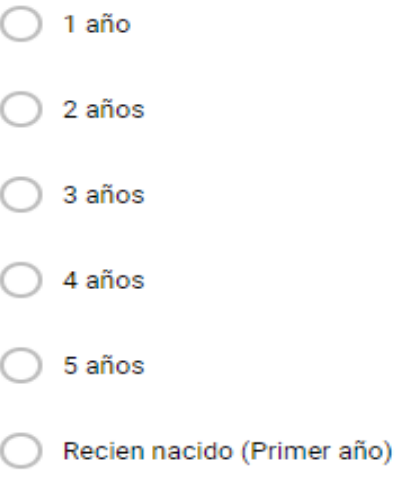

¿Compraria una lampara moderna y segura para niños/as en su primera infancia (0-5 años) fabricada con tecnologías de corte láser y diseños innovadores?

Si

No

Elaboración propia 


\section{Anexo 3.}

Encuesta realizada: sección 3

\section{Intensidad de compra}

Aquí se medirá que tan probable es que realmente se realice la venta.

¿Que tan probable es que compre una lampara con estas características siendo 1 muy probable y 5 nunca?

$\begin{array}{llllll}1 & 2 & 3 & 4 & 5 \\ & 0 & \bigcirc & \bigcirc & \bigcirc\end{array}$

¿Cuanto estaría dispuesto a pagar por una lampara con estas características?
25
45
60
mas de 60

Elaboración propia 


\section{Anexo 4.}

Resultado de la encuesta: edad

\section{Edad}

$$
200
$$

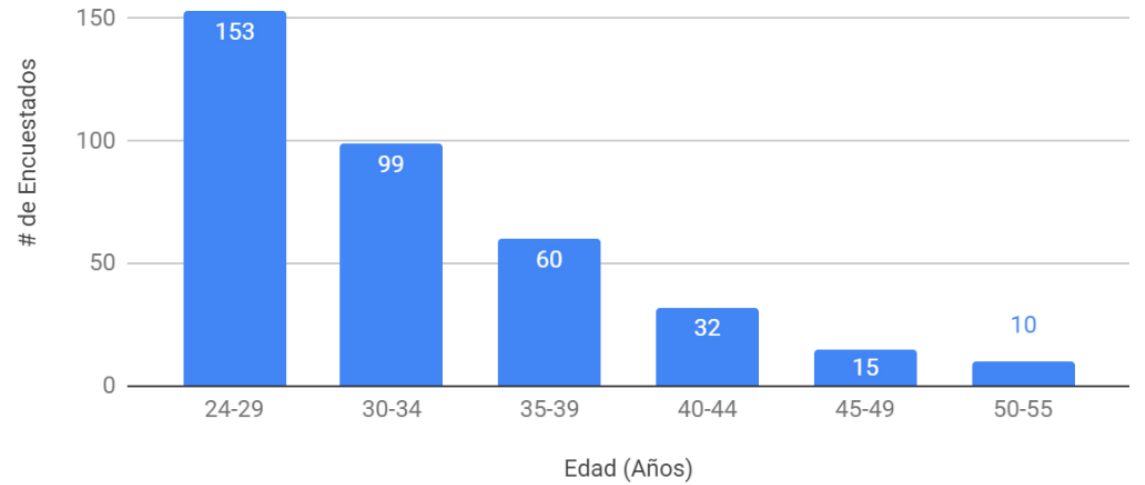

Elaboración propia

\section{Anexo 5.}

Resultados de la encuesta: Genero

\section{Genero}

369 respuestas

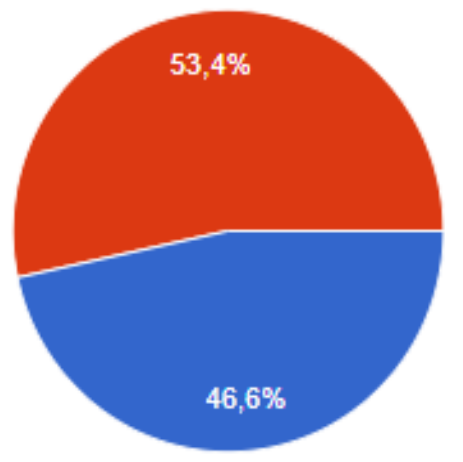

Elaboración propia 
Anexo 6.

Resultados de la encuesta: porcentaje de encuestados con hijos de 0-5 años de edad

\section{¿Usted tiene un/a hijo/a de 0 a 5 años de edad?}

\section{9 respuestas}

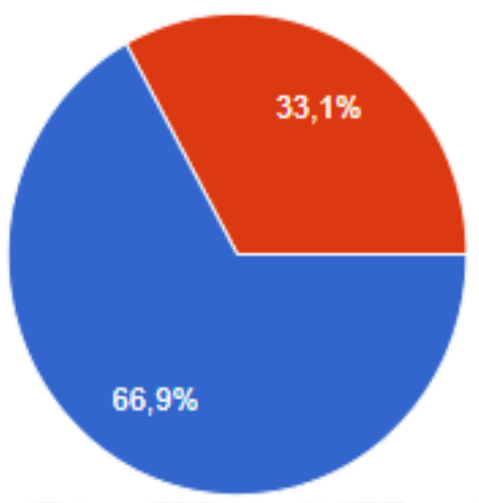

Elaboración propia

Anexo 7.

Resultados de la encuesta: intención de compra parte 1

\section{Intención de Compra}

¿Cuantos años tiene su hijo?

247 respuestas

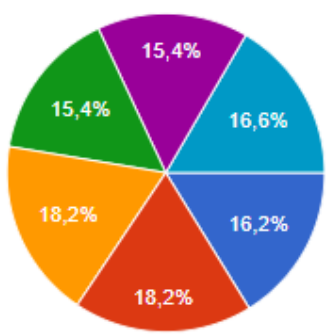

1 año

2 años

3 años

4 años

- 5 años

- Recien nacido (Primer año)

Elaboración propia 


\section{Anexo 8.}

Resultados de la encuesta: intención de compra parte 2

¿Compraria una lampara moderna y segura para niños/as en su primera infancia (0-5 años) fabricada con tecnologías de corte láser y diseños innovadores?

247 respuestas
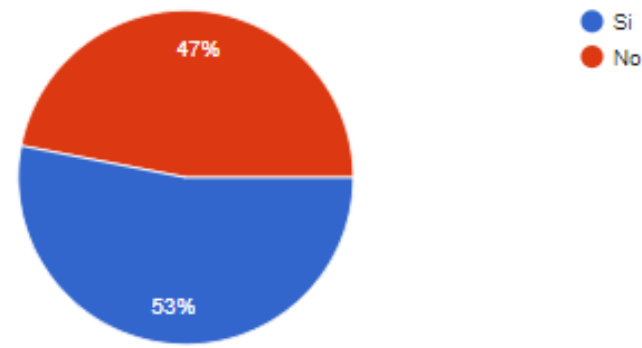

No

Elaboración propia

Anexo 9.

Resultados de la encuesta: Intensidad de compra parte 1

\section{Intensidad de compra}

¿Que tan probable es que compre una lampara con estas características siendo 1 muy probable y 5 nunca?

131 respuestas

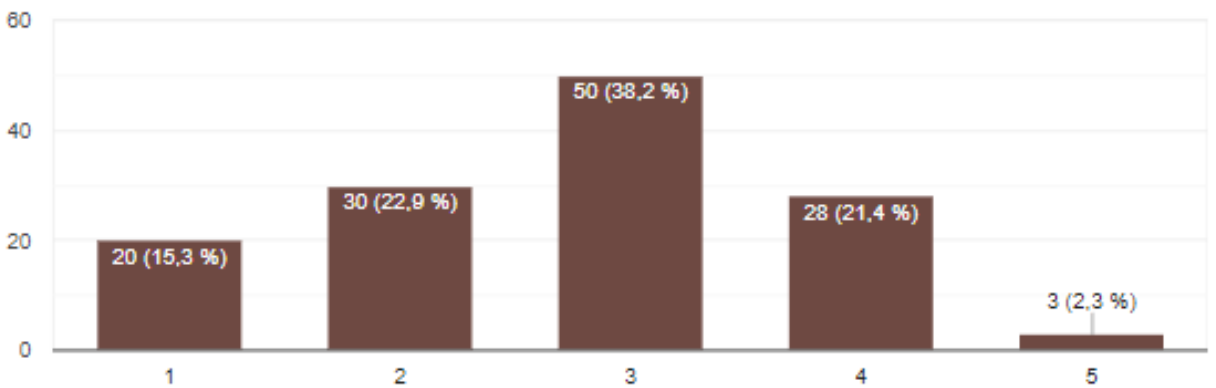

Elaboración propia 
Anexo 10.

Resultados de la encuesta: Intensidad de compra parte 2

¿Cuanto estaría dispuesto a pagar por una lampara con estas características?

131 respuestas

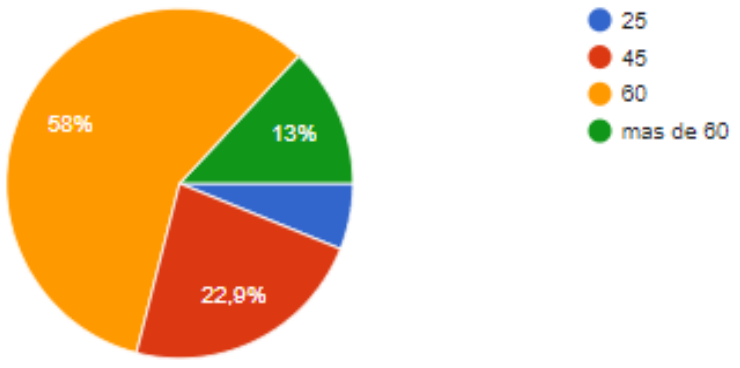

Elaboración propia 